University of Louisville

ThinkIR: The University of Louisville's Institutional Repository

Electronic Theses and Dissertations

$5-2010$

\title{
Analysis of candidate plasticity genes in visual cortex.
}

Paul Joseph Kiser 1969-

University of Louisville

Follow this and additional works at: https://ir.library.louisville.edu/etd

\section{Recommended Citation}

Kiser, Paul Joseph 1969-, "Analysis of candidate plasticity genes in visual cortex." (2010). Electronic Theses and Dissertations. Paper 758.

https://doi.org/10.18297/etd/758

This Doctoral Dissertation is brought to you for free and open access by ThinkIR: The University of Louisville's Institutional Repository. It has been accepted for inclusion in Electronic Theses and Dissertations by an authorized administrator of ThinkIR: The University of Louisville's Institutional Repository. This title appears here courtesy of the author, who has retained all other copyrights. For more information, please contact thinkir@louisville.edu. 


\title{
ANALYSIS OF CANDIDATE PLASTICITY GENES IN VISUAL CORTEX
}

By

Paul Joseph Kiser

B.S., The Florida State University, 1993

M.S., Univeristy of Louisville School of Medicine, 1997

\begin{abstract}
A Dissertation
Submitted to the Faculty of the

Graduate School of the University of Louisville

In Partial Fulfillment of the Requirements

For the Degree of
\end{abstract}

\author{
Doctor of Philosophy \\ Department of Anatomical Sciences and Neurobiology \\ University of Louisville \\ Louisville, Kentucky
}

May 2010 


\title{
ANALYSIS OF CANDIDATE PLASTICITY GENES IN VISUAL CORTEX
}

\section{By}

\author{
Paul Joseph Kiser
}

B.S., The Florida State University, 1993

M.S., Univeristy of Louisville School of Medicine, 1997

A Dissertation Approved on

April 22, 2010

by the following Dissertation Committee

Disserration Director 


\section{DEDICATION}

This dissertation is dedicated to my parents

Rev. and Mrs. Joseph W. Kiser,

and my wife,

Jennifer B. Kiser

for all of the love and support they have shown me;

and my daughters,

Kaitlyn and Kayleigh Kiser

who have patiently wondered where there father has been

as I worked to both support them and finish this research

over the past several years. 


\section{ACKNOWLEDGEMENTS}

I would like to express sincere gratitude to my mentor, Dr. George Mower, for the friendship, advice, direction and patience he has shared with me throughout the course of this project. I also wish to share my appreciation for my committee members, Dr. Martha Bickford and Dr. Rita Collela, for their comments and guidance and an additional thank you for Dr. Charles Huscher and Dr. Woody Petry for not only their guidance but also the use of their laboratories and equipment for multiple components of this research. Thank you to Dr. Steven Wilt, Bellarmine University, for his advice and for handling all of the knockout mouse genotyping required by this project. An extra special thank you is extended to Dr. Cuibo Yang for the friendship she has shown me, the components she contributed to the overall project and the time she took to teach me several of the procedures used to complete this work. Thank you also to fellow lab partner and graduate student James Morris for his assistance during the course of this study.

Loving thanks is offered for my wife and family who have shown incredible patience while I disrupted our previously stable life through the pursuit of this degree in hopes that it will ultimately provide an even brighter future for us. 


\section{ABSTRACT \\ Analysis of Candidate Plasticity Genes in Visual Cortex}

Paul J. Kiser

April 22, 2010

The goals of this dissertation is to further the understanding of the roles of two genes identified by differential display polymerase chain reaction (ddPCR) of cat visual cortex as candidate genes to play a role in visual cortical plasticity. Analysis of normal and dark rearing of cats at five and twenty weeks identified Dab-1, the mammalian homologue of the disabled-1 gene found in drosophila and Munc13-3, the mammalian homologue of the c. elegans "uncoordinated" or unc-13 gene. Dab-1 transcription analysis showed a pattern of high levels during the peak ( 5 weeks) and low levels at the nadir ( 20 weeks) of the critical period in normally reared animals with opposite transcription levels in dark reared animals (the "plasticity" pattern). Munc13-3 showed the opposite pattern with low levels of transcription at the peak of the critical period and high levels at the nadir in normally reared and opposite pattern in dark reared animals ("anti-plasticity" patterm).

This project extended the mRNA findings on Western blot analysis to study protein expression of both genes in the visual cortex during the critical period in both cats and mice. This analysis confirmed both Dab-1 and Munc13-3 as candidate plasticity 
genes showing "plasticity" and "anti-plasticity" patterns of protein expression, respectively, in visual cortex.

Immunohistochemical labeling of Dab-1 in cat visual cortex revealed a consistent developmental decline in density of immunopositive cells across all cortical lamina from birth through the critical period. Comparisons of Dab-1 immunohistochemistry in normal and dark reared cats at the peak and nadir of the critical period showed staining patterns consistent with the results of the total protein expression studies. There was a greater immunopositive cell density in normal vs. dark reared animals at the peak of the critical period and greater cell density in dark reared than normal at the nadir of the critical period.

Through the use of genetic mutants lacking the Dab-1 gene, additional Western blot analyses were performed to assess potential relationships between Dab-1 and expression of NMDA receptor subunits during the visual critical period. An inverse relationship was found between mutant and wild-type mice in the ratio of expression of NR2A and NR2B subunits between normal and dark-reared animals indicating a strong relationship between the proteins.

While future experiments need to be conducted to further elucidate more details on the specific functions of both genes, this research provides substantial evidence that Munc13-3 and Dab-1 are both genes with significant roles in the critical period of visual cortical development. 


\section{TABLE OF CONTENTS}

PAGE

DEDICATION

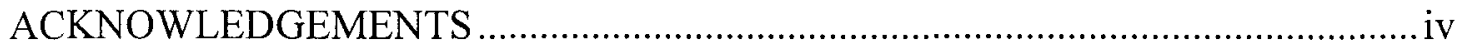

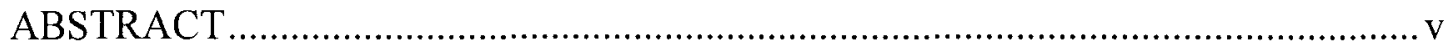

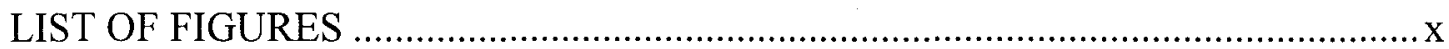

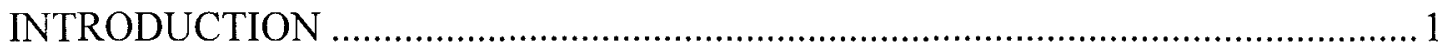

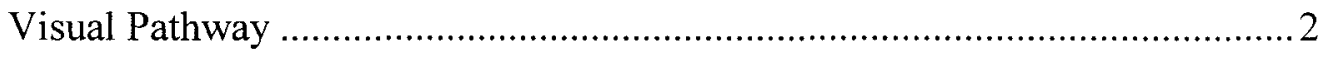

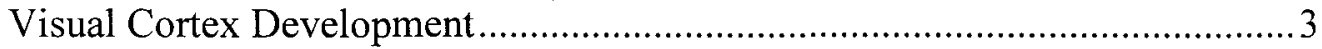

Neuronal Composition of Visual Cortex .................................................. 7

Molecular Deprivation:

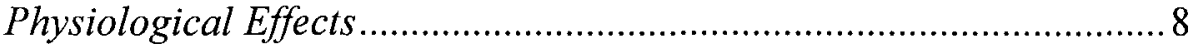

Anatomical Effects ................................................................ 9

Critical Period: ........................................................................................... 10

Time Course of Critical Period.......................................................... 11

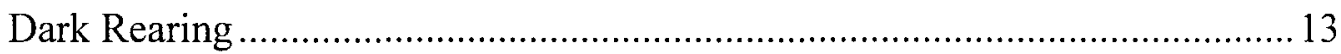

Effects on the Critical Period ............................................................... 14

Anatomical and Physiological Effects ............................................ 15

Monocular Deprivation Effects: Revisited ................................................. 18

Genes Regulating Neuroplasticity in Visual Cortex ................................... 21

Identification of Candidate Plasticity Genes................................................2 22

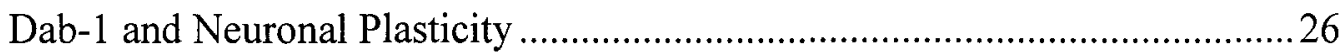

Munc13s and Neuronal Plasticity ..........................................................28

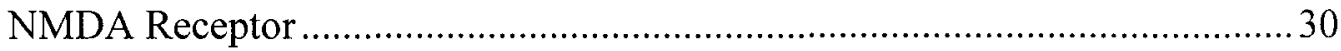


Plasticity in Mouse vs. Cat Visual Cortex ............................................... 32

Benefits of Mice for Mechanistic and Mutation Studies ............................... 34

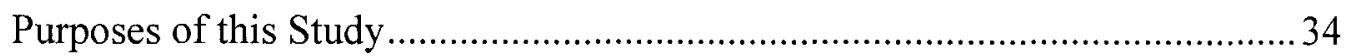

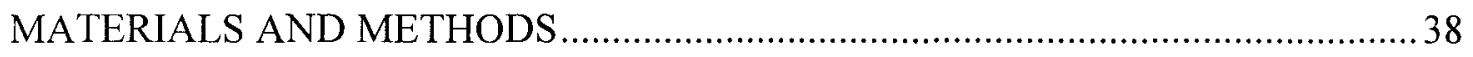

Animal Breeding and Rearing Conditions

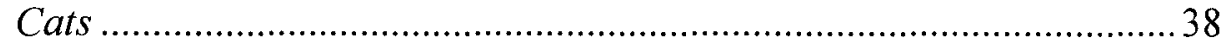

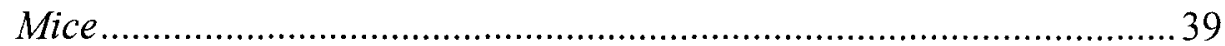

Western Blot Procedures

Sample Preparation ................................................................. 45

Total Protein Quantification ......................................................... 46

Protein Separation .............................................................................. 46

Protein Staining .......................................................................... 47

Quantification of Protein Expression Levels ..................................... 48

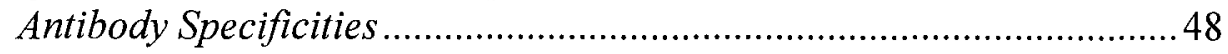

Immunohistochemistry Procedures

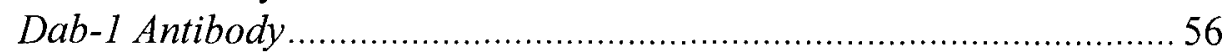

Staining Procedures

Immunohistochemistry ..................................................... 56

Cresyl Violet...................................................................... 58

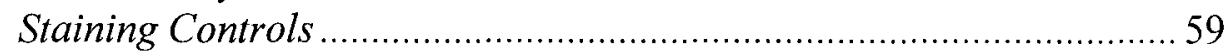

Immunohistochemistry Quantification and Analysis ..........................59

Electrophysiological Surgical and Recording Procedures .............................61

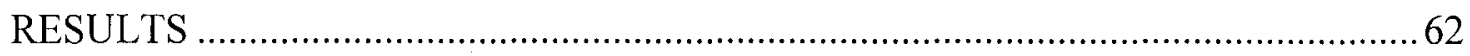

Western Blot Analysis of Dab-1 and Munc13-3 Protein Expression

Bidirectional Regulation of Dab-1 Protein in Cat and Mouse Visual

Cortex..

Bidirectional Regulation of Munc13-3 by Age and Dark Rearing in the

Visual Cortex

Immunohistochemical Analysis of Dab-1 Laminar Distribution in Visual

Cortex 72

Effect of Dab-1 Mutation on NMDAR Subunits 
Establishing Procedures for Recording Evoked Potentials from Visual

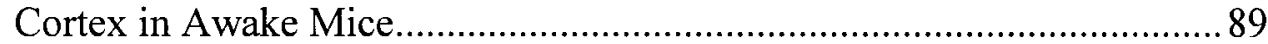

Electrode Implantation Procedure ....................................................89

Monocular Deprivation Procedure................................................... 94

Visual-Evoked Potential Recording ............................................... 95

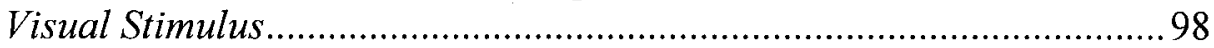

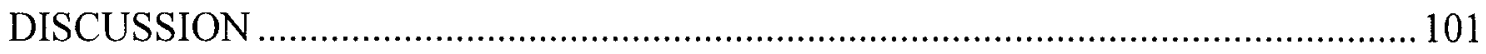

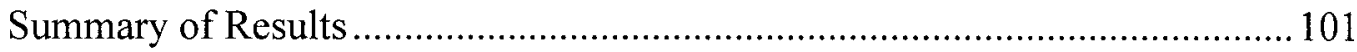

Candidate Plasticity Gene Protein Expression Analysis and Critical Period

Neuronal Plasticity

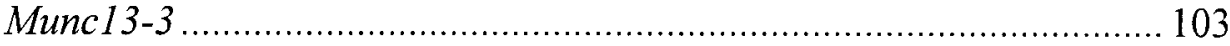

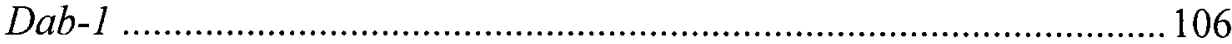

Effect of Dab-1 Mutation NMDA Receptor Subunits during the Critical

Period

Immuohistochemical Analysis of Dab-1 Cortical Expression

Developmental Expression of Dab-1

Dab-1 Immunohistochemistry in the Critical Period in Normal and Dark Reared Cats

Candidate Plasticity Genes and the Critical Period in Visual Cortex .. 112

Visual Evoked Potentials - Establishment of an Electrophysiological

Recording Protocol

Future Directions 


\section{LIST OF FIGURES}

FIGURE

PAGE

1. Layers of visual cortex as seen by cresyl violet staining ................................. 5

2. Schematic illustration of effects of dark rearing on the critical period................... 17

3. Illustration of mouse visual pathway and picture of primary visual cortex............44

4. Dab-1 antibody specificity testing; Western blot and immunohistochemistry ........51

5. Dab-1 antibody specificity demonstration compared with in situ staining.............53

6. Western blots showing antibody specificity for Munc13-3, NR2A and NR2B ......55

7. Western blot comparisons of Dab-1 protein expression in visual cortex, cerebellum and frontal cortex 64

8. Western blot and histogram showing normal and dark reared Dab-1 expression at 3.5 and 9.5 weeks in mouse visual cortex

9. Western blot and histogram showing normal and dark reared Dab-1 expression at 3.5 and 9.5 weeks in mouse frontal cortex.

10. Western blot and histogram showing normal and dark reared Munc13-3 expression at 3.5 and 9.5 weeks in mouse visual cortex

11. Western blot and histogram showing normal and dark reared Munc13-3 expression at 3.5 and 9.5 weeks in mouse frontal cortex.

12. Photomicrographs of Dab-1 immunoreactivity in cat visual cortex during postnatal

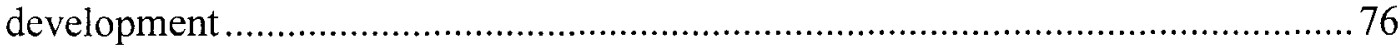

13. Line graphs showing quantification of Dab-1 immunoreactivity during postnatal development 
14. Photomicrographs of Dab-1 immunoreactivity in normal and dark reared cat visual cortex at peak and nadir of critical period. 81

15. Line graphs showing quantification of Dab-1 immunoreactivity in normal and dark reared cat visual cortex at peak and nadir of critical period

16. Photomicrographs of Dab-1 immunoreactivity in normal and dark reared mouse visual cortex at peak and nadir of critical period 86

17. Histogram showing effects of Dab-1 mutation on expression of NMDA receptor subunits 88

18. Surgical fixation apparatus for stereotaxic electrode placement 92

19. Restraint system for awake recording of mouse visual evoked potentials 97

20. Representative records of visual evoked potentials from binocular zone of 3.5 week old mouse visual cortex in normal and monocularly deprived animals. 100 


\section{INTRODUCTION}

Visual cortex development is a complex series of anatomical and physiological processes that can be altered by visual experience. Through a combination of spontaneous activity and stimulus-driven responses, connections are fine-tuned in the cortex ultimately leading to the normal mature state. In the mid-1960s, Hubel and Wiesel discovered that there was a period of early postnatal development (a "critical period") during which the visual cortex has increased levels of malleability in response to visual experience. Experiences occurring within this developmental window yield permanent modifications to the anatomy and physiology of the circuitry of the cortex (Hubel et al., 1977). This phenomenon is the classic demonstration of the widely used term, neuronal plasticity. Critical period plasticity of the visual cortex results from an interaction of genetics and visual input.

The primary purpose of this study is to analyze two genes identified by our lab as possible candidate genes controlling neuronal plasticity during the critical period: Dab-1 and Munc13-3 (Yang et al., 2002; Yang et al., 2006). This introductory section will review important background information including: 1) the development of anatomical

and physiological components of visual cortex; 2) the central tenets of the critical period 
and neuronal plasticity; 3) known roles and properties of Dab-1 and Munc13-3; and 4) experimental benefits of mouse versus cat studies in visual cortex.

\section{Visual Pathway}

In the cat visual system, stimuli are predominantly perceived through the primary visual pathway, also called the retinogeniculocortical pathway. Originating in the eye, retinal ganglion cells form fibers that are carried through the optic nerve (cranial nerve II). Those from the nasal retina of the contralateral eye decussate to merge with fibers from the temporal retina of the ipsilateral eye to form the optic tracts. This partial decussation of retinal fibers transmits the right visual hemi-field to the left side of the brain and the left visual hemi-field to the right side of the brain. The optic tracts each carry information from the contralateral visual hemi-field. These neurons synapse in the lateral geniculate nucleus (LGN) of the thalamus. Visual inputs from the two eyes are segregated in the six different layers of the dorsal LGN. The fibers from the ipsilateral eye synapse in layers 2, 3 and 5 and those from the contralateral eye synapse in layers 1 , 4 and 6. Post-synaptic neurons from the LGN then travel through the optic radiations to the primary visual cortex in the occipital lobe. The projections from individual layers of the LGN remain segregated as alternating columns in layer IV of the primary visual cortex. The anatomically segregated pattern forms the basis for ocular dominance columns which will be discussed later in this chapter. Other brain regions receiving retinal afferent signals include the pretectal nucleus of the optic tract (for pupillary reflexes), the superior colliculus (for eye movements and tracking), and the 
suprachiasmatic and ventrolateral preoptic nuclei (for circadian rhythms and sleep regulation) (Sherman and Spear, 1982).

\section{Visual Cortex Development}

Perinatally, there are five distinct layers present in the visual cortex. From pial surface to white matter, they are : layer I, a compact zone (CZ), a cortical plate (CP), layer V, and a combined layer VI/subplate (SP). The subplate is a transient embryonic layer that disappears within the first two to three postnatal weeks. The compact zone and the upper third of the cortical plate develop into layers II and III and the lower two-thirds of the cortical plate develops into the mature layer IV. During the first several postnatal weeks, neuronal migration and synaptogenesis result in the mature laminar pattern becoming evident by the third week of postnatal development (Luskin and Shatz, 1985a, b; Shatz and Luskin, 1986). The adult cat visual cortex consists of six different layers, numbered I-VI sequentially from the pial surface to the white matter (O'Leary, 1941) (Figure 1). These lamina are distinguished by the size, shape, packing density and receptive field properties of the cells, along with the afferent and efferent connections of these cells with other sites (Garey, 1971; Garey and Powell, 1971; Hubel and Wiesel, 1972; Hollander, 1974; Palmer and Rosenquist, 1974; Lund et al., 1975; LeVay and Gilbert, 1976; Gibson et al., 1978; Gilbert and Wiesel, 1979). 
Figure 1. The layering of cat visual cortex as seen in a mature brain demonstrated by cresyl violet staining. There are six layers, numbered I - VI, from the pial surface to the white matter. WM: White matter. Calibration bar $=100 \mu \mathrm{m}$ 


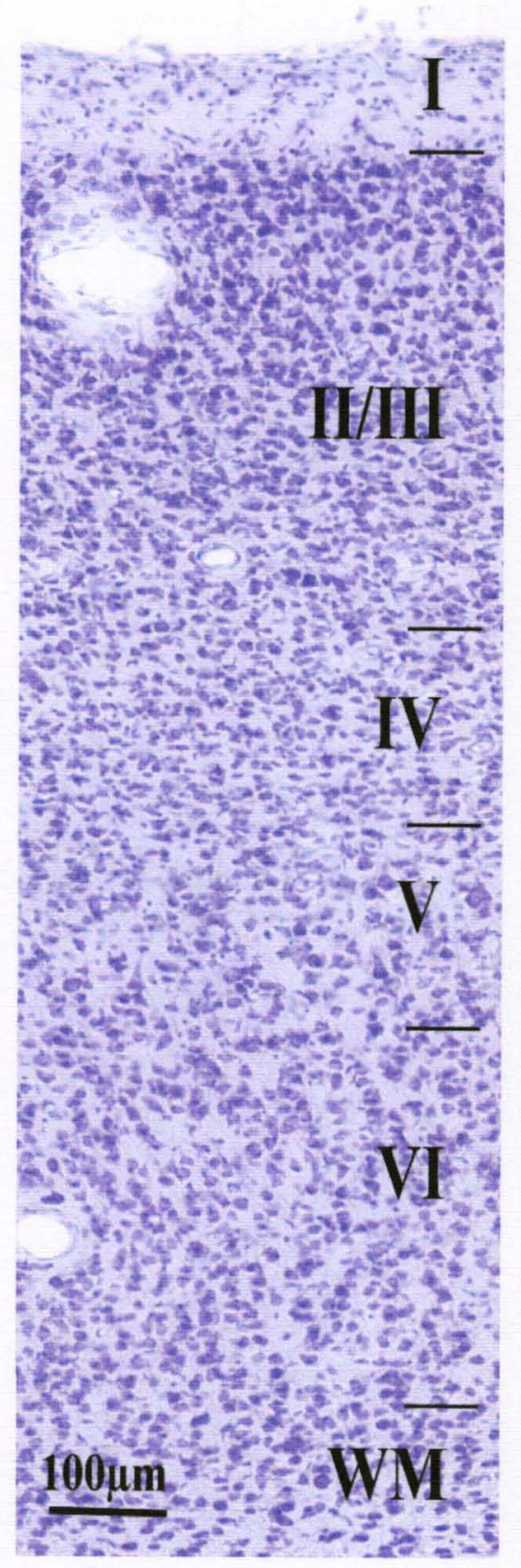

Figure 1 
Developmental birth-dating studies by radioactive labeling of individual neurons show an "inside-to-outside" patterns of neurogenesis. In the cat cells in layer VI are generated early, between embryonic day 31 (E31) and E38, and cells in more superficial layers are generated progressively later (layer V, between E33 and E40; layer IV, between E37 and E44; layer II and III, between E40/41 and E57). Cumulatively, it takes approximately one week for cells in layers VI, V, and IV and two weeks for cells in layers II and III combined to develop ((Luskin and Shatz, 1985a, b)

As mentioned previously, in normal development afferent signals from the left and right eyes remain segregated, synapsing in different lamina of the LGN of the thalamus and ultimately entering layer IV of the visual cortex where they synapse on the cortical neurons. From layer IV these signals are carried primarily to nearby cells in layers II and III where they synapse and then relay to layers V and VI creating a columnar arrangement of the cells in cortex that respond to the same tiny region of the visual field. In primary visual cortex, area 17 , there is a single representation of the cat's entire visual hemi-field. This retinotopic map in area 17 contains a first order transformation of the visual hemifield in which every adjacent point in that portion of the visual field is represented as an adjacent point in the cortex (Tusa et al., 1978). Within primary visual cortex there are individual neurons that respond to stimuli from either eye, the binocular segments. Columns in the binocular segments, although capable of being stimulated by either eye, do show distinct physiological preferences for stimulation by one eye or the other. There are also cortical regions in which neurons are specifically 
driven by stimuli from only one eye, the monocular segment, found in area 17 of the hemisphere contralateral to the stimulated eye (Lowel and Singer, 1987).

In normally reared cats and primates, the projections from the LGN to layer IV of the visual cortex terminate in anatomically distinct clusters representing axon terminals from geniculocortical afferents from each eye. These anatomical features, called ocular dominance columns, have been demonstrated by injecting radioactive labels into one eye producing, through transsynaptic neuronal transport, an alternating pattern of stained and unstained regions in layer IV (Shatz et al., 1977). Confirming the fact that this layer IV staining is representative of the projections from the injected eye through the LGN is the especially prominent and continuous staining pattern in the monocular segment of the contralateral eye and absence of staining in the ipsilateral monocular segment (Shatz et al., 1977).

\section{Neuronal Composition of Visual Cortex}

There are two principal types of cortical neurons. They are stellate cells and pyramidal cells which differ primarily in the shapes of cell bodies and lengths of axons. Pyramidal cells possess larger cell bodies and longer axons (Gilbert and Wiesel, 1979; Nicholls et al., 2001). Pyramidal cells are predominantly found in layers II, III, V, and VI, and stellate cells are mainly present in layer IV (also named the granular layer). Layer I has very few neuronal somas. Layers II and III receive input from layer IV and project to areas 18 and 19 . There is no readily distinguishable border between these two 
layers; however, layer II is characterized by irregular clusters of superficial pyramidal cells. Layer IV receives the majority of the terminal input from the LGN and projects to layer II and III. Layer V receives input from layers II and III and projects back to layers II and III and superior colliculus and pontine and pulvinar nuclei. Layer VI also receives afferent information from the LGN and it projects back mainly to the LGN of the thalamus (Nicholls et al., 2001; Huppe-Gourgues et al., 2006).

\title{
Monocular Deprivation
}

\author{
Monocular Deprivation: Physiological effects
}

Hubel and Wiesel discovered that monocular visual deprivation, surgically closing or occluding one eye, during specific periods of development can lead to irreversible losses of binocularity of individual cells in the visual cortex (Hubel et al., 1977). Physiologically, effects are seen in response properties of the binocular cells in visual cortex that are typically driven by a preference for stimulation by one eye or the other. When one eye is closed by monocular deprivation through the critical period, these binocular cells lose their ability to respond to stimulation to that eye, instead responding only to the experienced eye (Hubel and Wiesel, 1977; Olson and Freeman, 1980). This is supported by the behavioral effects experienced by cats deprived of visual stimulation in one eye during this sensitive period of development showing permanent blindness in the closed eye when that the eye is opened and normal stimulus is restored (Mitchell, 1988). 
Further experiments have demonstrated numerous other neuroanatomical and physiological effects of monocular deprivation. Some of these effects include decreases in stereoscopic depth perception (Timney, 1983), decreases in visual orienting skills (Sherman, 1973) and decreased visual acuity (Giffin and Mitchell, 1978).

Monocular Deprivation: Anatomical effects

The physiological effects of monocular deprivation were correlated by an anatomical basis for altered binocular receptivity. Monocular deprivation during the critical period produces alterations in both the LGN and visual cortex. In the LGN, monocular deprivation yields a reduction in cross-sectional area of cells in the layers that receive afferents from the deprived eye (Wiesel and Hubel, 1963; Guillery and Stelzner, 1970). In visual cortex, ocular dominance columns are affected such that the columns representing the deprived eye are reduced in area while those representing the nondeprived eye are expanded, implying a physical takeover of cortical region by the experienced eye (Shatz and Stryker, 1978; Mower et al., 1985). It has been shown that the physiological response to monocular deprivation is the result of rapid (within one week) activity-dependent remodeling via shortening of the terminal arborization of the geniculocortical afferents to layer IV. This fairly rapid reduction in connections from the deprived eye is contrasted by a slower increase in branching and rearrangement of geniculocortical terminals from the non-deprived eye. The evidence suggests that this reorganization of synaptic terminals results in projections from the non-deprived eye 
developing a broader arborization within layer IV and a decrease in the extent of the terminal arborization of the deprived afferents. This increased projection area yields a greater cortical representation of the non-deprived afferent neurons, thus providing a mechanism for the "takeover" of the cortex previously representing the deprived eye (Antonini and Stryker, 1996).

\section{Critical Period}

The critical period during which the developing cortex is most sensitive to experiential modification varies between species. Since Hubel and Wiesel's original cat experiments, that began the research into the developmental periods when the cortex was more or less modifiable by experience (Hubel and Wiesel, 1970), there have been nearly forty years of studies on visual plasticity. Research during this period has encompassed investigations into definitive time periods of greatest cortical plasticity as well as possible mechanisms controlling and influencing these processes. In spite of the volumes of research on the subject, and although there is consensus as to the time frames of greatest plasticity in specific systems of individual species, there remains surprisingly little unanimous agreement by experts in the field on ultimate determination of genetic and molecular mechanisms initiating and terminating the critical period. Recent transgenic studies have shed light on the role of inhibitory mechanisms in regulating both the timing of the critical period (Huang et al., 1999) as well as the entire susceptibility of visual cortex to modification by sensory experience during the critical period (Hensch et al., 1998). This, along with other significant recent findings, will be discussed in more detail 
following an important review of the historical contributions to the research of the critical period and its traditional understanding.

\section{Time Course of Critical Period}

Cat visual cortex is a well documented, illustrative model for understanding neural development and plasticity at the cellular level. In the cat, the geniculocortical pathway is very immature at birth in terms of both its anatomy and physiology. By three weeks of age, cellular migration has completed formation of the mature lamination pattern in visual cortex, embryonic cells have disappeared, and geniculocortical afferents have reached their final position and begun the process of segregating into ocular dominance columns (Luskin and Shatz, 1985a; Shatz and Luskin, 1986). Correlated with these anatomical events is the appearance of adult-like physiological response properties, such as orientation selectivity, in visual cortex neurons by about 4 weeks of age and little change in response properties occurs thereafter (Pettigrew, 1974; Blakemore and Van Sluyters, 1975). Over the next several months these loosely established anatomical and physiological characteristics are stabilized under the guidance of visual experience. One major event during this period is synaptogenesis, which increases sharply from birth to a peak at about 5 weeks and then declines to adult levels at about 20 weeks of age (Cragg, 1975; Winfield, 1983). Maturation of both glial and neurotransmitter systems also occurs gradually over the first several postnatal months (Skangiel-Kramska, 1988; Muller, 1992). 
It is now clear that ocular dominance columns in layer IV are already present in a state of incomplete segregation at birth or prior to the onset of the critical period in a number of species (Rakic, 1976; Horton and Hocking, 1996; Crowley and Katz, 2000; Crair et al., 2001). In cats, the process leading to incompletely segregated columns is complete by 2 weeks (Crair et al., 2001), activity dependent ocular dominance columns are clearly evident around 6 weeks of age (LeVay et al., 1978) and ocular dominance columns are no longer sensitive to monocular deprivation between 12 and 16 weeks in cats and macaque monkeys (Mower et al., 1985; Horton and Hocking, 1997).

It is during this stage, 6-16 weeks, of cortical development when plasticity, the capacity for anatomical and physiological development to be altered by visual experience, is at its greatest levels. Visual cortex is susceptible to monocular deprivation only during this critical period of postnatal life. In cats, physiological susceptibility to monocular deprivation is absent until about 3 weeks, peaks at 6 weeks, then gradually declines to low levels at 20 weeks and disappears completely between six months and one year of age (Daw et al., 1992).

Another marker for the onset and termination of the critical period that goes beyond a single cortical adaptation to loss of stimulus from monocular deprivation are studies that evaluate the ability of the cortex to recover from this sensory deprivation. These studies have proven significant in understanding critical period time limitations. Studies have been conducted utilizing reverse occlusion, where one eye is monocularly deprived for a set period of time, thus initiating the normal loss of function in the 
deprived eye, then after several weeks, opened the original deprived eye and occluding the other to force all stimulation to the previously closed eye. These studies permit researchers to measure the amount of recovery of function in the originally sutured eye (Blakemore and Van Sluyters, 1975). This allows for a more specific determination of the actual period of true plasticity in visual cortex that includes not only a modification of the neural pathways based on a one-time alteration of stimulus but an assessment of the true period when ongoing cortical adaptations are possible as visual experience and afferent signals are changed over time. These studies of recovery from monocular deprivation with reverse occlusion confirmed the normal cat critical period as having plasticity beginning around two weeks, peaking at 5-6 weeks and diminishing to very low levels by week sixteen (Olson and Freeman, 1980; Fregnac and Imbert, 1984).

\section{Dark Rearing}

Dark rearing animals involves raising animals in a light-free environment from birth, preventing any visual experience for the period of confinement. Although the exact mechanisms remain undefined, it has been demonstrated repeatedly in the visual system that the critical period in not simply a process of maturation based on the age of the animal. There is a significant contribution of visual input during the critical period that affects both the anatomical and physiological development of visual cortex. As previously reviewed, in normally reared animals, approximately the first two weeks of cortical development, prior to segregation of ocular dominance columns, is a process independent of visual input, likely guided by predetermined genetic cues. Although these 
early stages of cortical development in dark-reared animals appear concurrent with those raised in normal light conditions, as development continues anatomical and physiological differences quickly begin to become apparent between the two rearing conditions. Over subsequent developmental weeks, in normal light conditions, the competitive process guides the formation of mature ocular dominance columns. Through dark rearing experiments, this columnar maturation has been shown to be dependent on visually driven neuronal activity since the process does not occur in dark reared animals, where ocular dominance columns remain in a state of incomplete segregation (Swindale, 1981; Mower et al., 1985).

Dark Rearing: Effects on the Critical Period

Most importantly, rearing in total darkness extends the critical period and prolongs neuronal plasticity far beyond its normal age limits (Cynader and Mitchell, 1980; Mower et al., 1981). Monocular deprivation studies in dark-reared animals have shown that the length of time that effects of the procedure can be seen in visual cortex extend for a significantly longer period of time than the standard critical period (Cynader and Mitchell, 1980; Mower et al., 1981; Mower, 1991). As discussed, the critical period for susceptibility of normal cat visual cortex to monocular deprivation is low at two weeks, peaks at approximately 5 weeks and gradually declines over the next $4-5$ months. Dark-reared cat visual cortex has low susceptibility to manipulation through the first five weeks, peaks at approximately 12 weeks of age and remains high in much older animals. As seen in Figure 2, it is important to acknowledge that this effect of extending the 
critical period through dark-rearing is not accomplished through prevention of either onset or decline of plasticity in the cortex, but instead slows down the entire time course and prolongs the entire process, both the rise and decline (Mower, 1991; Beaver et al., 2001). Dark rearing thus provides a means to dissociate changes associated with the state of visual cortical plasticity from changes associated with the general age-based maturation of the animal. This makes it is an ideal system for isolating changes in gene expression potentially involved in controlling neuronal plasticity.

Dark Rearing: Anatomical and Physiological Effects

Visual cortical neurons in kittens raised in normal light environments take on adult-like properties, specifically, orientation specificity, by 5-6 weeks of age (Fregnac and Imbert, 1978). Animals raised from birth in complete darkness show a significant reduction in the percentage of orientation selective cells (Blakemore and Van Sluyters, 1975; Buisseret and Imbert, 1976; Kratz and Spear, 1976; Fregnac and Imbert, 1978). This is not, however, due to an overall lack of receptiveness by visual cortical neurons because most of the neurons in the binocular segment of the dark-reared visual cortex remain receptive to stimuli from either eye (Cynader, 1983; Mower et al., 1985). In cat visual cortex, at two weeks of age, orientation-specific cell responsiveness is the same in both normal and dark-reared animals. However, beyond 17 days of dark-rearing, instead 
Figure 2. The effects of dark rearing on the critical period. Cell recording studies show the effect of dark-rearing slows the entire time course of the critical period. The results of this are that near the peak of the critical period ( 5 weeks in cat visual cortex development) normal cats are more plastic than dark reared cats. Likewise, near the end of the critical period ( 20 weeks) dark reared cats are more plastic than normal. Deprivation Index (y-axis) is a measure of the percentage of cells that show responsiveness to the open after a period of two days of monocular deprivation. This graph is adapted from Mower (1991). 


\section{Dark Rearing and the Critical Period}

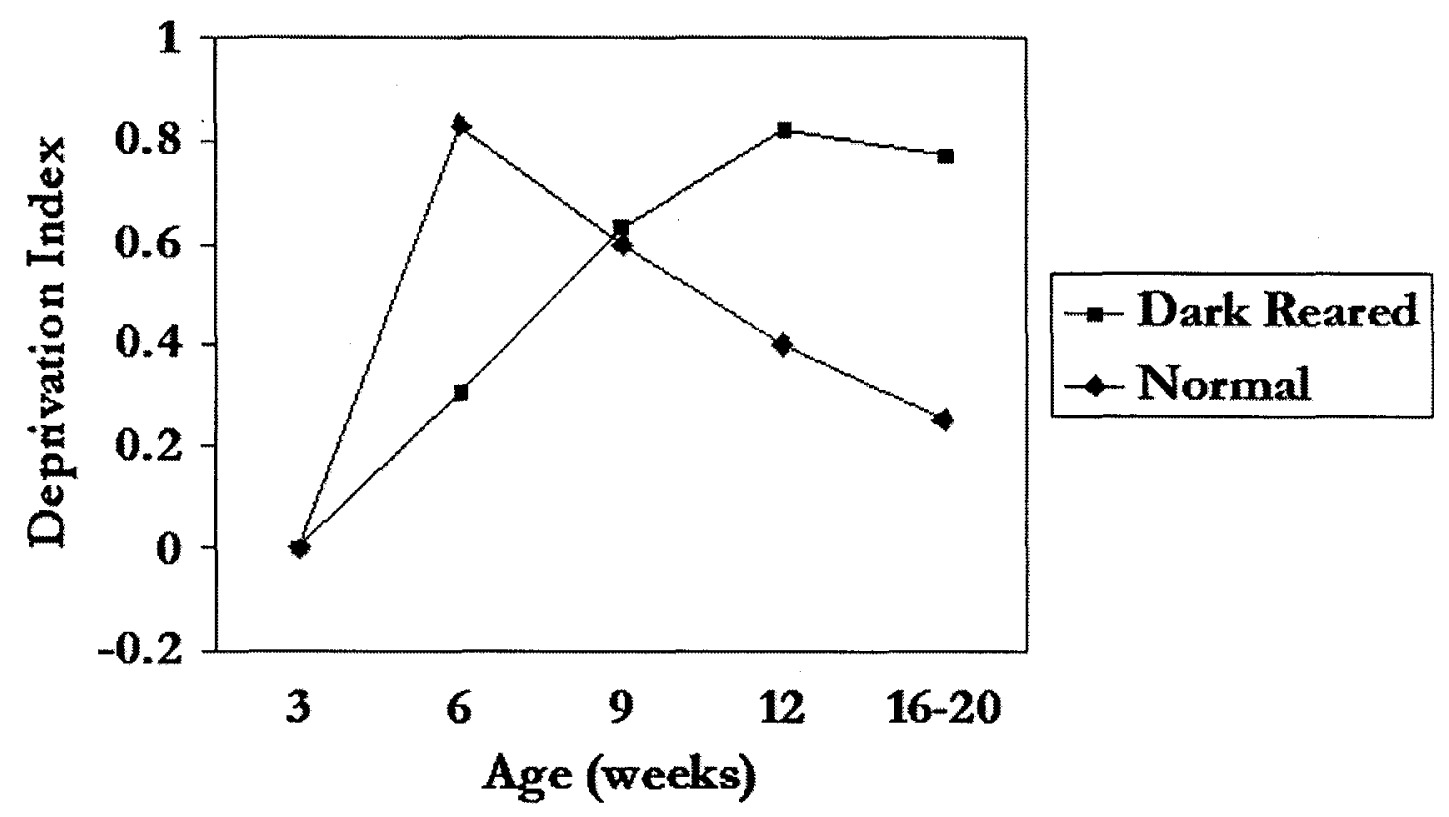

Graph adapted from Mower, 1991. Dev Bran Res 58:151-158.

Figure 2 
of continuing the normal maturation process of cortex involving increases in the ratio of orientation specific to non-specific and unresponsive cells (Fregnac and Imbert, 1978), there is a discontinuation of this process. Dark-rearing essentially freezes this maturation in an undeveloped physiological state leaving a higher ratio of non-selective to orientation selective cells in older dark-reared cortex.

Studies of ocular dominance columns and their susceptibility to monocular deprivation in animals that were dark-reared beyond the normal critical period revealed no anatomical changes in the distribution of the thalamocortical afferents to layer IV of area 17 and no alterations in the ocular dominance columns (Mower et al., 1985). This demonstrates that the anatomical plasticity of cortical area 17, unlike the physiological effects described above, is a product of age dependent processes and proceeds independent of visual experience.

\section{Monocular Deprivation Effects: Revisited}

As studies of plasticity in the visual cortical critical period continued to develop the research progressed from simple analyses of the thalamocortical effects in layer IV and began to assess impacts of monocular deprivation and the associated plasticity in other layers of cortex. There is a columnar arrangement of cerebral cortex perpendicular to the pial surface that extends beyond the ocular dominance columns previously described in layer IV (Hubel and Wiesel, 1962; Hubel et al., 1977; Shatz et al., 1977; Horton and Adams, 2005). The cells in the extragranular layers of these columns have 
similar receptive fields and are linked through intracortical synapses. Although the effects of monocular deprivation were classically thought to result from anatomical reorganization of thalamocortical input to ocular dominance columns in layer IV, it is now clear that there is an extragranular mechanism for critical period plasticity. Numerous studies have revealed differences in critical periods in different cortical layers (LeVay et al., 1980; Daw et al., 1992). Layer IV has been shown to have a critical period that closes prior to that of the extragranular layers (LeVay et al., 1980) and is considerably less plastic than other layers (Mower et al., 1985; Daw et al., 1992). Specifically, monocular deprivation tests at week 14 in normal and dark-reared cats have shown layer IV to be least plastic and layers V and VI to be the most plastic, with layers II and III demonstrating intermediate plasticity (Beaver et al., 2001). However, like layer IV, the extragranular layers show similar effects of dark-rearing with an overall delay and prolonging of the effects of monocular deprivation in dark-reared animals (Mower et al., 1985; Beaver et al., 2001).

Perhaps the most significant finding of studies of the extragranular layers' roles in plasticity was that the immediate effect of brief monocular deprivation is outside layer IV. Extragranular layers show physiological responses to monocular deprivation prior to changes in layer IV (Trachtenberg et al., 2000). Since visual pathways primarily carry information from the LGN to layer IV, to layers II and III, and then to layers V and VI it is now certain that this extragranular mechanism, connected by intracortical synapses in the orientation column, is a primary factor in neonatal monocular deprivation, persisting 
longer in the normal maturation of visual cortex, and is selectively maintained by dark rearing (Mower et al., 1985; Daw et al., 1992; Trachtenberg et al., 2000).

An intriguing implication of these results is that there is complex retrograde signaling from the extragranular layers back to cells in layer IV, which in turn feed back to geniculocortical afferents to guide relative expansion and contraction of eye specific ocular dominance patches in layer IV. Due to the differing states of cortical plasticity between normal and dark-reared developing animals of the same age, with associated differences in gene expression and physiological activity, dark rearing provides an ideal means to study this critical extragranular mechanism. Genes important to maintaining or preventing cortical plasticity will be differentially expressed in developing animals of the same age raised in the different rearing conditions. Those genes that promote plasticity would likely be expressed more highly in light-reared animals at the peak of the normal critical period and lower in dark-reared animals of the same age. These same genes would have their expression reversed in older animals, aged beyond the normal critical period, in which case the light-reared animals would have lower levels of expression while these genes in the dark-reared animals, with their prolonged critical period would, be more highly expressed. These opposing patterns of expression of these genes would contrast with genes that were simply developmentally regulated based on age which would be similarly expressed without regard to rearing condition. 


\section{Genes Regulating Neuroplasticity in Visual Cortex}

Differential gene screening techniques (subtractive hybridization, differential

display PCR [ddPCR], gene arrays) provide the means to identify genes whose expression is specifically elevated in one population compared to another. Numerous studies have manipulated neuronal activity levels to identify genes which may be important for neuronal plasticity, and this approach has proven fruitful in identifying candidate plasticity genes involved in the response of neurons to electrical (Yamagata et al., 1993) and chemical seizures (Nedivi et al., 1993; Qian et al., 1993) or blockade of neuronal activity in the visual system (Corriveau et al., 1998). These approaches have resulted in a great deal of important information on a number of genes which are responsive to visual input, regulated during the critical period and involved in structural and functional plastic responses (Corriveau et al., 1998; Lanahan and Worley, 1998; Corriveau et al., 1999; Huh et al., 2000). Differential screening techniques have been used to specifically identify genes involved in cat visual system plasticity. Shatz's group used ddPCR to screen for genes whose expression in the cat lateral geniculate nucleus is regulated by spontaneously generated action potentials present prior to vision (Corriveau et al., 1998). Results for one gene have been reported and they implicate a role in synaptic plasticity for a class of molecules classically thought to be involved only in the immune response. Cynader's group used subtractive hybridization and Arckens' group proteomics to identify candidates that are differentially expressed in cat visual cortex at the peak of the critical period versus adult animals (Prasad and Cynader, 1994; Van den 
Bergh et al., 2003). While many genes can be identified by this approach they may simply be developmentally regulated and not related to visual cortical plasticity.

The following set of criteria had been proposed by Daw for any substance to be considered as a candidate for involvement in critical period neuroplasticity: 1) the substance should be present in young animals and absent in adults; 2) the substance should follow the critical period (high levels at the peak of the critical period and subsequently fall); 3) the substance should show changes in laminar expression that correspond to known variations with cortical layers and 4) the substance should change in accordance with procedures that change the time course of the critical period (dark rearing) (Daw, 1994).

\section{Identification of Candidate Plasticity Genes}

Based on the evidence that light reared cats have the greatest cortical plasticity at the peak of their critical period around 5 weeks and dark-reared animals do not reach the peak of their critical period until 12 weeks, the Mower lab established a stringent criterion to identify potential genes of importance for plasticity in visual cortex. Through the use of ddPCR one can identify expression levels of individual genes in animals of different ages raised in differing conditions. Genes that show different levels of expression indicate potential functional differences in the differing conditions. As it relates to plasticity and development, those genes most important to plasticity will show differences in expression between normal and dark reared cats that are of opposite 
direction in young versus older animals. The gene screening criterion of opposite direction differences, bidirectional gene expression screening, due to age and dark rearing offers a promising alternative to approaches based on seizures or blockade of neuronal activity for identifying genes important for neuronal plasticity. First, it provides a means to dissociate genes associated with the state of synaptic plasticity from genes associated with the general maturation of the animal. Second, it eliminates genes whose expression is tied directly to neuronal activity and focuses on genes whose expression is regulated according to synaptic plasticity. Dark rearing reduces the responsiveness of visual cortical neurons in both young and older cats (Fregnac and Imbert, 1984; Czepita et al., 1994) but does not affect spontaneous activity (Czepita et al., 1994). Therefore, the overall level of neuronal activity (including visual responses as well as spontaneous activity) in light reared animals is higher than in dark reared animals at all ages, inconsistent with the opposite direction criterion. Third, it is based on a physiologically salient manipulation of synaptic activity with effects restricted to the targeted (visual) pathway. Fourth, because the screen detects steady state levels of expression in the age/rearing condition combinations, it is less likely to detect transient genes such as transcription regulators and more likely to target long lasting effector genes.

In a recent series of studies, the Mower lab has utilized this criterion to identify candidate plasticity genes (Yang et al., 2001; Yang et al., 2002; Yang et al., 2006; Yang et al., 2007). Differential display PCR (ddPCR) screening of theoretically $96 \%$ (GenHunter Corp.) of the expressed genes in the visual cortex of normal and dark reared cats at 5 and 20 weeks was conducted to directly identify candidate plasticity genes that 
show bi-directional gene expression differences. Two patterns of differential expression due to age and dark rearing were uncovered.

One pattern of differential expression is an elevation of gene product in normal cats at 5 weeks and an elevation in dark-reared cats at 20 weeks. This is the difference that the electrophysiology predicts, and it could indicate genes whose expression is required for neuronal plasticity ("plasticity" genes). The other pattern is the opposite: elevation in dark-reared cats at 5 weeks and elevation in normal cats at 20 weeks. This pattern could indicate genes whose expression is suppressed to allow for neuronal plasticity to occur ("anti-plasticity" genes). The finding of these complementary patterns of expression fits with current thinking that a balance between activator and repressor genes controls neural plasticity. The importance of a balance between activator and repressor genes has been documented in a number of systems such as tumorigenesis, axon guidance, synaptic growth and learning and memory (Abel et al., 1998). The visual cortical critical period also likely involves opposing processes with overlapping, but distinct, temporal profiles. One process maximizes adaptive responsiveness to external input while the other promotes crystallization of semi-immutable mature response properties. Identification and characterization of genes showing "plasticity" and "antiplasticity" profiles is a promising new direction for insight into these interactive developmental mechanisms.

Visual cortical plasticity has historically been attributed to excitatory neuronal activation mechanisms, but recent evidence has indicated that repressor processes also 
play an important role. Chondroitin sulphate proteoglycans (CSPGs), a part of the extracellular matrix, have been implicated as inhibitory for visual cortical experience dependent plasticity. CSPGs organize at a time coincident with the end of the critical period, and more importantly, degradation of CSPGs in the adult restores ocular dominance plasticity (Pizzorusso et al., 2002). $\gamma$-Amino Butyric Acid (GABA) inhibition has also been implicated as a plasticity repressor. Mice engineered to overexpress BDNF show advanced maturation of glutamic acid decarboxylase, GAD65, a GABA synthetic enzyme, excessive cortical inhibition and a premature closure of the critical period for monocular deprivation (Huang et al., 1999). These results are consistent with the notion that inhibition acts as a plasticity "gate" whereby once a critical level of inhibition is exceeded, plasticity is lost (Kirkwood and Bear, 1994). Other evidence indicates a more complex role for GABA inhibition (Hensch et al., 1998; Fagiolini and Hensch, 2000; Iwai et al., 2003; Hensch and Fagiolini, 2005). GAD65 knockout mice show reduced plasticity during the rise of the critical period but pharmacological enhancement of GABA inhibition in young GAD65 mutants restores plasticity (Fagiolini and Hensch, 2000; Iwai et al., 2003). Pharmacological enhancement of inhibition in wild type animals prematurely closed the critical period (Hensch and Fagiolini, 2005). These pharmacological results suggest that a threshold of inhibition activates plasticity mechanisms. The combined results of these BNDF and GAD65 gene manipulation results suggest that inhibition plays a role both in activating plasticity mechanisms when they are low and in repressing plasticity mechanisms when they are high. Recent studies on normally raised adult rats deprived of light for 10 days reveal an adult susceptibility to 
monocular deprivation that is also driven by significant decreases in inhibition to levels similar to those seen in juvenile animals (He et al., 2006).

This proposal will focus on two candidate plasticity genes Dab-1 and Munc13-3, which, respectively, show "plasticity" and "anti-plasticity" bidirectional gene expression patterns for age and rearing condition.

\section{Dab-1 and Neuronal Plasticity}

Dab-1 has been shown to display the "plasticity" pattern of bidirectional gene expression in normal and dark-reared cats and mice: highly expressed in normally reared cats at five weeks and low in dark reared and highly expressed in dark reared cats at the 20 weeks and low in normally reared animals. (Yang et al., 2006). Dab-1 is the mammalian homologue of the disabled-1 gene in drosophila. It forms part of the Reelin/Dab-1 signaling pathway that controls neuronal positioning during brain development. Dab-1 acts downstream of Reelin in the signaling pathway as an intracellular, adaptor protein that is phosphorylated when the Reelin ligand binds to very low density lipoprotein receptor and Apolipoprotein E Receptor-2 (VLDLR and ApoER2) receptors on migrating neurons (Howell et al., 1997a; Rice et al., 2001). Recently research suggests that Dab-1 is important as more than just an adapter protein activating multiple kinases but also as structural component to facilitate downstream reactions in the Reelin pathway during development (Feng and Cooper, 2009). 
In mice, Dab-1 is found in both adult and developing brains. In the mature brain, it is expressed in extragranular cortical pyramidal neurons. In embryonic and post-natal mice, the gene has been shown to play a central role in directing the migration of cortical neurons (Rice et al., 2001). Mutants lacking the Dab-1 gene are viable, and appear behaviorally normal until post-natal day 10 at which time they develop a characteristic ataxia, however, they do survive into adulthood (Howell et al., 1997b). Morphologically these mutants show an abnormal cortical development that produces an inversion of cortical layers, as found in reeler mice (a mutation that does not produce Reelin) disrupting neuronal migration and altering lamination patterns in cortex, hippocampus and cerebellum (Howell et al., 1997b; Rice et al., 1998; Pesold et al., 1999; Deguchi et al., 2003).

5-Bromodeoxyuridine (BrdU) labeling of embryonic cells on different days of development demonstrates that neurons typically "born" on earlier dates (those that undergo their final S-phase and maintain a high concentration of the label) are normally found in deep layers of the cortex. In contrast, in the Dab-1 mutants they are found superficially. Cells born on later dates, which typically are found superficially in the cortex, are located in deep layers in the Dab-1 mutant mice. As would be expected with the removal of a downstream component in the Reelin/Dab-1 pathway, the Dab-1 mutation does not impact Reelin production or release and mutant mice do appropriately express Reelin in cortex (Sheldon et al., 1997; Rice et al., 1998). Surprisingly, the retinotopic map, electrophysiological membrane properties, single cell receptive field properties and afferent/efferent connections are largely unaffected in reeler mice 
(Lemmon and Pearlman, 1981; Simmons et al., 1982; Silva et al., 1991); the same is likely true in Dab-1 mutants.

Several lines of recent functional evidence, in postnatal and adult hippocampus, directly implicate the Reelin/Dab-1 pathway in synaptic plasticity. Interference with Reelin signaling reduces long-term potentiation (LTP) and perfusion of Reelin enhances LTP in the hippocampus (Weeber et al., 2002; Beffert et al., 2005). Developmentally, changes in levels of exogenous Reelin affects normal developmental changes in NMDA receptor currents (Sinagra et al., 2005) and impairs dendritic maturation (Niu et al., 2004). Although it remains to be determined if the intracellular mechanisms of Reelin/ Dab-1 signaling in postnatal brain are similar to or different from those in embryogenesis, the pathway is a promising newly identified player in postnatal and adult synaptic plasticity. Gene screening results from our lab clearly indicate a likely role for Dab-1 in the postnatal critical period of both cat and rodent visual cortical development (Yang et al., 2006).

\section{Munc13s and Neuronal Plasticity}

In contrast to the "plasticity" pattern of bidirectional expression shown by Dab-1, recent studies show that Munc13-3 demonstrates the "anti-plasticity" pattern of gene expression in visual cortex (Yang et al., 2002; Yang et al., 2007). Munc13-3 is a member of a family of genes that also includes Munc13-1 and Munc13-2. The Munc13 gene family is the mammalian homologue of the Caenorhabditis elegans 
"uncoordinated" gene $u n c-13$, which has been shown to express a protein that plays a significant role in exocytosis of synaptic vesicles and neurotransmitter release (Brose et al., 1995; Betz et al., 1997; Augustin et al., 1999a; Basu et al., 2007). The onset of expression of all three isoforms of the Munc13 gene corresponds to synaptogenesis, which includes no embryonic expression but a steady increase from birth through postnatal days 15-22. In mammalian brains, the expression patterns of the three genes are localized to different regions. In both cat and rats, mRNA for the predominant isoform Munc13-1 is expressed throughout the brain, but Munc13-2 and Munc13-3 mRNAs are primarily localized to rostral and caudal brain regions respectively (Brose et al., 1995; Yang et al., 2002), suggesting a primary function of Munc13-1 with complementary functions of Munc13-2 and Munc13-3 in differing brain regions. All three of these Munc13 proteins are found in differing subcellular compartments but they all are specifically targeted to presynaptic active zones and have all been shown to play an essential role in vesicle release at glutamatergic and GABAergic synapses (Brose et al., 1995; Betz et al., 1997; Augustin et al., 1999b). Munc13-3 mutants develop grossly normal brain anatomy but behaviorally express difficulty in learning motor tasks attributed to physiological impairments in synaptic transmission (Betz et al., 1998). Numerous studies indicate that Munc13-3 likely plays a role in short-term synaptic plasticity (Zucker, 1989; Augustin et al., 2001; Junge et al., 2004; Zikich et al., 2008; Shin et al., 2010). 
Current published research indicates that Munc13-3 is normally an important upregulator of neurotransmitter release, decreasing paired-pulse facilitation, at synapses supporting its potential role as a candidate gene impacting overall neuronal plasticity.

\section{NMDA receptor}

$\mathrm{N}$-methyl-D-aspartate (NMDA) receptors are ionotropic glutamate receptors that likely play a role in neuronal plasticity of the visual cortex (Nakanishi, 1994; Sawtell et al., 2003; Philpot et al., 2007). Due to their relationship and subcellular colocalization with Dab-1 in the post-synaptic density, they are logical targets for study in Dab-1 mutant mice (Beffert et al., 2005; Chen et al., 2005).

NMDA receptors are multimeric proteins composed of NR1 and NR2 subunits. To date, seven subunits, NR1, NR2A-D and NR3A-B have been identified (Perez-Otano et al., 2001). NR1 is the mandatory subunit for all functional receptors and is necessary for the major characteristic properties. NR2A-2D contribute functional variability to the receptor (Nakanishi, 1992, 1994) and NR3A-B further that variability ((Perez-Otano et al., 2001; Rambhadran et al., 2010). NR1, NR2A and NR2B are the dominant subunits found in cerebral cortex (Monyer et al., 1994; Sheng et al., 1994).

In visual cortex, NMDA receptor activation has been implicated as critical for anatomical and physiological plasticity during early postnatal life. Inhibition of these receptors significantly reduces the shift in ocular dominance caused by monocular 
deprivation in the critical period of visual cortex development (Bear et al., 1990; Roberts et al., 1998; Daw et al., 1999). Subunit composition of the NMDA receptor has been shown to change throughout development providing a mechanism for functional differences of the receptor in distinct anatomical regions at different periods of development (Perez-Otano et al., 2001; Chen et al., 2005; Chen and Bear, 2007). At birth NR2B and NR1 are the predominant subunits in rats and cats. NR2A increases in expression over the first 5 postnatal weeks. NMDA receptor subunit composition in visual cortex is bidirectionally regulated by visual experience and dark rearing reduces this increase in NR2A.(Quinlan et al., 1999; Chen et al., 2000) There are no significant effects of dark rearing on the levels of NR2B and NR1 (Chen et al., 2000). A recent study in mouse visual cortex found that translation of NR2B and the ratio of NR2A:NR2B expression is likely a major point of regulation. This implicates the differential translational regulation of NR2A and NR2B as a potential key contributor to experiencedependent modification in visual cortex plasticity.(Chen and Bear, 2007)

NMDA receptor activity has been shown to be enhanced by Reelin in wild-type cortical neurons but not in Dab-1 deficient cells (Chen et al., 2005). Recent research has shown that blocking exogenous Reelin can reversibly decrease the NR2A:NR2B ratio in hippocampal cultured neurons (Campo et al., 2009) further solidifying the justification for additional research into the relationship between Dab-1 and these two proteins. 


\section{Plasticity in Mouse vs. Cat Visual Cortex}

The studies described here utilized both cat and mouse models; the bidirectional gene expression screening approach was extended to mice since mutant gene knockouts are possible.

Cat and primates have historically been studied as the definitive models for determining the chemical, anatomical and molecular markers that play a role in visual cortical plasticity. Studies in cats, where specific laminar changes are well documented (Shatz and Stryker, 1978; LeVay et al., 1980; Mower et al., 1985; Daw et al., 1992; Antonini and Stryker, 1993), and in rodents, show a number of parallels between the visual systems. The most prominent difference between them is that although rodents do have cortical regions, visible with optical imaging by transneuronal tracing, that are innervated by monocular or binocular afferents, they do not have highly organized ocular dominance columns as in higher mammals (Antonini et al., 1999). A primary factor in this differential cortical organization is that while LGN afferents in cats and primates terminate almost entirely in Layer IV, in rodents, these thalamocortical projections are not as localized, terminating not only in layer IV, but also in supragranular layers II and III and infragranular layers V and VI (Gordon and Stryker, 1996). The majority of the literature review in this dissertation comes from studies conducted in cats and primates implicating the importance of laminar differences in cortical plasticity. Since ocular dominance columns are not present in layer IV of rodents, but are well documented in cats, cats will be predominantly used for the histological analysis of Dab-1 expression. 
Physiological and anatomical analyses of the critical period of the mouse visual corticex indicate other similarities and differences to cats (Gordon and Stryker, 1996; Antonini et al., 1999). Differences in the effects of monocular deprivation seen in rodents as compared to cats include the size and retinal location of the binocular visual field, quantitative differences in the magnitude of the physiological effect of monocular deprivation, and dramatic differences in the effects of monocular deprivation between hemispheres (Gordon and Stryker, 1996). In similarity with the cat, the mouse shows a measurable effect of monocular deprivation, a critical period for such effects, a prolongation of the critical period by dark rearing (Gordon and Stryker, 1996) and effects of monocular deprivation on terminal arbors of geniculocortical axons representing the open and closed eye (Antonini et al., 1999).

The normal critical period of cat visual cortex begins around 3 weeks, peaks around 5 weeks of age, diminishes and diminishes to low levels by week 20 (Daw et al., 1992) and ends around 30 weeks (Daw, 1994). Rodent visual cortical critical periods are shorter than those found in other mammals, with the classical definition of the mouse critical period beginning at eye opening, peaking around 3.5 weeks, diminishing thereafter and ending around 9.5 weeks (Guire et al., 1999; Fagiolini et al., 2003; Sawtell et al., 2003). Greater understanding of this time frame is being gained through finding that the balance of cortical excitatory/inhibitory signals and their rate of responsiveness to changes in visual experience (Gandhi et al., 2008) plays a significant role in its determination. New research indicates that molecular alterations can be made to 
significantly extend or even "reopen" the critical period in adult animals through the introduction of inhibitory neurons to developed cortex (Southwell et al., 2010).

\section{Benefits of Mice for Mechanistic and Mutation Studies}

Although higher mammals have been the basis for the majority of the mechanistic studies of cortical development, murine models are becoming more popular for understanding the mechanisms responsible for activity dependent plasticity because they have been found to share many of the same mechanisms that are thought to guide this development. Beyond these similarities, however, mouse models have the distinct advantage of genetic manipulation which makes them more useful as a species to study the molecular and cellular mechanisms that contribute to cortical plasticity. Viable transgenic mice with specific exclusions ("knockout") or inclusions ("knockin") of genes thought to play roles in any system allow for detailed examination of those genes' contributions to the system. Several studies in this proposal will utilize Dab-1 knockout mice, in different rearing conditions, to specifically examine potential relationships between Dab-1 and other candidate genes identified through gene screenings and their roles in plasticity of the visual cortex.

\section{Purposes of this Study}

This project studied the potential role in critical period neuronal plasticity of visual cortex of two genes, Dab-1 and Munc13-3, which had been previously identified 
as candidate plasticity genes (CPGs) through RNA analysis by our laboratory. This research was conducted in cats and mice to determine whether the results of the RNA screening can be extended to Dab-1 and Munc13-3 protein expression levels in the critical period, whether Dab-1 laminar expression in visual cortex correlates with known laminar differences in physiological plasticity during the visual cortical critical period, whether the laminar expression levels of Dab-1 are dependent upon visual input, and whether or not mutations in Dab-1 alter expression of other CPGs. [A secondary objective was to develop a reliable laboratory set-up and protocol to record mouse visual evoked potentials for future testing of physiological effects of Munc13-3 and Dab-1 mutations through the established plasticity model of monocular deprivation.]

To accomplish these objectives, four distinct aims were developed:

1. An important criterion for a molecule to be considered a candidate for critical period plasticity is that its expression should be changed by a manipulation that can alter the time course of the critical period, such as dark rearing. This predicts that if a molecule is critically involved in visual cortical plasticity there should be opposite directions of difference in the level of expression between normal and dark reared cats at 5 versus 20 weeks of age (peak and nadir of the critical period). Previous research by the Mower lab has identified numerous genes through ddPCR screening that were likely candidates to play a role in visual cortical plasticity. Published RNA analysis, by Northern blot, confirmed Dab-1 and Munc13-3 as two likely genes. This study expanded that analysis to 
determine whether or not the RNA results could be extended to protein expression during the critical period in both cats and mice. To conduct this analysis protein from visual cortex of normal and dark-reared mice at 3.5 and 9.5 weeks of age were analyzed by quantification of Western blots.

2. Monocular deprivation studies have demonstrated that the critical period is different among lamina of cat visual cortex. Plasticity in layer IV ends earlier than the superficial (I, II and III) or deeper (V and VI) layers. If genes are involved in plasticity of the critical period the level of expression of the gene would likely be regulated during development in a manner that correlates with the known developmental laminar differences over the time course of the critical period. Dab-1 laminar protein expression was studied through immunohistochemical staining of cat visual cortex throughout development of the critical period ( $1 \mathrm{wk}, 5$ wks, 10 wks, 20 wks and adult).

3. Numerous genes have been identified through the bidirectional paradigm as potentially playing a role in the critical period of visual cortex development. It is plausible that there exists a relationship between Dab-1 expression and the function or expression of other candidate plasticity genes. Through the use of normal and dark reared Dab-1 mutant mice (homozygous recessive mutants) at 3.5 and 9.5 weeks it was determined that other candidate plasticity gene proteins were impacted by the absence of Dab-1 during the critical period. Specifically, the proteins studied included NMDA receptor subunits that have been identified as 
likely to play a role in visual cortical plasticity (NR2A and NR2B).

4. There is a well-documented physiological response to monocular deprivation during the critical period of mouse visual cortex in which binocular cells shift their response from primarily being driven by stimulation to the contralateral eye to a stronger ipsilateral response following suture of the contralateral eye. This project included establishment of a reliable laboratory set-up and experimental protocol to temporarily deprive mice of monocular visual experience and record visual evoked potentials (VEPs) in the Mower lab. Establishment of this protocol will permit future physiological experiments testing whether mice that are knockouts for Dab-1 and Munc13-3 show VEP responses to monocular deprivation that differ from normal. 


\section{MATERIALS AND METHODS}

\section{Animal Breeding and Rearing Conditions}

\section{Cats}

Cats were purchased from Liberty Laboratory (New Jersey) and Snowhill Breeding Kennels (West Harrison, IN). They were raised in the Research Resource Center, University of Louisville. The procedures conform to the guidelines of the National Institutes of Health and were approved by the Institutional Animal Care and Use Committee. Our lab and this researcher have an extensive history of dark rearing animals and records indicated no difference from the lighted colony in terms of survival rate and body size.

Normal cats were raised in a 12-h light/dark cycle until 1, 5, 10, 20 weeks or adult age. Dark reared cats were reared in complete darkness from birth and were sacrificed at 5 and 20 weeks without exposure to light.

Cats were sacrificed by an overdose of sodium pentobarbital $(75 \mathrm{mg} / \mathrm{kg}$ i.p. or $50 \mathrm{mg} / \mathrm{kg}$ i.v.). For western and northern/slot blot studies, fresh brain tissue (all of Area 17 
and possibly a small part of 18 , frontal cortex and cerebellae) were dissected, immediately frozen in liquid nitrogen, and stored at $-80^{\circ} \mathrm{C}$ until use. For immunohistochemistry studies, perfusion was performed intracardially through the left ventricle with $37^{\circ} \mathrm{C}$ PBS $(0.91 \mathrm{NaCl}$ in 0.1 phosphate buffer, $\mathrm{pH}=7.4)$ until fluid from right atrium ran clear indicating complete flushing of blood from systemic circuit. This was immediately followed by perfusion of $4 \%$ paraformaldehyde in PBS at $4{ }^{\circ} \mathrm{C}$ for approximately 20 minutes. Brains were removed and blocked into cerebral hemispheres divided into anterior and posterior regions, cerebellar hemispheres and brainstem structures. The tissues were post-fixed in $4 \%$ paraformaldehyde in PBS overnight at $4{ }^{\circ} \mathrm{C}$. Finally, the tissues were then cryoprotected by immersion in $30 \%$ sucrose in PBS at $4{ }^{\circ} \mathrm{C}$ until they sank. The blocked sections were frozen in crushed dry ice and stored at $-80^{\circ} \mathrm{C}$ until use.

Mice

Mutant mice that have been genetically engineered as knockouts for Dab-1 were obtained from Jackson Labs (CBy.129S4-DabI $\left.I^{t m I C p r} / \mathrm{J}\right)$. They were raised in the Research Resource Center (RRC), University of Louisville. The procedures conform to the guidelines of the National Institutes of Health and were approved by the Institutional Animal Care and Use Committee. Homozygous recessive mice for the Dab-1 knockout demonstrate a characteristic ataxia noticeable by postnatal day 14 . Mice heterozygous for the knockout gene, as determined by multiplex PCR genotyping of the Dab-1, were identified and cross-bred to establish a breeding colony. Heterozygous breeding pairs 
were kept in the barrier facility in the RRC barrier facility as back-up animals in the unlikely event that due to unforeseen circumstances the colony in the RRC needed to be depopulated. Every pup was ear-tagged and genotyped in order to maintain the most genetically diverse population possible.

Mice with a spontaneous mutation in Dab-1, "scrambler" (Jackson Labs, $A / A$ $D a b 1^{s c m} / \mathrm{J}$ ) were also ordered as a supplemental colony to the knockout mice. While no genotyping protocol is available from Jackson Labs to determine wild-type homozygotes from heterozygotes, the homozygous recessive animals demonstrate the same characteristic ataxia and other known phenotypes of the knockout mice. It was the experience of this researcher that homozygous recessive scrambler pups have a much higher survival rate that those of the Dab-1 knockout, especially when dark reared.

Experimental mice were kept in 12-hour light/dark cycles or dark reared from birth. Dark-reared animals were housed from birth in standard mouse cages within a light tight enclosure. The cages were changed three times per week when the animals were fed. During cleaning and feeding, the investigator wore infrared amplifying goggles with an attached infrared light source filtered by a double-layer Wratten filter to reduce potential extraneous light. This allowed for visual inspection of the dark-reared animals on a regular basis without exposing them to visible light. The standard dark rearing periods for the mice in these experiments were from birth until 3.5 and 9.5 weeks. 
While Dab-1 knockouts raised in normal 12-hour light/dark cycles had high survival rates, several months of dark-rearing of litters with Dab-1 knockout homozygous animals failed to produce survival of any mutants for more than two-weeks post-weaning (approximately 6-7 weeks of age). Their wild-type litter-mates survived normally. Subsequent to the onset of this rearing protocol, research was published indicating abnormal development of the rostral migratory stream and severe neuroanatomical defects in the olfactory bulb of Dab-1 mutant mice (Andrade, et.al. 2007). These olfactory deficits of the knockout mutants, combined with the ataxic phenotype, impair the mutants' abilities to smell and access food and water that they cannot see suspended above them in the standard mouse cage. Once the mothers had been removed postweaning the homozygous mutants were apparently unable to find food or water in the cage. This situation did not occur in the light-reared cages. It is believed that the normally reared animals could see other mice consuming the food/water and thereby learn the behavior and survive. The post-weaning loss of mutant pups in dark-reared cages was somewhat alleviated through the introduction of "Napa Nectar" pouches (a gel-based water source) and food placed on the floor of the cage. Even with the added precautions, 9.5 week survival rates of dark-reared homozygous knockout pups were extremely low. The survival rate of dark-reared scrambler pups, a spontaneous Dab-1 mutant with identical phenotypes to Dab-1 knockout mutants, when given the same precautions, was markedly higher. The precise reasons for this are unknown but could be attributed to a hardier background mouse strain (agouti vs. white). 
For western blot analysis, mice were sacrificed by an overdose of sodium pentobarbital prior to tissue dissection ( $75 \mathrm{mg} / \mathrm{kg}$, i.p.). The animals were then decapitated and visual cortex (monocular and binocular regions), frontal cortex and cerebellum were immediately dissected, weighed and frozen in liquid nitrogen. The tissue was stored at $-80^{\circ} \mathrm{C}$ until used for protein analysis.

Figure 3 demonstrates the region of the mouse brain representing both the monocular and binocular regions of mouse primary visual cortex. It is important to emphasize that both regions are included in this dissection meaning that any findings of altered gene expression in these experiments could be conservative underestimates of the effects in the binocular zone.

Tissue for immunohistochemistry was obtained from mice injected with an overdose of sodium pentobarbital ( $75 \mathrm{mg} / \mathrm{kg}$, i.p.) and perfused intracardially through the left ventricle with $37^{\circ} \mathrm{C}$ PBS $(0.91 \mathrm{NaC} 1$ in 0.1 phosphate buffer, $\mathrm{pH}=7.4)$ until fluid from right atrium ran clear indicating complete flushing of blood from systemic circuit. This was immediately followed by perfusion of $4 \%$ paraformaldehyde in PBS at $4{ }^{\circ} \mathrm{C}$ for approximately 20 minutes. Brains were removed and blocked into cerebral hemispheres divided into anterior and posterior regions, cerebellar hemispheres and brainstem structures. The tissues were post-fixed in $4 \%$ paraformaldehyde in PBS overnight at $4^{\circ} \mathrm{C}$. Finally, the tissues were then cryoprotected by immersion in $30 \%$ sucrose in PBS at $4^{\circ} \mathrm{C}$ until they sank. The blocked sections were frozen in crushed dry ice and stored at $-80^{\circ} \mathrm{C}$ until use. 
Figure 3. A. The primary visual cortex of the mouse, schematic diagram of the central visual pathway in the mouse. Retinal ganglion cell axons project to eye-specific regions of the LGN. Geniculocortical projections carrying information from the two eyes converge in the lateral one third of the primary visual cortex (V1), in the binocular zone. B. Image from Mouse Atlas of Gene Expression showing VI of mouse visual cortex that was removed for protein analysis. 

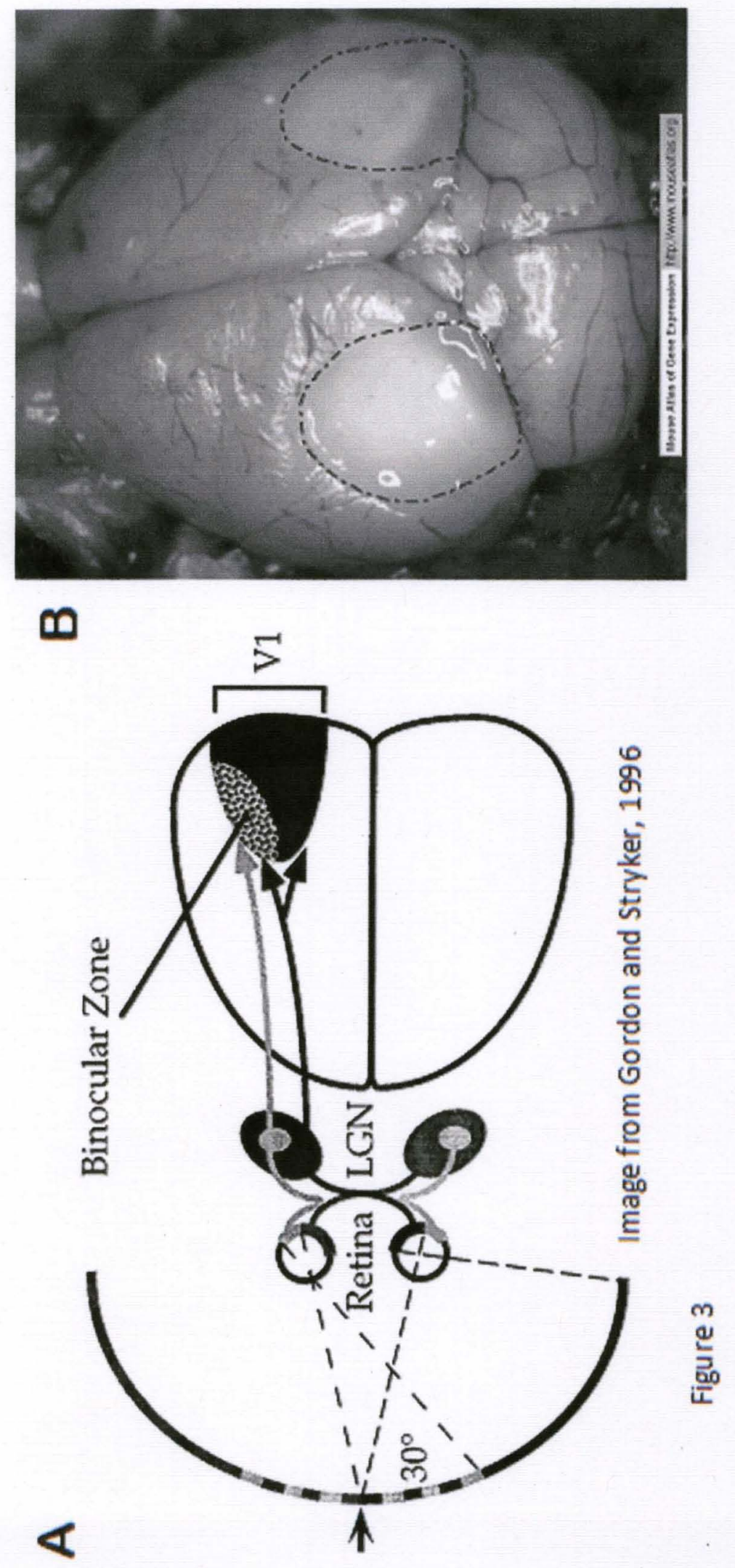
The tissue was mounted with OCT and sectioned coronally $(30 \mu \mathrm{m})$ on a cryostat (Cryocut 1800, Reichert-Jung, Austria). Sections were collected and stored in PBS $\left(4^{\circ} \mathrm{C}\right)$ until processed. For each section processed for immunohistochemistry, an adjacent section was stained with cresyl violet (details below).

\section{Western Blot Procedures}

Sample Preparation

Homogenates of visual cortex were prepared on ice in the presence of a standard cocktail of homogenization buffer with protease inhibitor (PI) (aprotinin, $0.1 \mathrm{mg} / \mathrm{ml}$; leupeptin, $0.1 \mathrm{mg} / \mathrm{ml}$; antipain, $0.1 \mathrm{mg} / \mathrm{ml}$ pepstain, $0.01 \mathrm{mg} / \mathrm{ml}$ in Tris- $\mathrm{HCl}$ buffer [ 40 $\mathrm{mM}, \mathrm{pH}$ 7.4] containing $1 \mathrm{mM}$ EDTA- $\mathrm{Na}_{2}$ and $0.2 \mathrm{mM}$ PMSF). For mice, visual cortex

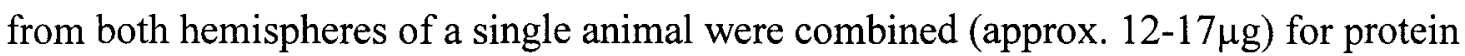
extraction. Crude synaptosomal fractions were obtained by the addition of $250 \mu 1$ of homogenization buffer with PI to each sample. The samples were homogenized with a $4.5 \mathrm{~mm}$ Tissue Tearor ${ }^{\mathrm{TM}}$ rotor/stator tissue homogenizer. [50 $\mu$ l of homogenization buffer were then added to bring sample to $300 \mu 1$.] Samples were centrifuged at 3000 RPM (900G) at $4^{\circ} \mathrm{C}$ for $10 \mathrm{~min}$. The supernatant (S1) was removed and collected in a separate tube. An additional $250 \mu$ of homogenization buffer with PI was added to resuspend the pellet (P1) and was again centrifuged for $10 \mathrm{~min}$ at $3000 \mathrm{RPM}(900 \mathrm{G})$ at $4^{\circ} \mathrm{C}$. The supernatant (S1') was removed and combined with S1. The combined supernatants were centrifuged at $9900 \mathrm{RPM}(10000 \mathrm{G})$ at $4^{\circ} \mathrm{C}$ for $20 \mathrm{~min}$. The supernatant (S2) was removed 
(cytoskeleton, microsomes and soluble proteins) and stored separately. The remaining pellet was dissolved in $100 \mu$ l of homogenization buffer with PI. This solution (crude synaptosome fraction) was divided into equal parts, quantified as described below, and stored at $-80^{\circ} \mathrm{C}$ until used.

\section{Total Protein Quantification}

Protein quantification was performed by Bradford assay in a BioRad SmartSpec ${ }^{\mathrm{TM}}$ Plus spectrophotometer. 2.5 $\mu$ l of each sample was placed in a tube and brought to $50 \mu \mathrm{l}$ with $47.5 \mu \mathrm{l}$ of double-distilled $\mathrm{H}_{2} \mathrm{O}\left(\mathrm{ddH}_{2} \mathrm{O}\right) .950 \mu \mathrm{l}$ of BioRad Protein Assay (diluted 1:5 with $\mathrm{ddH}_{2} \mathrm{O}$ ) was added for quantification. Protein standards using bovine serum albumin (BSA) were freshly made; a new standard curve was developed for each protein quantification. The standard curve was created with appropriately diluted aliquots of BSA concentrations ranging from $0-200 \mu \mathrm{g} / \mathrm{ml}$.

Protein Separation

Protein separation was performed by gel electrophoresis in a MiniPROTEAN II Cell apparatus (BioRad, Hercules, CA). Equal amounts of protein ( $20 \mu \mathrm{g}$ protein/sample) were denatured via incubation at $95^{\circ} \mathrm{C}$ with $2 \mathrm{X}$ Laemmli buffer (BioRad) for $4 \mathrm{~min}$ and cooled to room temperature before loading. Samples were loaded into individual wells of a 4-15\% Tris-HCl polyacrylamide SDS gel (BioRad Ready Gel 161-1122), separated by electrophoresis (104V for approximately 1.5 hours). The protein was then 
electrophoretically transferred to a nitrocellulose membrane using a Transblot SD semidry transfer apparatus (Biorad) at $25 \mathrm{~V}$ for approximately 50 minutes. After transfer, the membrane was stained with Ponceau Stain in $1 \%$ acetic acid to assure transfer then destained by washing three times in TBS-T.

\section{Protein Staining}

Western Blot protein analysis protocol was performed as follows:

1. Nonspecific binding sites were blocked with $5 \%$ non-fat milk and $0.5 \%$ Tween 20 in TBS for 1 hour.

2. Rinse in TBS-T for five minutes

3. Incubation with the primary antibody in TBS-T at room temperature for 2 hours (Control blots were identically processed with the primary antibodies replaced by antibody diluents)

4. Wash in TBS-T for five minutes X 3 .

5. Incubation with appropriate biotinylated secondary antibody in 5\% milk in TBS-T.

6. Wash in TBS-T for five minutes X 3 .

7. Protein visualization via ECL solution exposure (Amersham, Arlington, IL) for one minute.

8. Film exposure (0.5 to 3 minutes) to Hyblot CL autoradiography film

9. Film was developed in a Kodak X-OMAT 2000A automatic film processor. 
10. Filters were then stripped with Restore ${ }^{\mathrm{TM}}$ western blot stripping buffer (Thermo Scientific) for $15 \mathrm{~min}$ at $37^{\circ} \mathrm{C}$, rinsed completely with TBS-T (5 min $X$ 3) and reprobed with an antibody to $\beta$-actin to control for loading errors.

Quantification of Protein Expression Levels

The exposed films were quantified by computerized densitometric analysis (Alpha Innotech). Protein expression levels for each individual antibody were calculated as an average pixel density. Values were corrected by measured values of $\beta$-actin for each sample and normalized to the mean of all four samples for each blot. The means of animals in each age group/rearing condition from three independent samples were used to express the relative expression levels.

Antibody Specificities

For Western blot analysis of Dab-1, commercial rabbit polyclonal antibody (Santa Cruz) labeled a single band of appropriate size (approx. $80 \mathrm{kDa}$ ) (Figure 4A). For immunohistochemical analysis of Dab-1, rabbit polyclonal antibody (Rockland Immunochemicals, Inc.) was recommended by the laboratory of Dr. Jonathan Cooper. Western blot analysis of this antibody labeled the appropriate band (approx. 80kDa, Figure 4B). Immunohistochemical staining of the Rockland antibody in wild-type, mutant, and negative controls (no primary antibody), compared to in situ Dab-1 mRNA hybridization in normal 3.5 week mouse brain revealed appropriate staining levels and 
similar results between wild-type immunohistochemical and in situ staining patterns further confirming specificity of the antibody (Figures $4 \mathrm{C}$ and 5). The Munc13-3 antibody, provided by Drs. Nils Brose and Frederique Varoqueaux, labeled an appropriate band at $206 \mathrm{kDa}$ (Figure $6 \mathrm{~A}$ ). Rabbit polyclonal antibodies specific to NMDA receptor subunits NR2A and NR2B were obtained commercially from Millipore, Inc. Each antibody labeled a single band of appropriate molecular weight (NR2A: 180kDa and NR2B: 180kDa) (Figure 6B-C). 
Figure 4. Antibody specificity testing for the two different Dab-1 antibodies used for this project. A. The Santa Cruz antibody was utilized for the Western blot protein analysis and labeled an appropriately sized $80 \mathrm{kDa}$ band. B. The Rockland antibody was recommended by the laboratory of Dr. Jonathan Cooper for immunohistochemistry. It also labeled an appropriate band of approximately $80 \mathrm{kDa}$ in Western blot analysis. C. Comparisons of immunohistochemical tests of Rockland Dab-1 antibody to confirm its usage for analysis. Sections from four week old mice were stained for comparison including, from left to right, wild-type, Dab-1 knockout, no primary antibody (negative control) and an in situ stained section showing Dab-1 mRNA expression (unpublished results, Mower lab). 


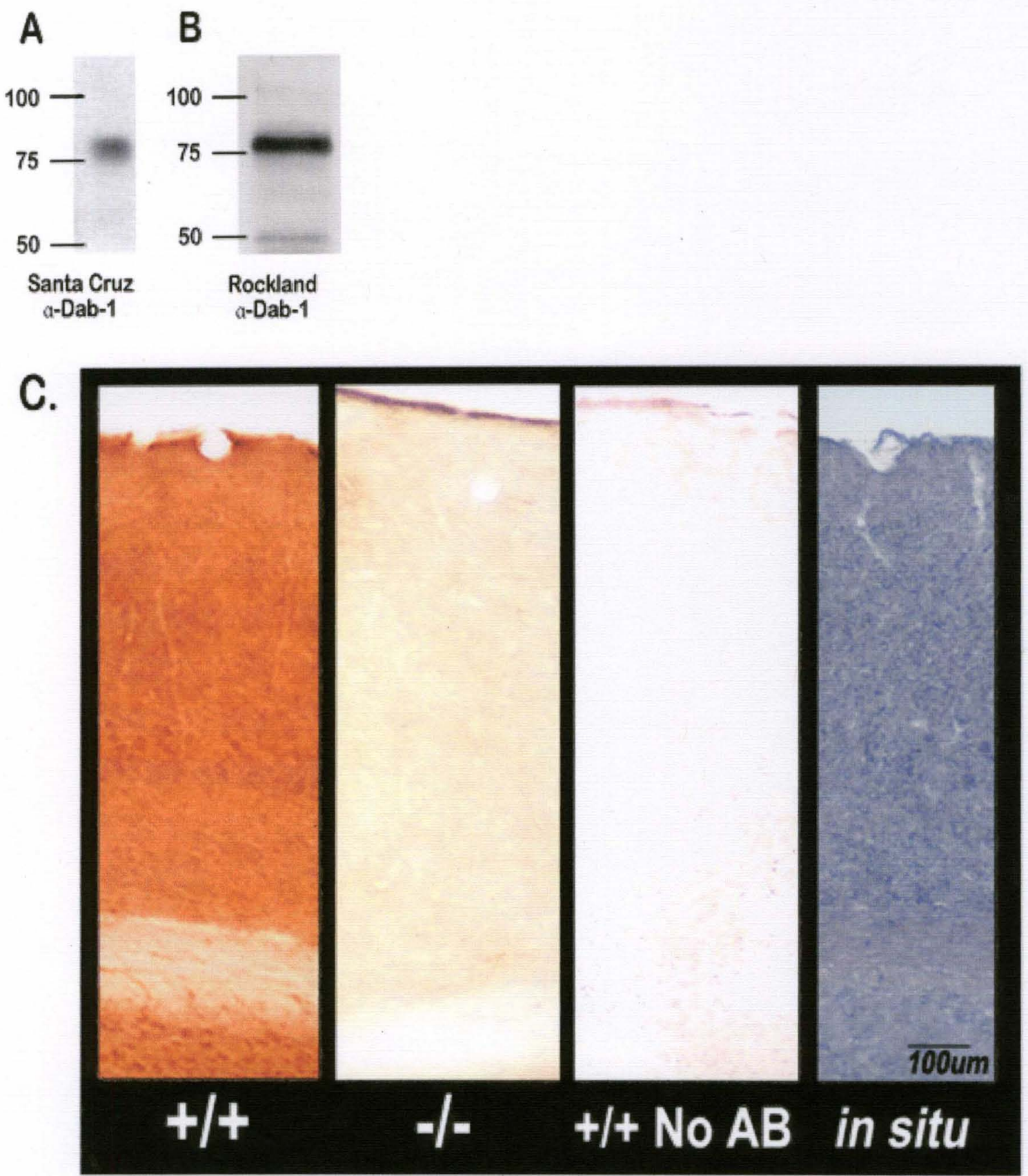

Figure 4 
Figure 5. Further specificity testing of Rockland antibody through comparisons of staining patterns of immunohistochemistry of Rockland Dab-1 antibody and in situ labelling of Dab-1 mRNA in full sections of four week old wild-type mouse brain. Note similar staining in hippocampus both sections confirming antibody specificity. 


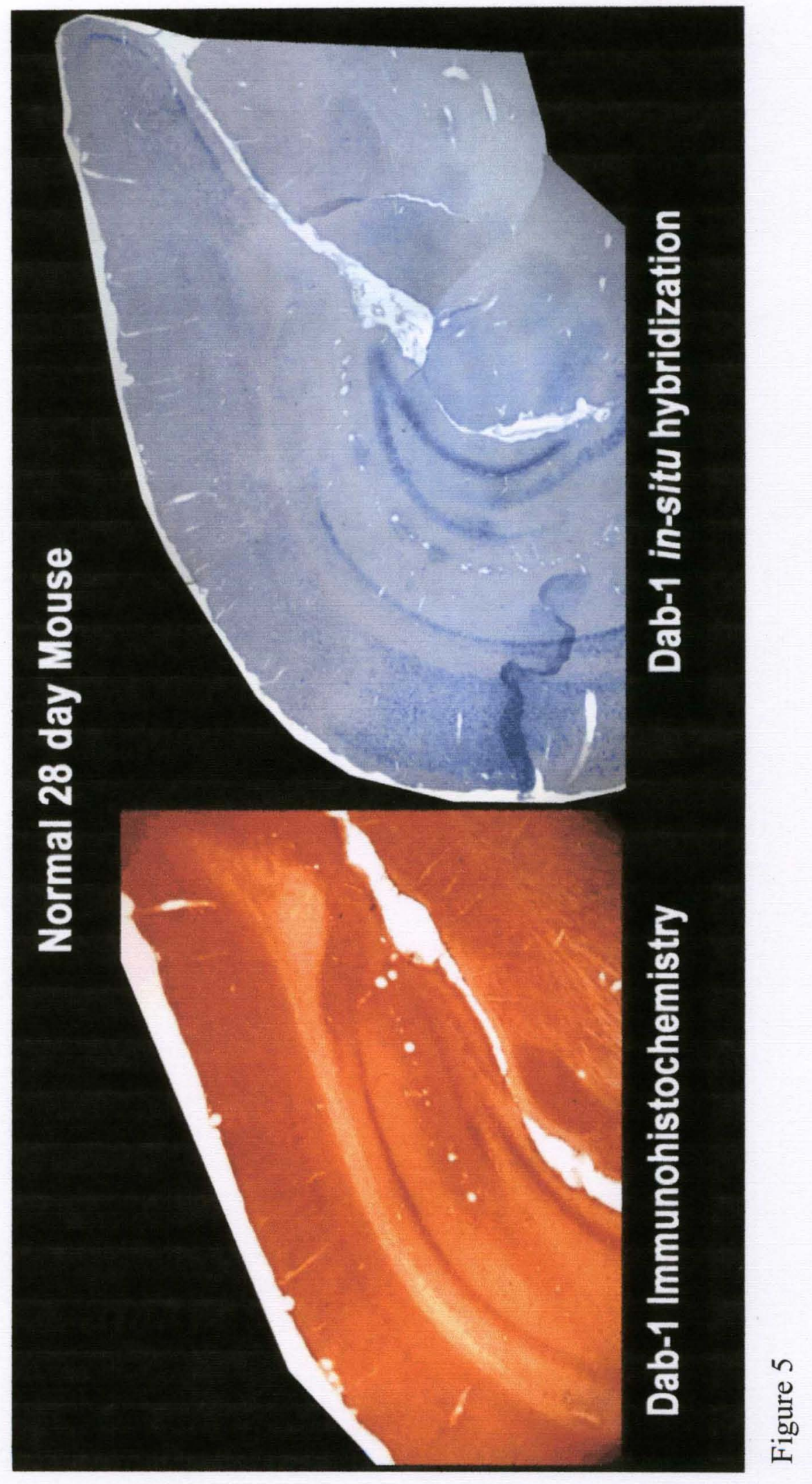


Figure 6. Western blotting showed the specificity of antibodies used for protein analysis in this dissertation. A. The antibody for Munc13-3 labeled an appropriate band at 206kDa Antibodies for NMDA receptor subunits NR2A (B) and NR2B (C) were obtained commercially from Millipore, Inc. Each antibody labeled a single band of appropriate molecular weight (approximately $180 \mathrm{kDa}$ ). 


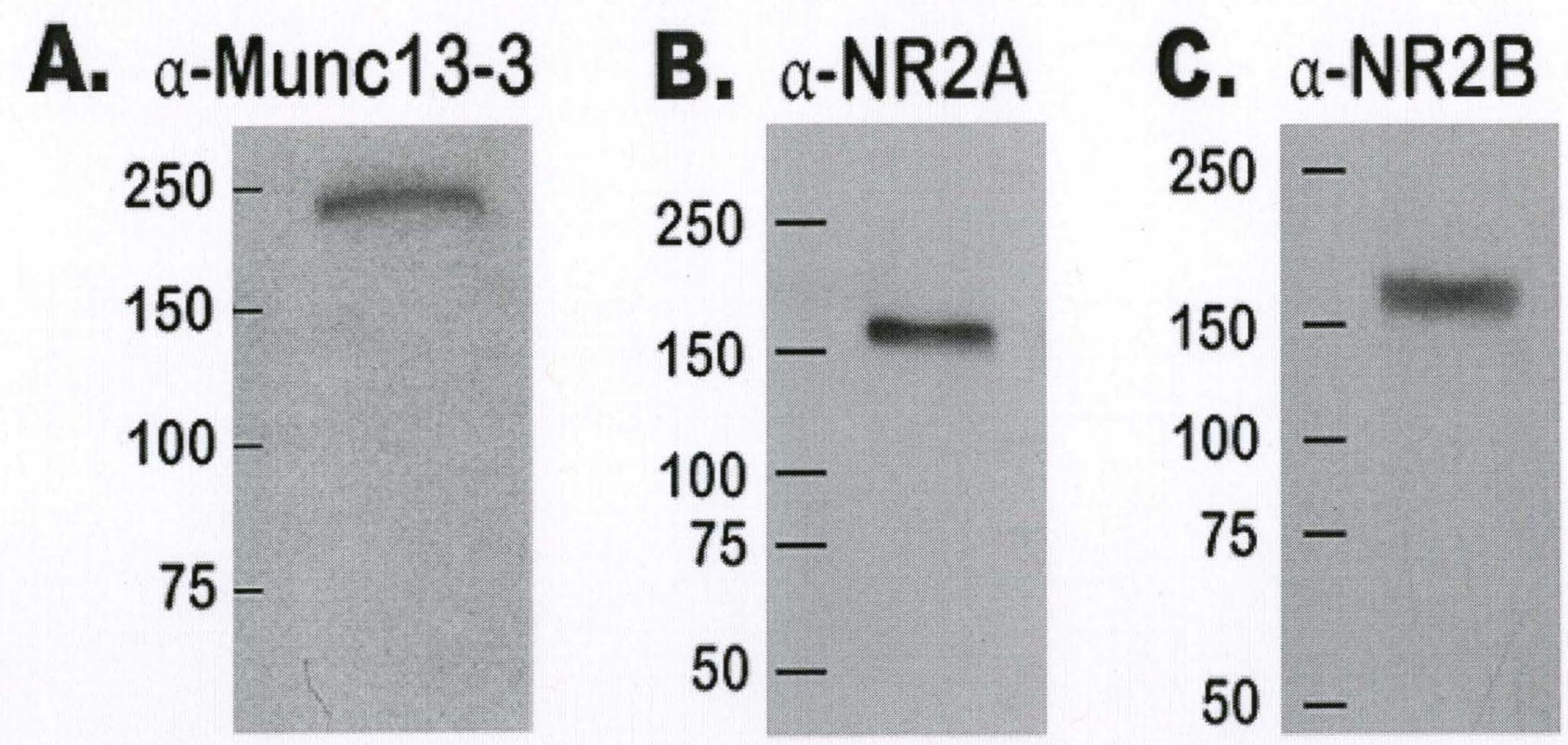

Figure 6 


\section{Immunohistochemistry Procedures}

Dab-1 Antibody

Rabbit polyclonal anti-Dab-1 from Rockland Immunochemicals, Inc.

(Gilbertsville, PA) was recommended by the laboratory of Dr. Jonathan Cooper for immunohistochemistry. Western blot analysis of this antibody labeled the appropriate band at $80 \mathrm{kDa}$. Biotinylated secondary antibody was included in a Rabbit IgG ABC Kit from Vector Laboratories (Burlingame, California) for the avidin-biotin immunoperoxidase reaction staining. Comparisons of immune-staining in wild-type tissue, Dab-1 knockout mutant tissue, and wild-type tissue incubated without primary antibody showed immunopositive labeling solely in the wild-type tissue exposed to the Dab-1 antibody. Adjacent sections of each sample were stained at different concentrations of primary antibody (1:4000 and 1:8000) to verify staining patterns within individual sample runs.

Staining Procedure: Immunohistochemistry

Free floating $30 \mu \mathrm{m}$ sections were used for this study and all steps were performed on a shaker table at room temperature except for the overnight incubation in primary antibody. 
The immunohistochemical protocol was performed as follows:

1. Wash/accomodate PBS $15 \min$ X 3 .

2. Blocking with $10 \%$ serum (eg. normal goat serum, NGS) in PBS with $0.1 \%$ Triton X-100 $60 \mathrm{~min}$ (animal serum used depends on source of secondary antibody).

3. Primary antibody incubation (in PBS with $1 \%$ NGS and $0.1 \%$ Triton X100 at $4^{\circ} \mathrm{C}$ ) overnight.

4. $4 \%$ NGS in PBS $15 \min X 3$.

5. Biotinylated secondary antibody incubation (1:200 per Vector ABC Kit) $45 \mathrm{~min}$.

6. Wash with PBS $15 \min \mathrm{X} 3$.

7. $A B C$ Reagent incubation (per Vector $A B C$ Kit) $1 \mathrm{hr}$.

8. Wash with PBS $15 \min X 3$.

9. DAB reaction $\left(0.05 \%\right.$ diaminobenzedine- $4 \mathrm{HCl}$ with $0.01 \% \mathrm{H}_{2} \mathrm{O}_{2}$ in 0.17M Tris-HCl) per DAB kit (Vector Laboratories, Burlingame, $\mathrm{CA}$ ) for approximately $3-5 \mathrm{~min}$ or until clearly visible brown reaction product appears.

10. Wash with PBS, $15 \min X 3$.

The sections were mounted onto subbed Superfrost/Plus slides and air-dried overnight. The sections were then dehydrated through a sequential series alcohols for 3 minutes each, $(50 \%, 70 \%, 95 \%, 100 \%)$, cleared in xylene ( $3 \min X 2)$, and coverslipped with Permount (Fisher Scientific). 
Staining Procedure: Cresyl Violet

The adjacent sections were stained with cresyl violet for laminar analysis and cellular quantification as follows:

1. Sections were mounted onto subbed Superfrost/Plus microscope slides and, airdried overnight.

2. Sections were cleared in xylene for $3 \mathrm{~min}$. and were then rehydrated through a sequential alcohol series for $3 \mathrm{~min}$. each $(100 \%, 95 \%, 70 \%)$

3. Sections were rinsed with $\mathrm{ddH}_{2} \mathrm{O}$ for $3 \mathrm{~min}$

4. Sections were them immersed in warm Cresyl violet ( $1 \mathrm{~g}$ Cresyl fast violet

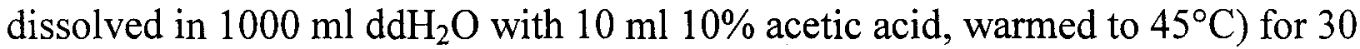
sec.

5. Slides were briefly rinsed in $\mathrm{ddH}_{2} \mathrm{O}$.

6. Differentiation in $70 \%$ alcohol for $1 \mathrm{~min}$ (with a few drops of glacial acetic acid)

7. The sections were dehydrated through a sequential series alcohols for 3 minutes each $(50 \%, 70 \%, 95 \%, 100 \%)$, and cleared in xylene ( $3 \mathrm{~min} X 2)$.

8. Sections were coverslipped with Permount (Fisher Scientific). 


\section{Staining Controls}

Several control procedures were used. The positive controls were 1) an appropriate size single band on western blots and 2) staining seen in regions known to express the target protein (eg. hippocampus). Negative controls include staining of sections that are incubated as described above, except that the antibody diluent with no primary antibody is used to replace the primary antibody in step 3. This procedural control eliminates all specific staining. A second negative control, which also produced no specific staining was performed on sections of visual cortex from Dab-1 knockout mice that do not express the Dab-1 protein.

Immunohistochemistry Quantification and Analysis

The slides were photographed using a computerized system (SPOT software, v2.2, SPOT Diagnostic Instruments, Inc.) to obtain both high (400X) and low (40X) magnification images of the visual cortex. Qualitative analysis was based on visual observation of potential laminar staining differences within a given same and between samples of different ages and rearing conditions. Quantitative analysis was conducted through blind manual cell counts in different lamina using AlphaView software (version 2.0.1.1, Alpha Innotech Corporation) as described below.

In order to obtain unbiased results, digital images of immunostained sections and their adjacent cresyl violet stained sections were formatted for software analysis 
(same file size and creation date) by this researcher and placed into folders on the computer desktop. A single copy of the coding key identifying each sample section was printed and, in the absence of the researcher, the project research advisor renamed each file with a random file name (numbers for immunolabeled and letters for cresyl violet sections) and recorded each on the code sheet. This sheet was kept secured in the advisor's office until quantification was complete.

Each unknown picture file was opened into the counting software. Two identical size counting area boxes were created for each layer examined (II/III, IV and V/VI) which were maintained across all samples analyzed. The boxes were placed within representative regions of the layers to be analyzed at a lower magnification to maintain accurate positioning within each layer. Once all boxes were positioned within an individual sample, magnification was increased in each box to accurately identify immunopositive cells. A cell was counted if it showed the avidin-biotin reaction product, had a definable soma and an evident nucleus. Cells intersecting the left and bottom margins of the counting box were not counted but those intersecting the top and right margins were included. Through the use of the software, a manual mouse-click on each cell marked it (with a green " $X$ ") as being counted, preventing it from being double-counted, and it was added to the running count maintained by the computer. Upon completion, the individual box cell count was recorded and reset each time for each box counted. Only after all samples had been counted and recorded were the codes revealed identifying which cell counts related to which ages and rearing conditions for data analysis. Immunohistochemical cell counts for both 
boxes per layer were averaged and corrected against an average of counts of the two boxes from the same layer of the adjacent cresyl violet section giving an average cell density ratio (immunopositive cells:cresyl violet cells) for each layer in each section.

\section{Electrophysiological Surgical and Recording Procedures}

A protocol for recording of visual evoked potentials was received from the laboratory of Mark F. Bear, $\mathrm{PhD}$ (MIT, Cambridge, MA) but numerous specifications needed to be adapted for successful recording in our lab. The development of this protocol is included here as a part of the total research for this project. Specific issues requiring adaptations included: proper anesthesia determinations for surgical survival, modifications to the design of both the surgical and recording apparati, manufacture of apparati, surgical techniques for electrode implantation and monocular deprivation, visual stimulus and trigger pulse modifications/synchronization and circuitry set-up for proper recording of VEPs. All procedures in the test animals conform to the guidelines of the National Institutes of Health and were approved by the Institutional Animal Care and Use Committee. 


\title{
RESULTS
}

\section{Western Blot Analysis of Dab-1 and Munc13-3 Protein Expression}

\author{
Bidirectional Regulation of Dab-1 Protein in Mouse Visual Cortex
}

Western blots in mouse visual cortex were conducted to extend previous Dab-1 mRNA results to protein. Dab-l was expressed at higher levels in visual and frontal cortex than cerebellum of normal 9.5-week-old mice (Figure 7). Dab-1 protein showed bidirectional regulation by age and dark rearing in the visual cortex of mice. When corrected against $\beta$-actin, densitometric analysis indicated Dab-1 was elevated 2.1-fold in normal visual cortex at 3.5 weeks and 2.3 -fold in dark-reared visual cortex at 9.5 weeks (Figure 8). Analysis of variance of protein levels showed a significant interaction between variables $(\mathrm{F}[2,8], \mathrm{P}<0.002)$, indicating that the effect of dark rearing depended on age. In normal development, Dab-l expression declined three-fold between the peak of the critical period ( 3.5 weeks) and its nadir (9.5 weeks).

To investigate the significance of Dab-1 for visual cortical plasticity we examined whether bidirectional regulation of its expression by age and dark rearing was specific to visual cortex or might also be seen in other cortical regions such as frontal cortex that 
Figure 7. TOP: Western blot showing comparisons of Dab-1 protein expression in visual cortex (V), cerebellum (C) and frontal cortex (F) of normal 9.5 week old mouse. BOTTOM: Same blot reprobed with $\beta$-actin. Molecular weights shown in $\mathrm{kDa}$. 


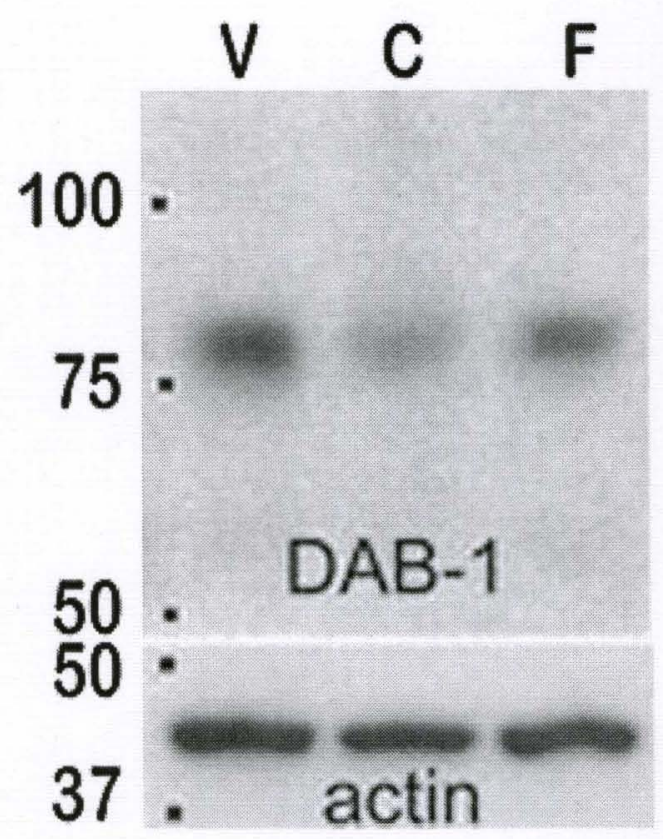

Figure 7 
Figure 8. A. TOP: Western blot analysis of levels of Dab-1 protein expression in mouse visual cortex showing higher levels in normal (N3.5) than dark-reared (D3.5) mouse visual cortex at 3.5 weeks and higher levels in dark-reared (D9.5) than normal (N9.5) mouse visual cortex at 9.5 weeks. BOTTOM: The same blot stripped and reprobed with $\beta$-actin to control for loading errors. Size standards are indicated on Western blots (in kDa). B. Densitometric results for Dab-1 protein levels in mouse visual cortex. Mean levels of Dab-1 protein expression as determined by densitometry (corrected against $\beta$ actin) from three independent groups of mice. Means and standard errors are plotted. Data from each group were normalized against N3.5 animals. 


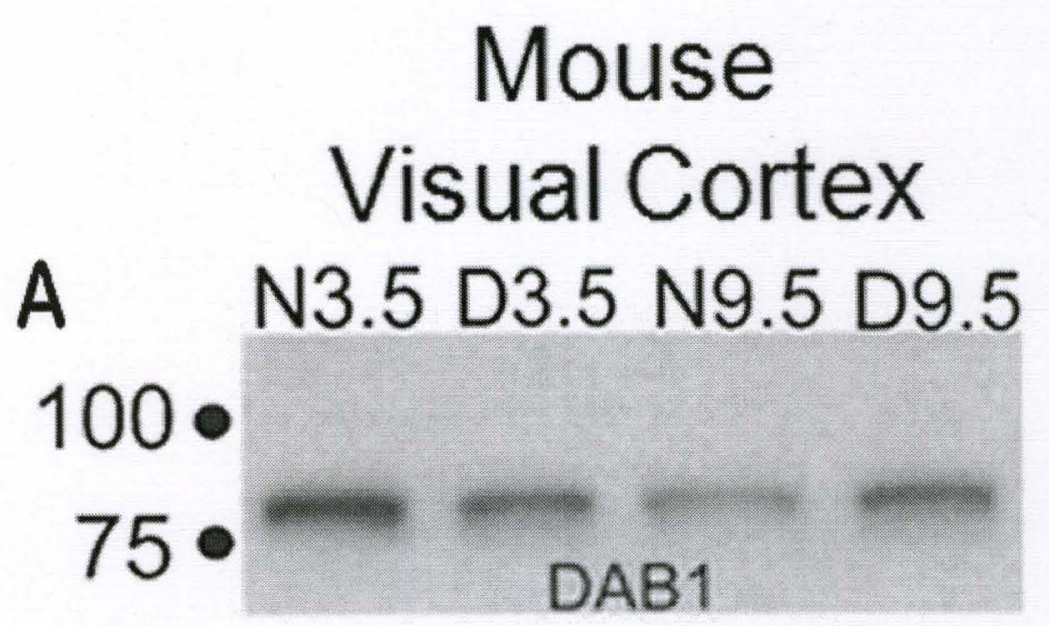

$50 \bullet$

37 - actin

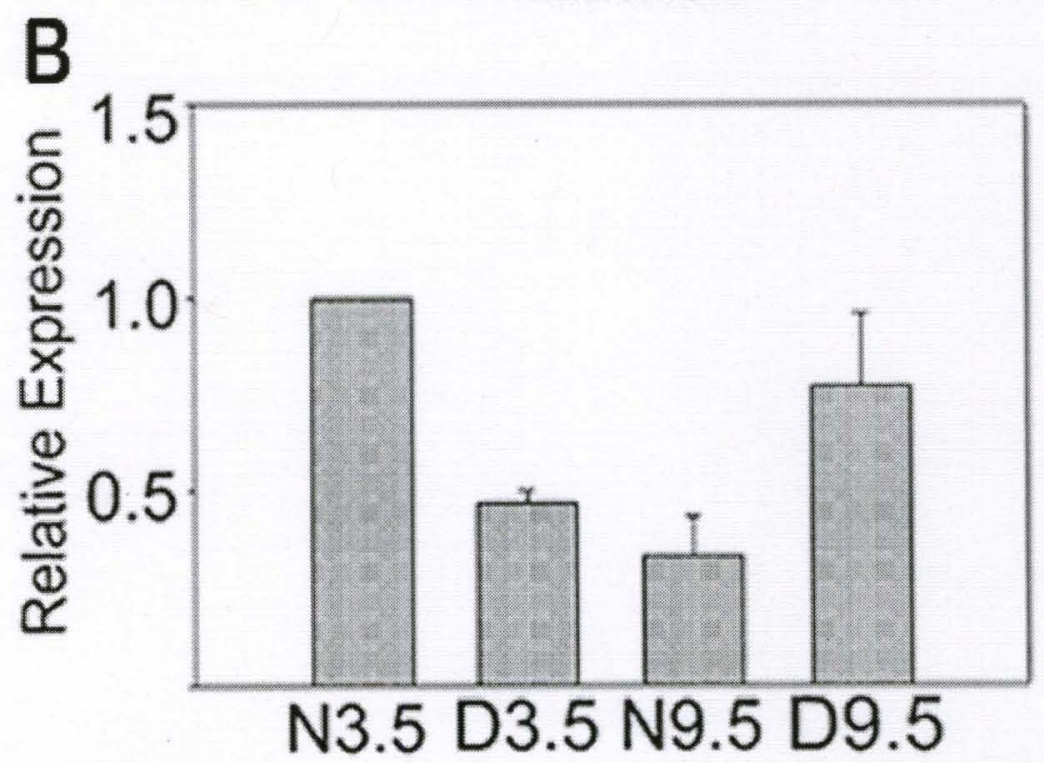

Figure 8 
would not be influenced by visual experience (Figure 9). Levels of Dab-1 expression were similar in all rearing/age conditions in mouse frontal cortex, and analysis of variance of densitometric results indicated no statistically significant interaction due to age and dark rearing for Dab-1. The bidirectional regulation of Dab-l protein expression was specific to visual cortex and was not present in mouse frontal cortex.

Bidirectional Regulation of Munc13-3 by Age and Dark Rearing in the Visual Cortex

Figure 10 shows Western blot analysis of visual cortex for three independent groups of three mice each. Each group contained the four age/rearing conditions (normal 3.5, dark reared 3.5, normal 9.5, dark reared 9.5). Standardized densitometric analysis indicated Munc13-3 was elevated 2.3-fold in dark-reared compared with normal mouse visual cortex at 3.5 weeks and two-fold in normal compared with dark-reared mouse visual cortex at 9.5 weeks. Analysis of variance showed a significant interaction between variables $(F[2,8]=508.26, P=0.001)$, indicating that the effect of dark rearing was age dependent. In normal development, Munc13-3 expression increased twofold between the peak of the critical period (3.5 weeks) and its nadir (9.5 weeks). Munc13-3 protein showed opposite direction regulation by age and dark rearing in the visual cortex of mice.

To investigate the significance of Munc13-3 for visual cortical plasticity we examined whether bidirectional regulation of its expression by age and dark rearing was specific to visual cortex or might also be seen in other cortical regions. Levels of 
Figure 9. A TOP: Western blot showing levels of Dab-1 protein expression in mouse frontal cortex in the four rearing and age conditions. BOTTOM: The same blot reprobed with $\beta$-actin. B. Mean level of Dab-1 protein expression in mouse frontal cortex as determined by densitometry (corrected against b-actin) from three independent groups of animals. Mean and standard errors are plotted. 

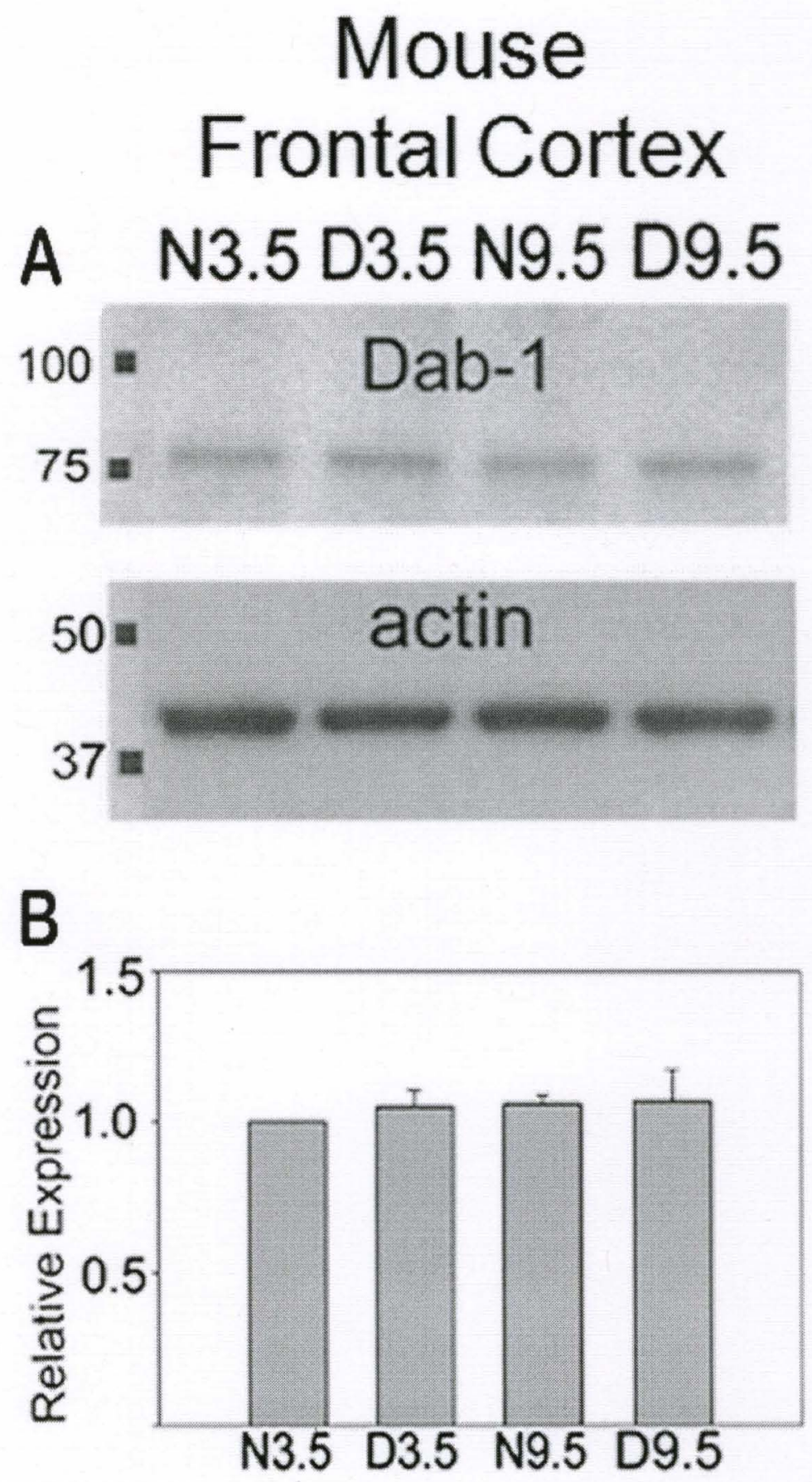

Figure 9 
Figure 10. A. TOP: Western blot analysis of levels of Munc13-3 protein expression in mouse visual cortex showing higher levels in dark-reared (D3.5) than normal (N3.5) mouse visual cortex at 3.5 weeks and higher levels in normal (N9.5) than dark-reared (D9.5) mouse visual cortex at 9.5 weeks. BOTTOM: The same blot stripped and reprobed with $\beta$-actin to control for loading errors. Size standards are indicated on Western blots (in $\mathrm{kDa}$ ). B. Densitometric results for Munc13-3 protein levels in mouse visual cortex. Mean levels of Munc13-3 protein expression as determined by densitometry (corrected against $\beta$-actin) from three independent groups of mice. For each of the three groups of mice, values for each age/rearing condition were normalized against the highest value in each group. Means and standard errors from the three groups for each age/rearing condition are plotted. 




Figure 10 
Munc13-3 expression were similar in all rearing/age conditions in frontal cortex, and analysis of variance of densitometric results (Figure 11) indicated no statistically significant interaction due to age and dark rearing for Munc13-3. The bidirectional regulation of Munc13-3 protein expression was specific to visual cortex and was not present in frontal cortex.

\section{Immunohistochemical Analysis of Dab-1 Laminar Distribution in Visual Cortex}

Figure 12 shows Dab-1 development in normally reared cat visual cortex. There is prominent Dab-1 immuno-staining across all layers at 1 week of age which diminished across all layers throughout the critical period. Cortical layers were identified and labeled following the designations of Luskin and Shatz ((Luskin and Shatz, 1985a, b) through cresyl violet staining of adjacent sections to those processed for Dab-1 immunohistochemistry (Figure 1). The observed developmental decline in Dab-1 cellular staining between each age was shown to be significant by analysis of variance of quantitative data obtained through cell counts which were corrected with total cell counts from the adjacent section stained with cresyl violet $(\mathrm{F}[2,18]=41.319, \mathrm{P}<0.001$, Tukey tests: 1 wk vs. $5 w k, \mathrm{P}<0.001 ; 1$ wk vs $20 \mathrm{wk}, \mathrm{P}<0.001 ; 5 \mathrm{wk}$ vs. $20 \mathrm{wk}, \mathrm{P}=0.007$ ) (Figure 13). Further analysis of laminar staining patterns throughout development revealed a significant difference between layers II/III and IV $(F[2,18]=8.143, p=0.003$, Tukey test: IIIIII vs.IV, $\mathrm{P}=0.002]$. 
Figure 11. A TOP: Western blot showing levels of Munc13-3 protein expression in mouse frontal cortex in the four rearing and age conditions. BOTTOM: The same blot reprobed with $\beta$-actin. B. Mean level of Munc13-3 protein expression in mouse frontal cortex as determined by densitometry (corrected against b-actin) from three independent groups of animals. Mean and standard errors are plotted. 


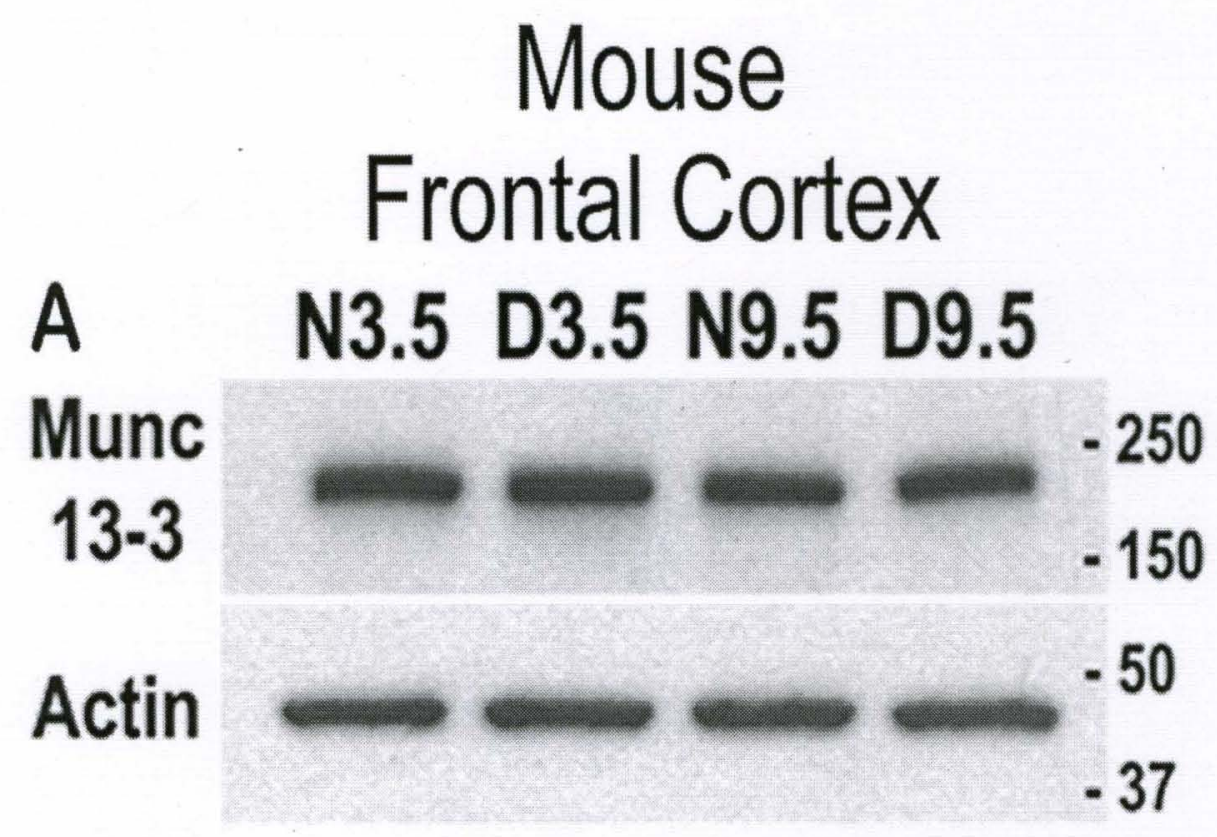

B

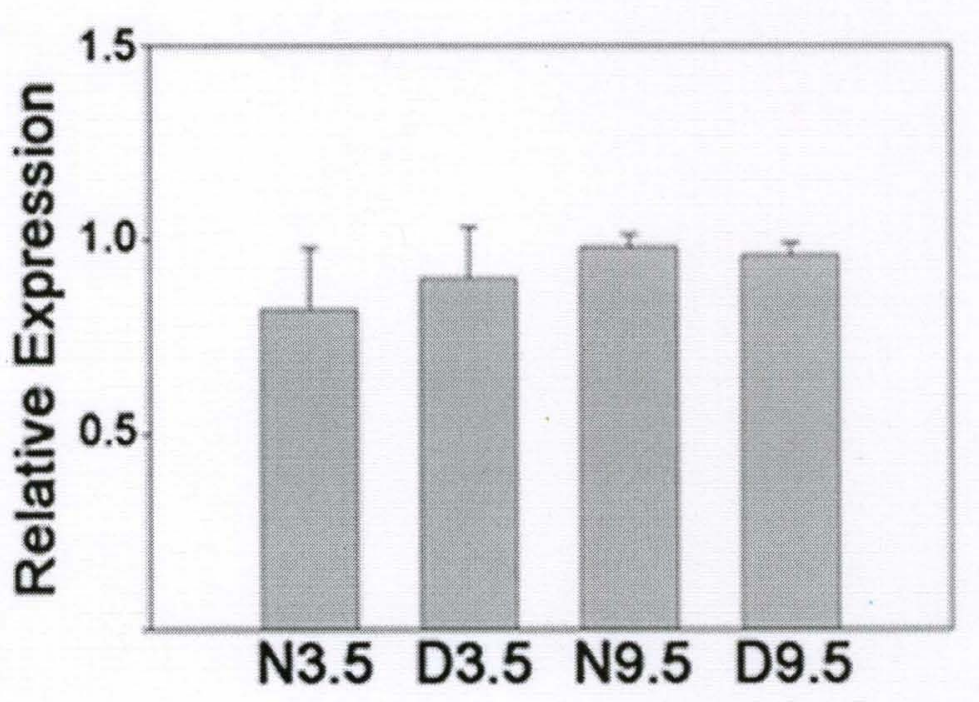

Figure 11 
Figure 12. Low power (40X) photomicrographs showing Dab-1 immunoreactivity in cat visual cortex during postnatal development. The panel shows representative images of coronal sections of area 17 in 1, 5, 10,20 week and adult cats. Cortical lamina are indicated and were determined by adjacent sections stained with cresyl violet. Rabbit polyclonal antibody to-Dab-1 (1:4000) was obtained from Rockland Immunochemicals, Inc. (Gilbertsville, PA) The slides were photographed using a computerized system (SPOT software, v2.2, SPOT Diagnostic Instruments, Inc.). 
Dab1 Normal Development in Cat Visual Cortex

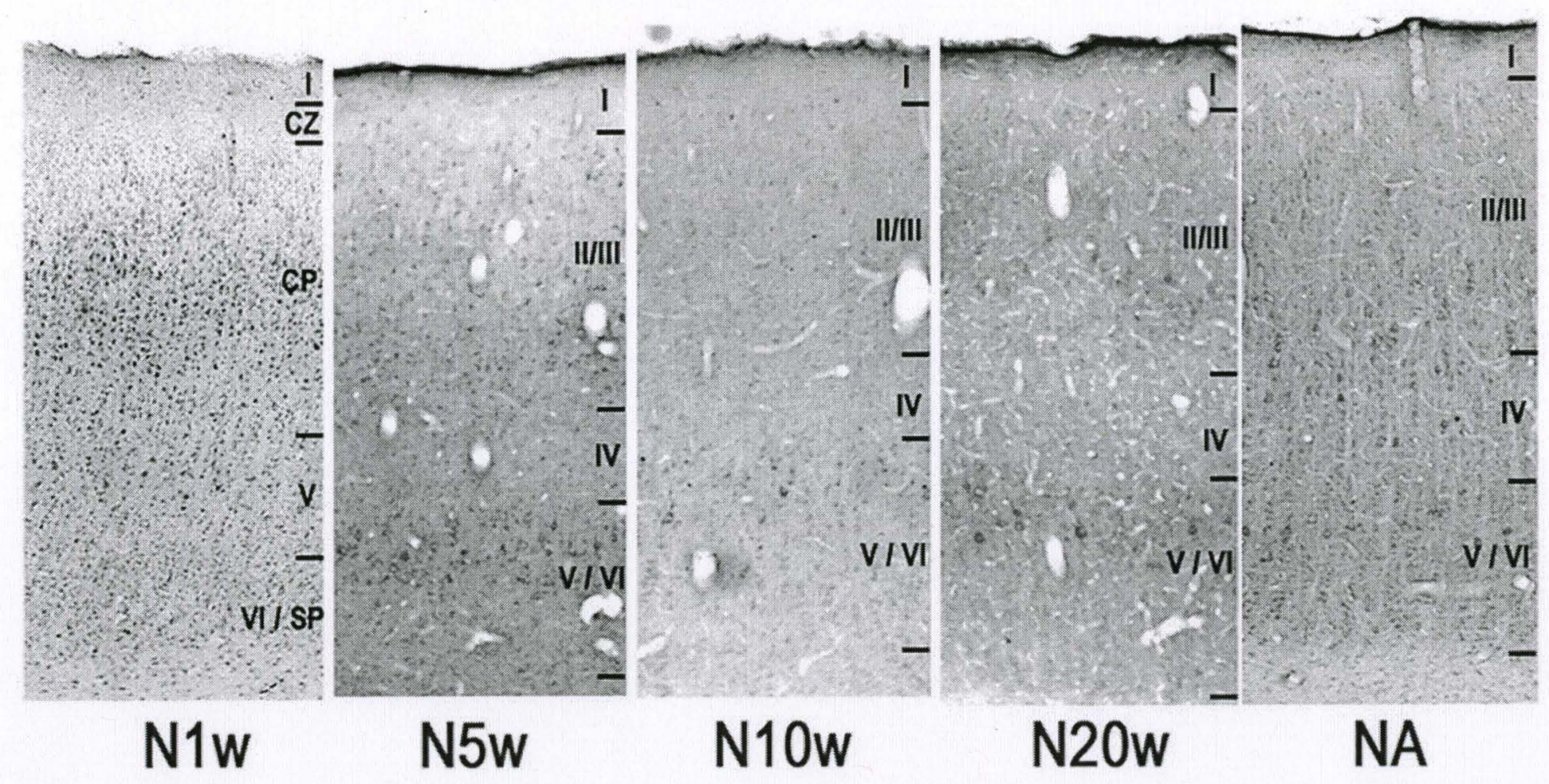

Figure 12 
Figure 13. Line graphs showing quantification of Dab-1 immunohistochemisty in postnatal development. Top: Dab-1 expression in cortical lamina. . Immunopositive cell counts were an average of four unique counts in each lamina of three different animals at each age and corrected with cell counts from adjacent cresyl violet stained sections. Each data point represents an average of two independent immunohistochemical runs. Bottom: Combined results of all cortical lamina. Individual counts as described above from each layer in each animal at each age were averaged together to determine data points. 

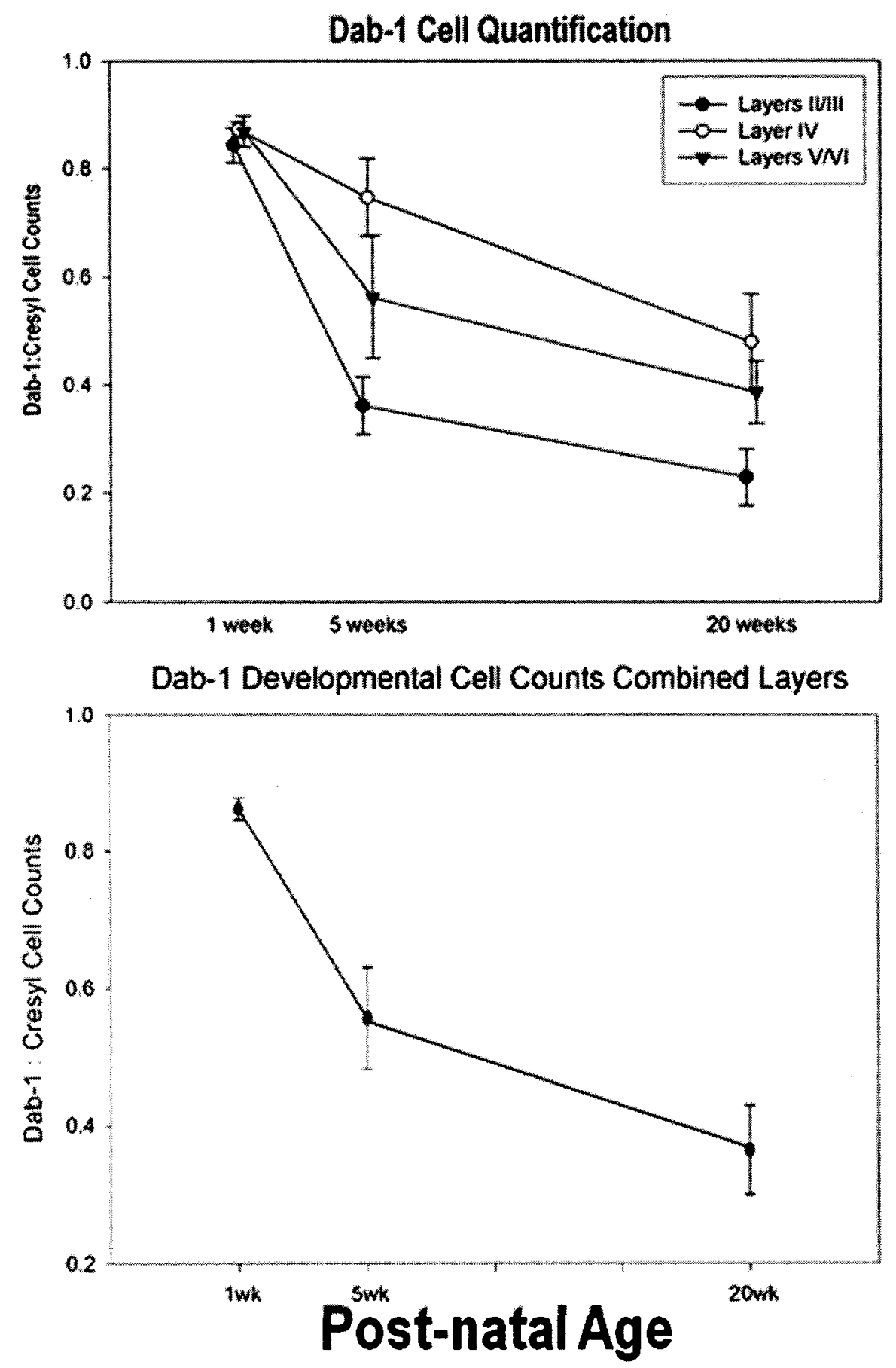

Figure 13 
Figure 14 shows differences in Dab-1 immunohistochemical labeling between normal and dark reared cats at the peak ( 5 weeks) and nadir ( 20 weeks) of the critical period. Analysis of variance of these differences (Figure 15) revealed significant interaction between age and rearing condition $(\mathrm{F}[1,24]=10.881, \mathrm{P}=.003)$ indicating that dark-rearing does have an effect on cellular expression of Dab-1 with significantly less Dab-1 labeled cells in the dark reared 5 week old cats compared to normal (Tukey test, N5wk vs. D5wk, $\mathrm{P}=0.003)$. This analysis also show significant reductions of Dab-1 immunopositive cells from normal 5 week to normal 20 week cats, as described previously (Tukey test: N5wk vs. N20wk, $\mathrm{p}=0.005$ ). While the data trend in an opposite direction at 20 weeks, there was no significant difference found between normal and dark reared animals at the end of the critical period. Analysis of variance also revealed a significant difference found between layers $(F[2,24]=12.262, P, 0.001)$ with specific differences between layers II/III and IV (Tukey Test, $\mathrm{P}<0.001$ ) and layers II/III and V/VI (Tukey test, $\mathrm{P}=0.040$ ). No statistical differences were found between layers IV and V/VI. When considering these results, it is noteworthy to also refer back to the similar results pattern seen in the Western blot protein analysis of Dab-1 expression in mouse visual cortex (Yang et al., 2006) (Figure 8). The reduced immunopositive cell staining in darkreared cats at five weeks of age when compared to normal animals and trending increases in dark-reared compared to normal at 20 weeks mirrors that seen in the total protein analysis of visual cortex. 
Figure 14. Low power (40X) photomicrographs showing Dab-1 immunoreactivity in cat visual cortex. The panel shows representative images of coronal sections of area 17 in normal and dark reared cats at the peak ( 5 weeks) and nadir ( 20 weeks) of the critical period. Cortical lamina are indicated and were determined by adjacent sections stained with cresyl violet. Rabbit polyclonal antibody to-Dab-1 (1:4000) was obtained from Rockland Immunochemicals, Inc. (Gilbertsville, PA) The slides were photographed using a computerized system (SPOT software, v2.2, SPOT Diagnostic Instruments, Inc.). 


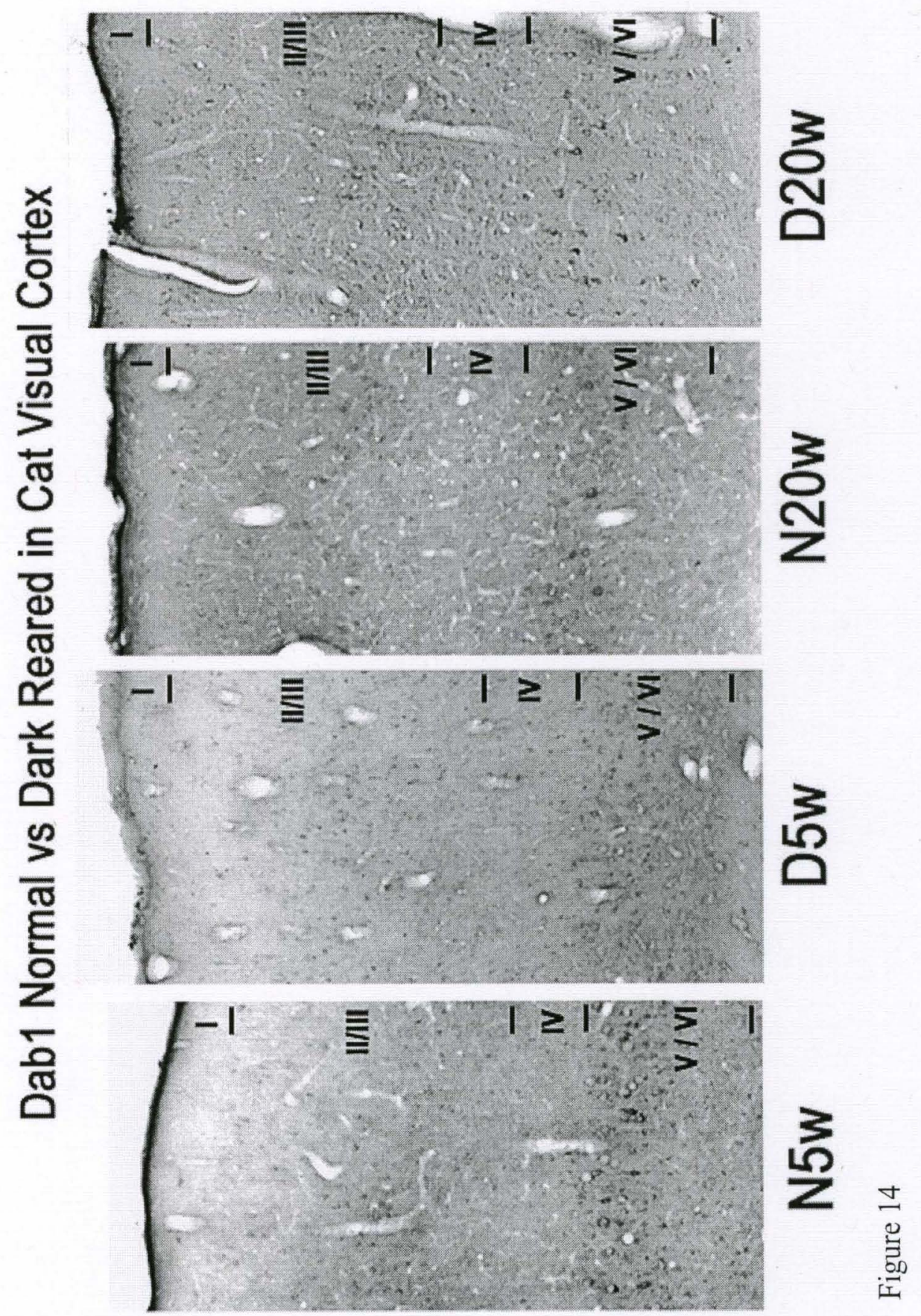


Figure 15 Line graphs showing quantification of Dab-1 immunohistochemisty in cortical lamina of cat visual cortex comparing normal and dark reared cats at the peak (5 weeks) and nadir ( 20 weeks) of the critical period. Top: Dab-1 expression in cortical lamina. Immunopositive cell counts were an average of four unique counts in each lamina of three different animals at each age and corrected with cell counts from adjacent cresyl violet stained sections. Each data point represents an average of two independent immunohistochemical runs. Bottom: Combined results of all cortical lamina. Individual counts as described above from each layer in each animal at each age were averaged together to determine data points. 

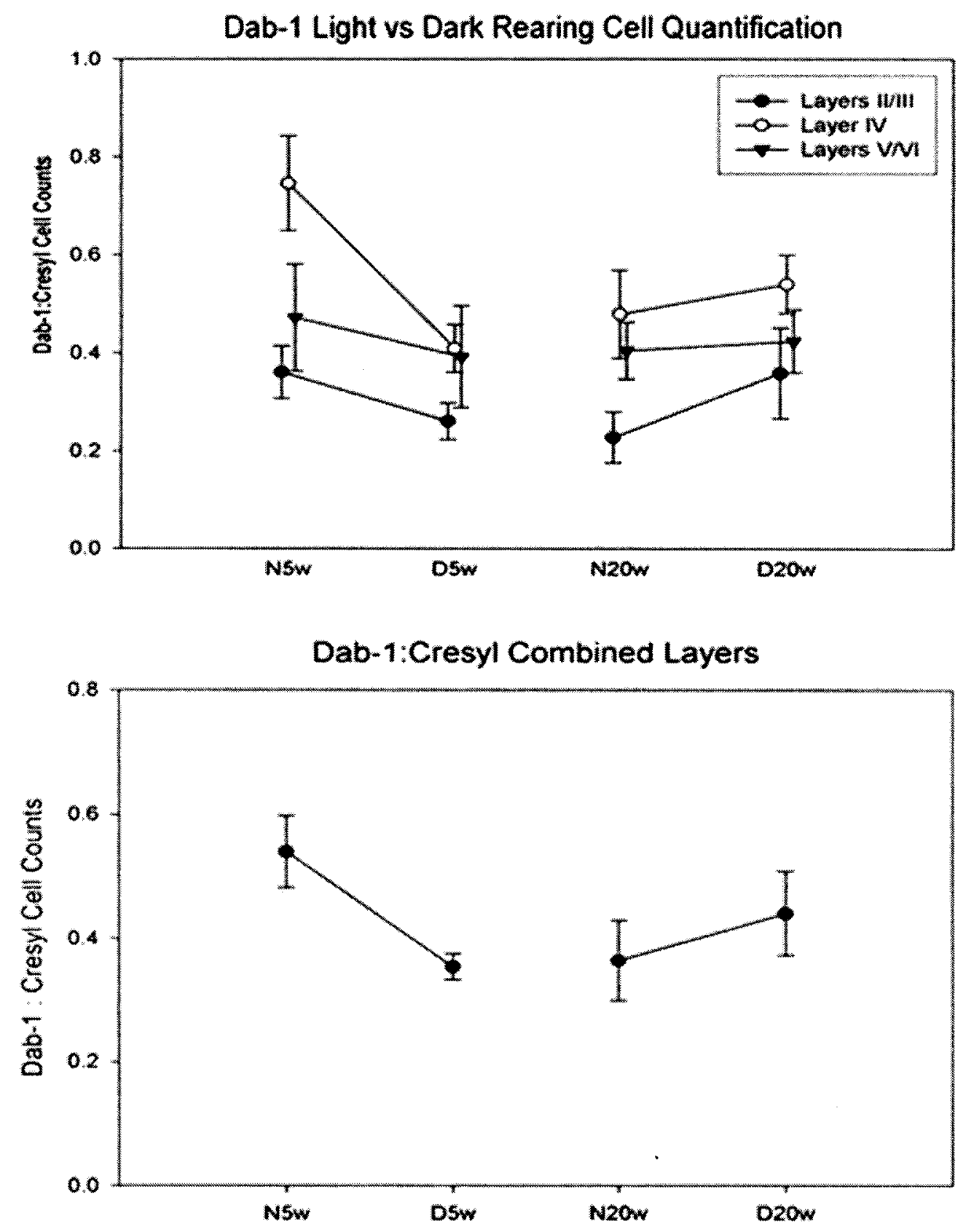

Figure 15 
Dab-1 immunohistochemistry was also performed on normal and dark reared mouse tissue (Figure 16) Dab-1 protein expression patterns were observed that support those found in the cat however due to extreme laminar differences in afferent terminal distribution between the species (described in the Introduction), quantitative analyses of the staining patterns were not conducted.

\section{Effect of Dab-1 Mutation on NMDAR Subunits}

Figure 17 shows the effect of Dab-1 on NMDAR subunits NR2A and NR2B. Analysis of variance revealed significant differences between Dab-1 mutants and wildtype animals in the ratio of NR2A to NR2B subunits $(F[1,8], \mathrm{P}<0.001)$. In wild-type animals, the NR2A:NR2B ratio shows a significant decrease from the peak to the nadir of the critical period when expressed as a percentage of dark reared to normally reared animals (DR/LR), (Tukey Test: Wild-type $3.5 \mathrm{wk}$ vs $9.5 \mathrm{wk}, \mathrm{P}=0.002$ ). This result is significantly different from the opposite effect that is observed in Dab-1 mutant animals where the percentage significantly increases from 5 weeks to 20 weeks (Tukey Test: Mutant, $3.5 \mathrm{wk}$ vs $9.5 \mathrm{wk}, \mathrm{P}=0.015$ ). Comparisons of animal differences at both ages also found significant effects. The DR/LR-NR2A:NR2B ratio is significantly lower in mutant animals at 3.5 weeks (Tukey Test: 3.5 wks, Wild-type vs Mutant, $\mathrm{P}=0.003$ ) and significantly higher in mutants at 9.5 weeks (Tukey Test: 9.5 wks, Wild-type vs Mutant, $\mathrm{P}=0.009)$. 
Figure 16. Low power (40X) photomicrographs showing Dab-1 immunoreactivity in mouse visual cortex. The panel shows representative images of coronal sections of area 17 in normal and dark reared mice at the peak ( 3.5 weeks) and nadir (9.5 weeks) of the critical period. Rabbit polyclonal antibody to-Dab-1 (1:4000) was obtained from Rockland Immunochemicals, Inc. (Gilbertsville, PA) The slides were photographed using a computerized system (SPOT software, v2.2, SPOT Diagnostic Instruments, Inc.). 
Dab-1 Light vs Dark Rearing in Mouse Visual Cortex

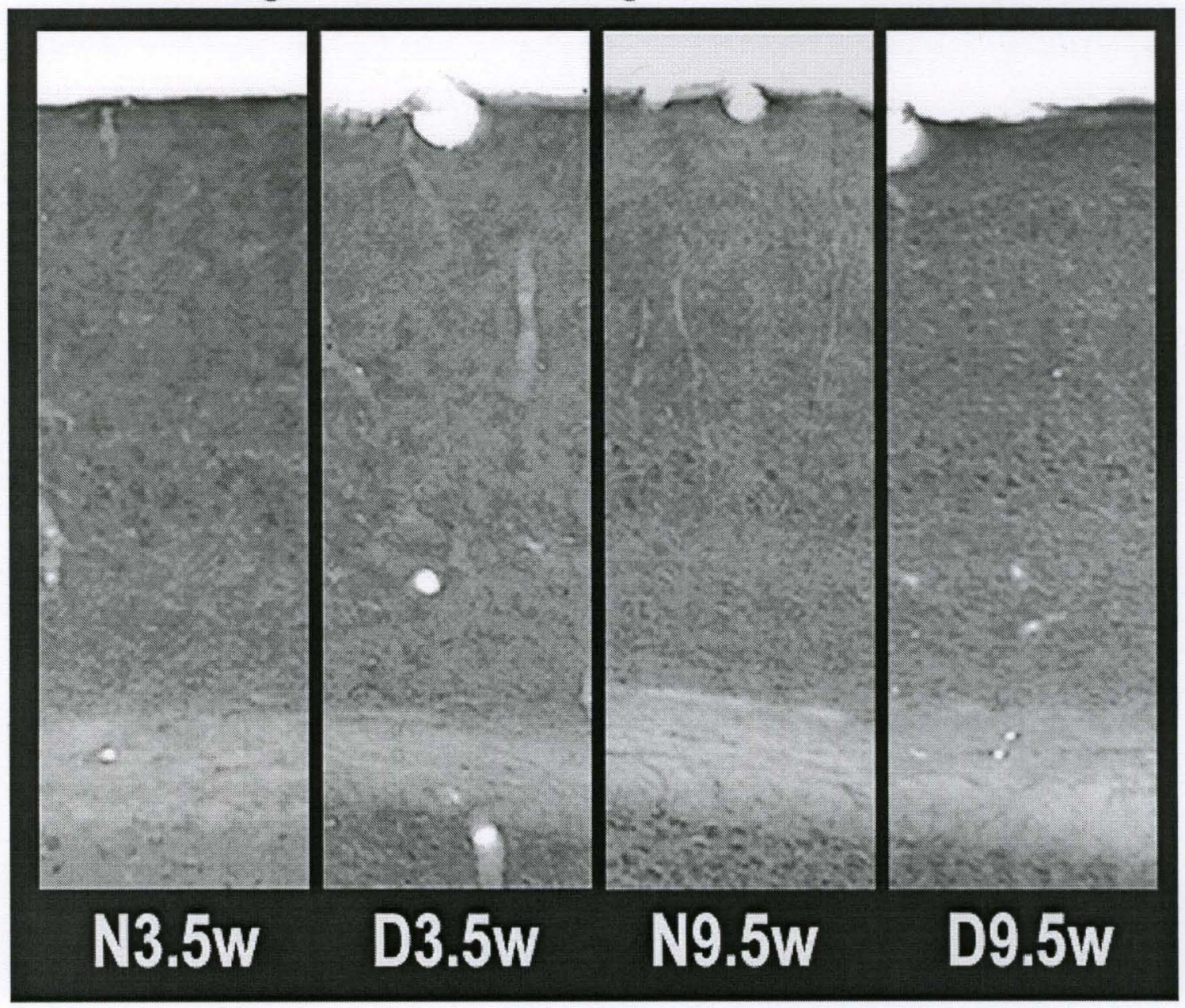

Figure 16 
Figure 17. Histogram showing the effect of Dab-1 mutation on NMDAR subunits NR2A and NR2B in mice at the peak ( 3.5 weeks) and nadir (9.5 weeks) of the critical period. Each bar represents the ratio of dark-reared expression of the NR2A:NR2B ratio to the normally reared expression of the same for each age in both wild-type and Dab-1 knockout animals. 


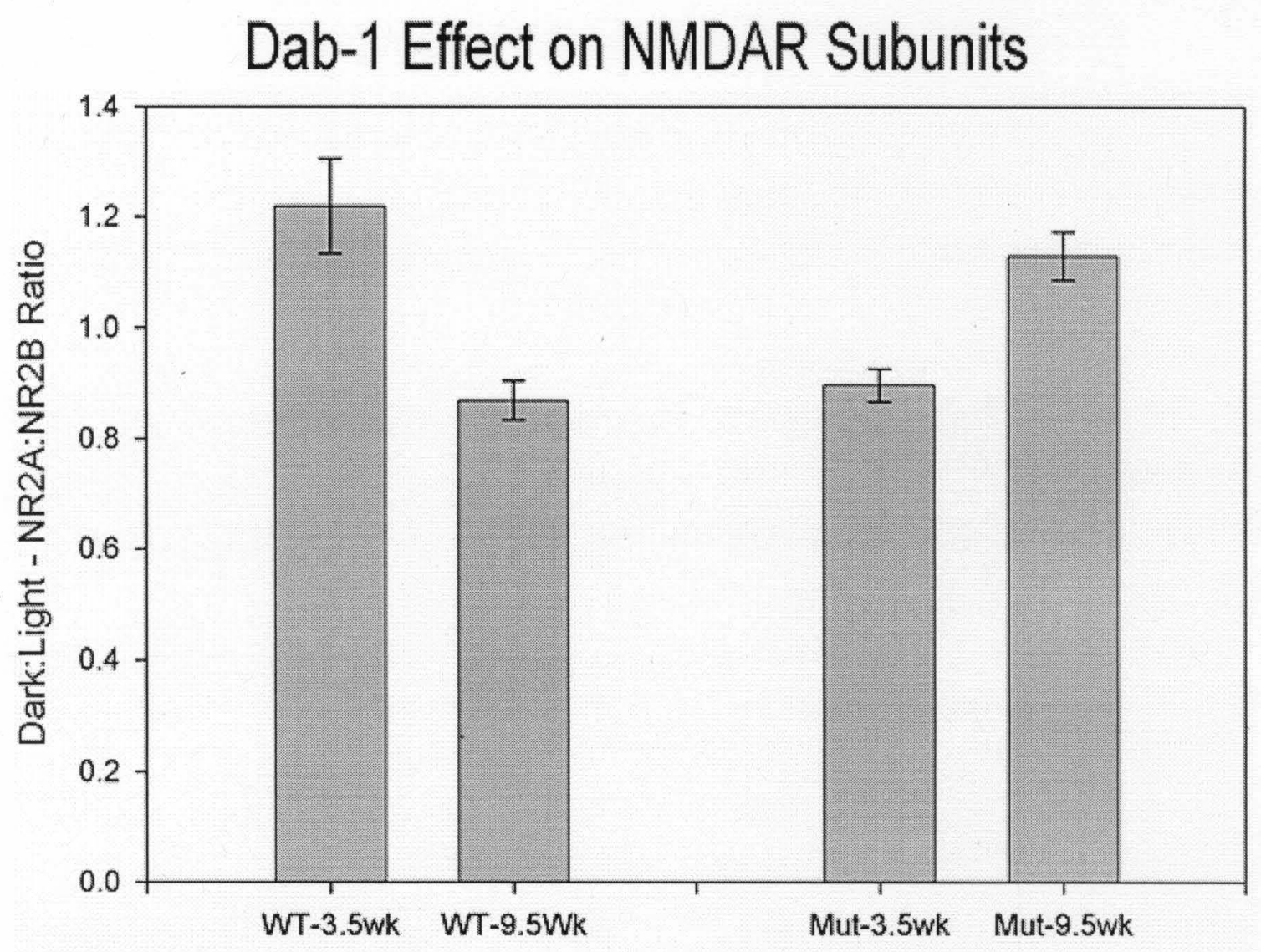

Figure 17 


\section{Establishing Procedures for Recording Evoked Potentials from Visual Cortex in Awake Mice}

The following protocol for recording of visual evoked potentials from awake mice is the result of the developmental efforts of this project.

Electrode Implantation Procedure

The developed protocol was adapted from published work of the laboratory of Mark F. Bear, $\mathrm{PhD}$ (MIT, Cambridge, MA). All procedures in the test animals conform to the guidelines of the National Institutes of Health and were approved by the Institutional Animal Care and Use Committee. Impedence of each tungsten recording microelectrode (\#UEWSECBN1C, FHC, Bowdoinham, ME) was measured prior to implantation with an FHC NeuroCraft ${ }^{\mathrm{TM}}$ Impedence Conditioning Module (\#55-70-0, FHC, Bowdoinham, ME).

Mice were anesthetized with a mixture of Ketamine and Xylazine $(90 \mathrm{mg} / \mathrm{kg}$ Ketamine $/ 9 \mathrm{mg} / \mathrm{kg}$ Xylazine). Levels of anesthesia were monitored throughout the entire procedure and supplemental "booster" injections of Ketamine only $(90 \mathrm{mg} / \mathrm{ml})$ were administered as needed during extended procedures to maintain deep level of general anesthesia. Sterile ophthalmic ointment (Puralube, NDC17033-211-38, Dechra Veterinary Products, Overland Park, KS) was applied to each eye to prevent desiccation of the cornea during the surgery and recovery. This was reapplied as necessary during the 
procedure. Prior to incision, approximately $0.1 \mathrm{ml}$ of $0.05 \%$ Lidocaine was also injected under the scalp to supplement general anesthesia. A mid-saggital incision was made exposing the skull. Approximately $3 \mathrm{~mm}$ of tissue was removed from both sides of the incision creating an oblong opening exposing the skull. The periosteal membranes above the skull were scraped away with the broad edge of a scalpel blade, the skull was wiped clean with sterile cotton swabs, swabbed with $70 \% \mathrm{EtOH}$ and left to dry completely for approximately 15 minutes.

A liquid cyanoacrylate adhesive (Loctite-495, Loctite Corp, Rocky Hill, CT) was utilized to adhere a fixation post (\#18 flathead nail cut to approximately $1 \mathrm{~cm}$ in length) to the dried skull just anterior to bregma. Curing of the adhesive was hastened through a single drop application of ZipKicker (Pacer Technology, Ranch Cucamonga, CA) cyanoacrylate accelerator. The mouse was secured by the post into a custom designed and fabricated, acrylic stereotaxic base (University of Louisville machine shop) for the remaining procedure (Figure 18).

A small hole (approximately $1 \mathrm{~mm}$ ) located $1 \mathrm{~mm}$ lateral to bregma for the reference electrode (\#19003-00, Fine Science Tools (USA), Inc, Foster City, CA with $1 \mathrm{~mm}$ silver wire tip) was drilled in the skull using a high speed micro drill (\#18000-17, Fine Science Tools (USA), Inc, Foster City, CA) with a 0.7mm burr bit (\#19008-07, Fine Science Tools (USA), Inc, Foster City, CA) This electrode was inserted and secured with a gel-based cyanoacrylate adhesive (Loctite-454, Loctite Corp, Rocky Hill, CT) directly 
Figure 18. This acrylic surgical fixation apparatus was designed to screw into a stereotaxic stand for precise measurements for electrode placement. Once the fixation post was adhered to the skull, the mouse was secured into the apparatus by the skull post stabilizing the head for both drilling and implantation. 


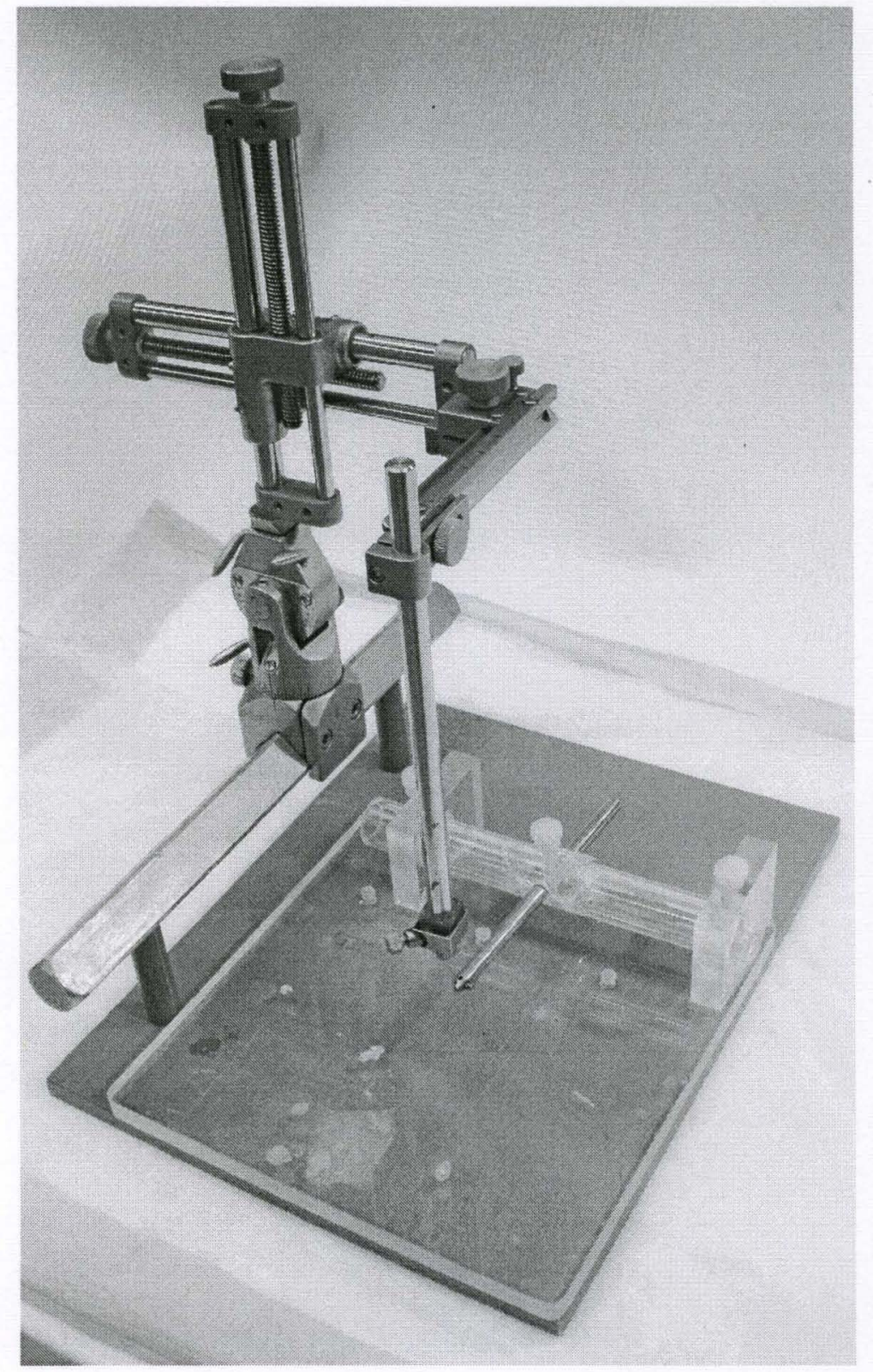

Figure 18 
to the skull, again accelerated by ZipKicker. The hole for the tungsten recording microelectrode placement was determined through stereotaxic positioning to allow for insertion into the binocular region of mouse visual cortex. This location was ipsilateral to the reference electrode, $3 \mathrm{~mm}$ lateral to lambda. The hole was made using the same rotary tool and burr bit however it was not simply drilled directly through the skull as the one made for the reference electrode. The recording electrode foramen was formed by the creation of subsequently deeper circles approximately $2 \mathrm{~mm}$ in diameter centered on the predetermined insertion point for the recording electrode. Once the depth of the ring had nearly penetrated the skull, a sterile hypodermic needle and micro-forceps were utilized to remove the remaining flap of bone (approximately $1 \mathrm{~mm}$ in diameter) inside the circle exposing the dura overlying the targeted visual cortex. The tungsten recording microelectrode was lowered stereotaxically until the tip of the electrode contacted the dura mater. A gentle tap was given to the entire apparatus to perforate the dura mater. The electrode was then lowered approximately $0.45 \mathrm{~mm}$ into the visual cortex. The gelbased cyanoacrylate adhesive was used to secure the resin bead of the electrode to the skull (and accelerated with ZipKicker) and the electrode guide wire was trimmed flush to the resin bead. The lead wire of the recording electrode and recording pin were then secured to the resin bead taking care to avoid direct contact between the wire and the skull to reduce potential interference.

The mouse was removed from the stereotaxic apparatus. The entire exposed skull, base of the fixation post and attachment points of both electrodes were then carefully covered with a non-conductive two-part, rapid setting dental acrylic (OrthoJet Liquid 
\#1304, methyl methacrylate monomer, and OrthoJet Acrylic Resin Powder, \#1300, Lang Dental Manufacturing Co., Inc., Wheeling, IL). This created an acrylic cap that not only protected and further secured the electrode placement but also completely sealed any exposed cut edges from the original scalp retraction/removal. Animals were given a 24 hour analgesic dosage of Ketoprofen $(4 \mathrm{mg} / \mathrm{kg})$ and were allowed to recover on a heating pad and returned to their cages when alert. Animals were monitored postoperatively for signs of infection and/or discomfort and allowed at least 24 hours recovery prior to the first recording session.

\section{Monocular Deprivation Procedure}

Mice were anesthetized with a mixture of Ketamine and Xylazine $(90 \mathrm{mg} / \mathrm{kg}$ Ketamine/9mg/kg Xylazine). Sterile opthalmic ointment (Puralube, NDC17033-211-38, Dechra Veterinary Products, Overland Park, KS) was applied to both eyes to prevent corneal dessication while under anesthesia. The area immediately surrounding the eye to be sutured (contralateral to recording electrode) was wiped with $70 \%$ ethanol. Lid margins were trimmed (less than $.5 \mathrm{~mm}$ from each eyelid), and the eye was flushed with saline and sterile ophthalmic ointment was applied to the eye. Two to three sutures were placed using 7-0 silk, opposing the full extent of the trimmed lids. The sutures and wound were sealed with VetBond cyanoacrylate tissue adhesive (\#1469SB, 3M, St. Paul, MN). Animals were given a 24 hour analgesic dosage of Ketoprofen $(4 \mathrm{mg} / \mathrm{kg})$ and were allowed to recover on a heating pad and returned to their cages when alert. Animals were checked daily to make sure that the eyes remained uninfected. After five days, the animal 
was anesthetized again with the Ketamine/Xylazine mixture $(90 \mathrm{mg} / \mathrm{kg}$ Ketamine $/ 9 \mathrm{mg} / \mathrm{kg}$ Xylazine), recording and reference electrodes were placed in the contralateral visual and frontal hemispheres, as described previously, and sutures were removed to open the deprived eye. If holes developed in the sutured closure prior to eye-opening the animal was eliminated from the study. Eyes were then flushed with sterile saline and checked for clarity. Mice with corneal opacities or signs of infection were excluded from further study. All procedures in the test animals conform to the guidelines of the National Institutes of Health and were approved by the Institutional Animal Care and Use Committee.

Visual-Evoked Potential Recording

A customized restraint system (Figure 19) was developed and manufactured in the University of Louisville machine shop for recording of visual evoked potentials (VEP). These recordings were then able to be conducted in awake, head-restrained mice through the use of a head-stage attached to a differential amplifier (A-M Systems Model 3000, high pass filter $=1 \mathrm{~Hz}$, low pass filter $=0.1 \mathrm{KHz}$, Notch $=$ "On" and gain $=100 \mathrm{X})$ and digital storage oscilloscope (TekTronix TDS 1001B). Following the postoperative recovery period, animals were habituated to the head restraint system. Once habituated, animals sat quietly in tube/head restraint system with minimal movement throughout the duration of a recording session (approximately 30 minutes). Visual stimuli were presented to both eyes, alternately to right and left eyes, and with both eyes blocked (60 sweeps averaged/record). Each stimulus condition was recorded at least six times over 
Figure 19. A custom restraint system was designed for awake recording of visual evoked potentials. The mouse was secured by the skull fixation post to a cross bar facing the visual stimulus while the body weight was supported by a plastic cylinder leaving the electrodes accessible for recording. A custom designed Faraday cage was built to reduce any noise that might mask the potential. Mice very quickly became accommodated to the set-up and would rest peacefully during the 20-30 minute recording sessions. A. Full view of recording set-up with mouse secured in recording apparatus in front of visual stimulus. B. Closer view of mouse resting in support tube while secured and facing the visual stimulus. C. Front view of mouse secured by fixation post and resting in support tube (Faraday cage removed). D. Top view of mouse secured in recording apparatus (Faraday cage removed). 

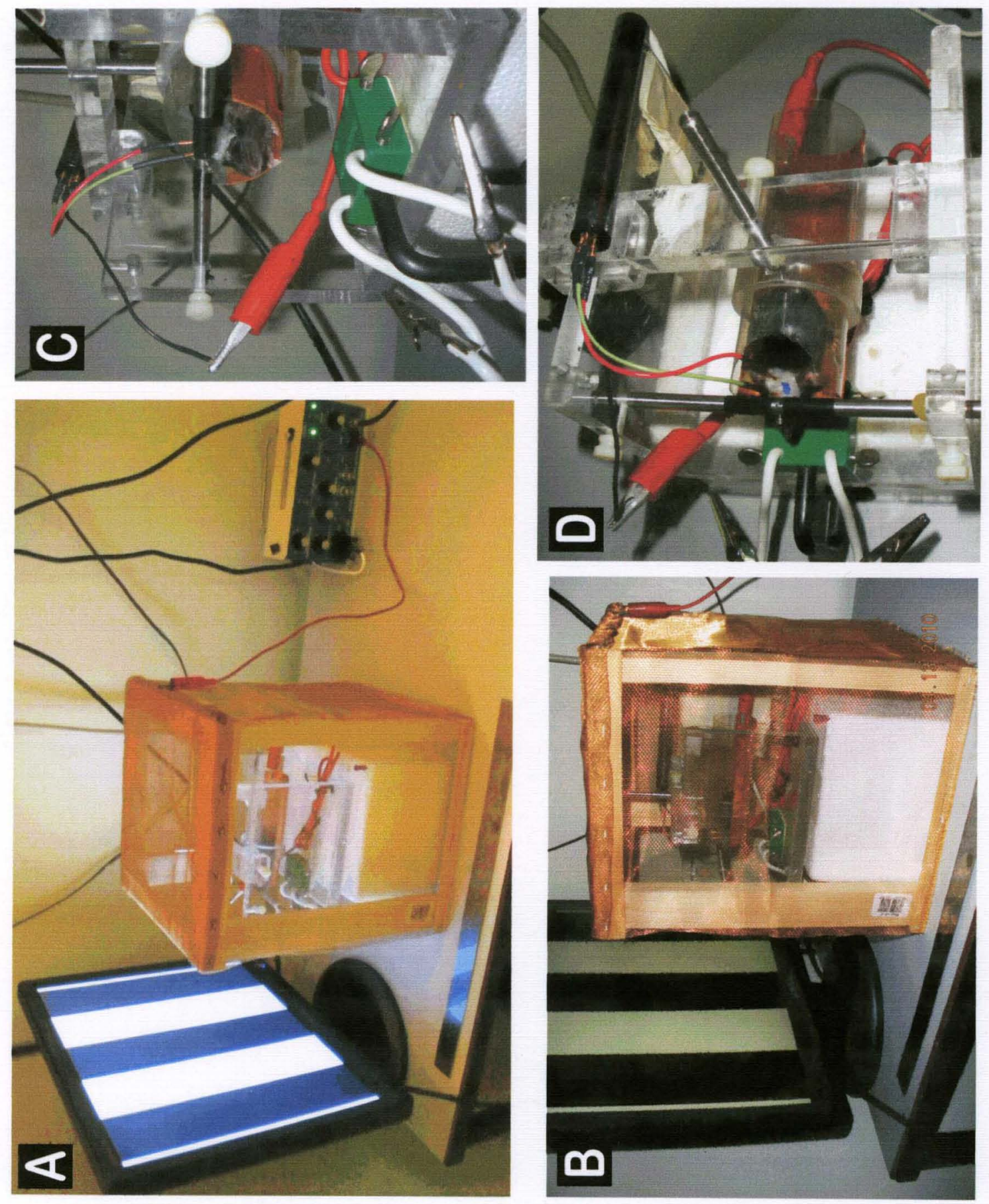

重 
the course of a single session. Individual recording sweeps were initiated by a simultaneous $3 \mathrm{mV}$ trigger directly to the oscilloscope synchronized to the onset of each stimulus generated by StimulusMaker (version 2.1.35, Vision Research Graphics, Durham, NH).

\section{Visual Stimulus}

Visual stimuli consisted of full-field $1.98 \mathrm{~Hz}$ counterphasing square-wave gratings of $100 \%$ contrast and 0.3 cycles/degree generated by an ATI Radeon graphics card and VisionWorks for Electrophysiology software (version 1.4.80, Vision Research Graphics, Durham, NH) presented on a Dell 19-inch flat-screen digital computer monitor. The display was positioned $20 \mathrm{~cm}$ in front of the mouse and centered on the midline.

Numerous challenges were encountered throughout the process as detailed in the Discussion section however protocols for monocular deprivation (MD) of animals and recording of VEPs were shown to be successful. Figure 20 shows VEPs recorded in the binocular region of visual cortex from stimulation to each eye in normal and MD mice in our lab. At 3.5 weeks, normal mice show a stronger response to stimulation to the contralateral over the ipsilateral eye. After five days of closure of the contralateral eye, followed by reopening of this eye, there is a marked depression in responsiveness of the deprived eye that significantly reduces the MD contralateral to ipsilateral ratio to about half of the normal ratio. This replicates published research on monocular deprivation in young mice (Frenkel and Bear, 2004) indicating successful protocol development. 
Figure 20. Representative records of visual evoked potentials recorded in the binocular zone of mouse visual cortex from stimulation to each eye in normal (top) and monocularly deprived (bottom) 3.5 week old mice. Left side of each panel was recorded from the eye contralateral to the hemispshere with the recording electrode. The right side of each panel is a record from the ispsilateral eye. The contralateral eye was deprived for a period of five days and reopened prior to recording for monocular deprivation experiments. Each record is an average of sixty potentials from one recording session. The visual stimulus was a 0.03 cycle/degree square-wave gradient at $100 \%$ contrast counter-phasing at $1.98 \mathrm{~Hz}$. 


\section{Normal 3.5 Week \\ Contralateral Eye \\ Ipsilateral Eye}
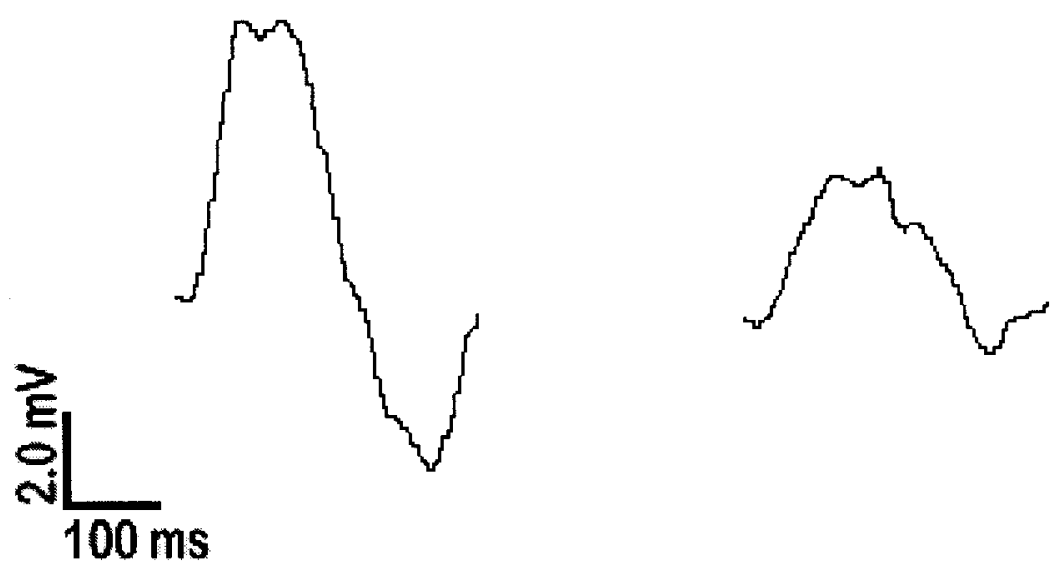

MD 3.5 Week

Contralateral Eye

Ipsilateral Eye
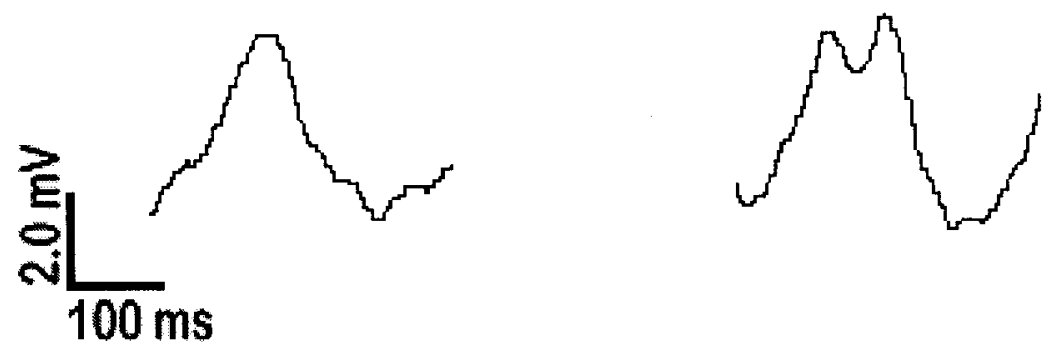

Figure 20 


\section{DISCUSSION}

\section{Summary of Results}

1) Analysis of visual cortical protein expression of both Dab-1 and Munc13-3 genes agreed with mRNA gene screening data conducted previously in the Mower lab (Yang et al., 2001; Yang et al., 2002) and the results reported here are now published (Yang et al., 2006; Yang et al., 2007). Dab-1 protein showed opposite direction regulation by age and dark rearing in the visual cortex of cats and mice. Dab-1 protein expression was found to be greater in normal than dark-reared visual cortex at the peak of the critical period ( 5 weeks) and greater in dark-reared than normal visual cortex at the end of the critical period (20 weeks). Munc13-3 protein showed differences in expression due to age and dark rearing in mouse visual cortex in a pattern opposite to that seen in the Dab-1 expression. Munc13-3 protein expression was found to be greater in dark-reared than normal visual cortex at the peak of the critical period and greater in normal than dark-reared visual cortex at the end of the critical period. This bidirectional regulation of expression was specific to Munc13-3 and did not occur in other members of the Munc13 gene family. Bidirectional regulation of Dab-1 and Munc13-3 was also restricted to visual cortex, indicating that it was not a non-specific cortical effect of dark rearing. In 
normal development, Dab-1 decreased three fold between the peak and nadir of the critical period and Munc13-3 increased two-fold during the same time.

2) Analysis of the effect of Dab-1 on the protein expression of NMDAR subunits NR2A and NR2B showed a significant differences between Dab-1 knockout mutants and wild-type animals in the ratio of NR2A to NR2B subunits with age. When expressed as a percentage of dark reared to normally reared animals (DR/LR) the NR2A:NR2B ratio shows a significant decrease from the peak to the nadir of the critical period in wild-type animals. This result is significantly different from the opposite effect that is observed in Dab-1 knockout mutant animals where the percentage significantly increases between 5 and 20 weeks.

3) Quantification of immunohistochemical study of cat visual cortex showed a neonatal peak in Dab-1 cellular staining with a significant decline in staining density in all cortical layers throughout the critical period. A significant difference in cell labeling was found at one week of age with a higher number of immunopositive cells in the supragranular (developing layers II and III) than granular (layer IV) layers (no difference was found in infragranular (layers V and VI) layers). This difference abates, however and was found to be insignificant by 5 weeks of age with no significant laminar difference remaining throughout development. Comparisons of normal versus dark rearing conditions indicated a significant age/dark rearing interaction that affected all layers similarly. Thus, in agreement with the Western blot results, age and visual experience bidirectionally regulate Dab-1 expression in all visual cortical layers. 
4) In support of laboratory efforts to conduct electrophysiological studies of the effects of Dab-1 and Munc13-3 on critical period cortical plasticity, appropriate methodology and procedures were developed as a part of this thesis to successfully implant electrodes into the binocular region of mouse visual cortex and reliably record visual evoked potentials with a square-wave counter-phasing gradient. Protocols were also developed to successfully monocularly deprive mice, open the deprived eye and repeat the results of published studies that show a shift in eye preference responses after monocular deprivation (Gordon and Stryker, 1996; Antonini et al., 1999). These methods and procedures will be used for future experiments to test physiological effects of mutations in the Dab-1 and Munc13-3 genes on cortical plasticity.

\section{Candidate Plasticity Gene Protein Expression Analysis and Critical Period Neuronal Plasticity}

Munc13-3

Munc13 isoforms, mammalian homologues of the C. elegans uncoordinated gene (unc-13), are phorbol ester receptors that form regulatory complexes, are specifically targeted to presynaptic active zones, and play an essential role in synaptic vesicle release

(Brose et al., 1995; Betz et al., 1997; Augustin et al., 1999a; Basu et al., 2007; Breustedt et al., 2009). Munc13 proteins have been shown to be differentially expressed with isoforms present in different regions of the brain. Munc13-1 is expressed throughout all 
brain regions, while Munc13-2 and Munc13-3 have been shown to be predominantly expressed in rostral and caudal brain regions respectively (Augustin et al., 1999b; Yang et al., 2002). This suggests a primary role for Munc13-1 in all synapses with a complementary role for either Munc13-2 or Munc13-3 depending on brain region. The results presented here further examine protein expression of Munc13-3 in cat and mouse visual cortex during the critical period of development.

Munc13-1 deletion mouse mutants do not feed and consequently die perinatally, but primary hippocampal cultures from these Munc13 mutant mice indicate an inability of docked vesicles to fuse in response to physiological stimuli in glutamatergic and GABAergic neurons (Augustin et al., 1999a; Varoqueaux et al., 2002). Study of Munc13-1, Munc13-2 and combined mutants in the hippocampus indicates that differential expression of Munc13 isoforms occurs within individual synapses and may be a mechanism that controls short- term plasticity by producing a mix of facilitating and depressing synapses (Rosenmund et al., 2002). This result has several potential implications. First, different types of synapses formed by the same axon may allow a given nerve cell to transmit different information to different target cells. Second, transforming depressing synapses into augmenting ones or vice versa by exchanging the Munc13 isoforms may represent a mechanism to induce lasting changes in synaptic efficacy that result from development and environmental input. Such mechanisms should be relevant to the ocular dominance shifts that define the visual cortical critical period. 
Munc13 isoforms have also been implicated in short-term synaptic plasticity by establishing complexes with calmodulin to regulate synaptic vesicle priming (Junge et al., 2004; Zikich et al., 2008). Recent research suggests that the unique $\mathrm{Ca}^{2+}$-binding site common to all Munc13 isoforms plays a significant role in short-term synaptic plasticity by offsetting synaptic depression induced by vesicle depletion caused by repeated action potentials (Shin et al., 2010).

Munc13-3 mutants have been studied in cerebellum. These mutants thrive and show grossly normal brain morphology, but there are impairments of synaptic transmission at cerebellar synapses and of motor learning (Augustin et al., 2001). Munc13-3 mutants show enhanced paired pulse facilitation at parallel fiber-Purkinje cell synapses which is indicative of decreased neurotransmitter release probability (Zucker, 1989). This suggests that Munc13-3 normally functions to increase release probability and decrease paired pulse facilitation. Conversely, mutation of BDNF, a molecule which promotes neuronal plasticity (Berardi and Maffei, 1999), results in decreased paired pulse facilitation at parallel fiber-Purkinje cell synapses (Carter et al., 2002). Thus, the data in cerebellum indicate that Munc13-3 acts to reduce synaptic plasticity, consistent with a potential repressor role in the visual cortical critical period. Firm conclusions must await determination of the function of Munc13-3 in visual cortex. The present results provide the basis for functional analysis of visual cortical critical period plasticity in Munc13-3 mutant mice. Overall, growing evidence indicates a role of Munc13 genes in presynaptic transmission and plasticity and Munc13-3 protein expression is a promising mechanism for regulating activity dependent critical period plasticity of visual cortex. 
$D a b-1$

The results of this study indicate that Dab-1 likely plays a role in a pathway important for visual cortical critical period plasticity. It has already been shown that Dab1 is an important component of the Reelin signaling pathway that controls cell positioning during early brain development and significant portions of the molecular apparatus of this pathway have been well described (Rice and Curran, 2001). Reelin is an extracellular protein secreted in developing cortex by Cajal-Retzius cells (Alcantara et al., 1998) and by GABAergic neurons in adult cortex and hippocampus (Pesold et al., 1998b). Reelin binds to its receptors, VLDLR and ApoER2, causing phosphorylation of intracellular Dab-1, which is a multifunction adaptor protein found in both phosphorylated and un-phosphorylated forms in both the cytoplasm and nucleus of labeled cells (Honda and Nakajima, 2006). Phosphorylated Dab-1 then recruits tyrosine kinases that are associated with the activation of a number of signaling pathways in migrating neurons and can function as a nonsynaptic mechanism to alter gene expression (Rice and Curran, 2001; Feng and Cooper, 2009). Dab-1 has also recently been identified as an intracellular scaffold for forming complex protein clusters with the intracellular Reelin receptor tails and numerous intracellular kinases and their target proteins. This suggests that Dab-1 is important as more than just an activator protein but also as structural component to facilitate downstream reactions in the Reelin pathway during development (Feng and Cooper, 2009). 
Both Reelin (Alcantara et al., 1998; Pesold et al., 1998b; Pesold et al., 1998a; Pesold et al., 1999) and Dab-1 (Pesold et al., 1999; Deguchi et al., 2003) are shown to be expressed in the adult brain but the role of the Reelin/Dab-1 pathway in postnatal and mature brain is just beginning to be understood. Evolving evidence indicates that in postnatal brain the pathway plays a role in synaptic plasticity. Histologically, in neocortex Reelin has been found primarily in inhibitory interneurons (Alcantara et al., 1998; Pesold et al., 1998b; Pesold et al., 1998a) and Dab-1 predominately in pyramidal cells (Pesold et al., 1999). Thus, the Reelin/Dab-1 pathway is well positioned to mediate excitatory-inhibitory interactions believed to be critical for visual cortical plasticity (Hensch and Fagiolini, 2005). Ultrastructurally, in embryological development Reelin is strongly associated with the extracellular matrix, but in adults Reelin expression is also elevated in dendritic spines, the postsynaptic density and axon terminals, suggesting Reelin has a significant role at the synapse in the mature brain (Roberts et al., 2005).

In addition to the morphological evidence, recent functional evidence in postnatal hippocampus directly implicates the Reelin/Dab-1 pathway in synaptic plasticity. Interference with Reelin signaling reduces long-term potentiation (LTP) and perfusion of exogenous Reelin enhances LTP (Weeber et al., 2002). This enhancement of LTP is mediated by activity dependent alternative splicing of the ApoER2 receptor, which is required for Reelin-induced phosphorylation of NMDA receptors (Beffert et al., 2005). Developmentally, interruption of Reelin signaling slows and exogenous Reelin accelerates the normal developmental changes in NMDA receptor currents, which reflect changing NMDA receptor subunit composition (Sinagra et al., 2005). Reelin secreted by 
adult GABAergic hippocampal neurons is implicated as an as in important trans-neuronal messenger required to maintain homeostasis of the subunit composition of NMDAR, suggesting that defects in the Reelin pathway could lead to significant disorders associated with lack of NMDAR regulation (Campo et al., 2009). Reelin has also been implicated in physiological enhancement of NMDA receptor activity by augmenting $\mathrm{Ca}^{2+}$ entry through the NMDA receptor. This effect is negated by the elimination of Dab-1 from the pathway (Chen et al., 2005) suggesting an important role for Dab-1 expression in NMDAR function.

Reelin mutation also impairs dendritic maturation and exogenous application of Reelin rescues this mutation deficit (Niu et al., 2004). Although it is still uncertain if the intracellular mechanisms of Reelin/Dab-1 signaling in postnatal brain are similar to or different from those found in embryogenesis, the pathway is a promising newly identified player in postnatal and adult synaptic plasticity. The protein analysis presented in this thesis further extends this evidence by directly correlating Dab-1 expression with the defined critical period of postnatal plasticity of cat and mouse visual cortex.

\section{Effect of Dab-1 Mutation on NMDA Receptor Subunits during the Critical Period}

Present results found significant differences between Dab-1 mutants and wildtype mice in the ratio of expression of NR2A to NR2B subunits of the NMDA receptor. In wild-type animals, the NR2A:NR2B ratio showed a significant decrease from the peak to the nadir of the critical period when expressed as a percentage of dark reared to 
normally reared animals (DR/LR). This agrees with published research that also found significant temporal reductions in the NR2A:NR2B ratio in dark-reared mice over the same time period (Chen and Bear, 2007). Changes in the ratio of NR2A:NR2B have been implicated as a potential mechanism for experience-dependent modulation of synaptic plasticity in the visual cortex (Quinlan et al., 1999; Chen and Bear, 2007). This result is significantly different from the opposite effect that is observed in Dab-1 mutant animals where the ratio significantly increases from 5 weeks to 20 weeks. Likewise, differences between mutant and wild-type animals at both ages also found significant effects. The percentage of dark to light reared NR2A:NR2B ratios is significantly decreased in mutant animals at 3.5 weeks and significantly higher in mutants at 9.5 weeks.

While the physiological implications of these differences remain to be determined, a review of current literature shows numerous relationships between NMDAR and components of the Reelin/Dab-1 pathway that might contribute to the significant differences in the absence of Dab-1. There is a colocalization of NMDAR and Dab-1 in neuronal postsynaptic densities (Beffert et al., 2005; Chen et al., 2005) and Reelin has been shown to enhance glutamate stimulated $\mathrm{Ca}^{2+}$ influx through NMDAR. This effect is negated in the absence of Dab-1 (Chen et al., 2005) confirming a regulatory role for Dab-1 in NMDAR functions. Recent research has shown that blocking exogenous Reelin can reversibly decrease the NR2A:NR2B ratio in hippocampal cultured neurons (Campo et al., 2009) which, when considered with findings presented here implicates Dab-1 as a critical intermediary in a pathway regulating not only physiological - as an adapter protein required for phosphorylation and activation of numerous other 
proteins - but also anatomical differences in the subunit composition of the NMDAR. As additional studies continue to examine the roles of the relationship of the NMDAR subunits to neuronal plasticity, future physiological studies of cortical plasticity in Dab-1 mutants will provide additional insight into the role of Dab-1 during the critical period and bring to light greater understanding of their interactions.

\section{Immunohistochemical analysis of Dab-1 Cortical Expression}

\section{Developmental Expression of Dab-1}

In cat visual cortex, ocular dominance column formation resulting from segregation of LGN axon terminals within layer IV occurs throughout the critical period extending from approximately three to six weeks of age (LeVay et al., 1978). Physiological cortical plasticity, as determined by monocular deprivation, varies in its time course among different layers of the visual cortex. Several studies have shown that plasticity in layer IV ends earlier than the deeper or superficial layers (LeVay et al., 1980; Mower et al., 1985; Daw et al., 1992). Results from this thesis of quantitative assessments of Dab-1 laminar development in cat visual cortex show some correlations between known anatomical or physiological critical period developmental events. There is a developmental decline in total immunopositive cell density across all layers that is significant through the critical period. The greatest decline in cell density is found between one week and the peak of the critical period. There is, however, also a 
significant decline in total Dab-1 positive cell density from the peak (five weeks) to the nadir ( 20 weeks) of the critical period.

Prior to the critical period there is a significant difference in cell density between developing cortical lamina at 1 week of age with more immunopositive cells in the upper cortical plate (developing layers II/III) than the lower CP (developing layer IV). This disparity disappears by the peak of the critical period (five weeks) and remains insignificant throughout development.

A potential role for Dab-1 expression in facilitation of critical period events is furthered by the immunohistochemical analysis of visual cortex seen in this study. While the developmental changes are not specific to any laminar processes, quantitative analysis shows a uniform pattern of Dab-1 protein expression across all cortical layers that is higher at the peak of the critical period and declines significantly through the nadir.

Dab-1 Immunohistochemistry in the Critical Period in Normal and Dark Reared Cats

Immunohistochemical studies of Dab-1 cortical localization comparing normal and dark reared cats at the peak and nadir of the critical period found cellular staining patterns that also support the visual cortex total protein expression data presented. This provides further support for a potential role of Dab-1 in visual cortex critical period development. 
Candidate Plasticity Genes and the Critical Period in Visual Cortex

There is a moderate conundrum found in the above immunohistochemical expression patterns that will require additional research. While protein and immunohistochemical analysis of Dab-1 demonstrate the lower levels of expression normally seen in candidate plasticity genes in dark-reared animals at the peak of the critical period, with Dab-1 this is apparently not merely of a delayed onset of expression as previously suggested (Mower, 1991). In normally reared animals, Dab-1 cellular staining was found at higher cell densities across all layers prior to the critical period and was already in decline by the peak. This would indicate that if dark rearing was to simply delay Dab-1 expression, it should be higher in dark-reared five week animals compared to normal. Likewise, at the nadir of the critical period, if Dab-1 were to simply be expressed on a delayed time course by dark rearing, it should be lower than the levels expressed in dark reared, five- week visual cortex. The results presented here showed the opposite effect. One possible explanation for this theoretical conflict is the proposed dual roles for Dab-1 in embryonic vs. postnatal development and function of the nervous system. Clearly, the Reelin/Dab-1 pathway is integral in neuronal migration during development of numerous parts of the nervous system (Bock et al., 2003; Stolt et al., 2005; Andrade et al., 2007; Yabut et al., 2007; Frotscher et al., 2009). It has also been shown to play an important role as not only a kinase switch but also a structural scaffold for numerous signaling complexes (Feng and Cooper, 2009). Likewise, Dab-1 has been demonstrated to play a role in the regulation of NMDA receptor subunit organization and facilitation (Beffert et al., 2005; Chen et al., 2005; Sinagra et al., 2005; Campo et al., 
2009). Perhaps visual experience upregulates some of these functions early in normal development causing the high concentrations of Dab-1 expression seen in normal one week animals but those components of Dab-1 function that operate regardless of experience, possibly playing a role in critical period plasticity, follow the typical "plasticity" pattern of bidirectional regulation seen in the protein analysis and immunohistochemical comparisons of normal and dark reared animals presented. Future studies that may elucidate some of these issues should include electrophysiology to determine any functional differences in cortical plasticity between normal and Dab-1 mutant animals.

This observation also causes one to question our proposed understanding of the "anti-plasticity" protein expression pattern, such as that of Munc13-3, seen in comparisons of normal and dark reared animals at the peak and nadir of the critical period. This pattern shows lower expression in normal than dark reared at the peak of the critical period and higher in normal than dark at the nadir. As in the Dab-1 analysis, there is a potential conflict if one interprets this data as a simple delay in the entire time course of plasticity caused by dark rearing. If this hypothesis is to be considered without other influences, it would indicate that Munc13-3 expression must be very high at, or even prior to, birth and quickly be down-regulated postnatally to reach the low levels seen in normal 5 week animals. As the critical period wanes, protein expression then increases back to the high levels seen at the nadir. Further developmental research both prior to and after the critical must be conducted to investigate this proposal. 


\section{Visual Evoked Potentials - establishment of an electrophysiological recording protocol}

In order to continue research on the physiological effects of Dab-1 and Munc13-3 mutations on critical period plasticity a significant amount of time was devoted to the development of a successful laboratory set-up and protocol to monocularly deprive mice and reliably record visual evoked potentials (VEPs) from the binocular segment of visual cortex in awake mice. Although a basic protocol was generously shared with our laboratory by the laboratory of Mark F. Bear, PhD (MIT, Cambridge, MA), our facility was not originally equipped to perform these experiments and many structural and procedural adaptations needed to be developed to reliably record awake VEPs. These adaptations included: proper anesthesia determinations for surgical survival, modifications to the design of both the surgical and recording apparati, surgical techniques for electrode implantation and monocular deprivation, visual stimulus and trigger pulse modifications/synchronization and circuitry set-up for proper recording of VEPs. The finalized protocol is presented in the Results section of this dissertation but some of the more significant protocol issues are discussed below.

The initial issue arose with attempts to anesthetize mice with a survivable level dosage of general anesthesia for the extended surgical procedures (greater than 45 minutes) required to permanently implant recording electrodes in visual cortex. Ultimately a proper dosage of a Ketamine/Xylazine mixture was determined $(90 \mathrm{mg} / \mathrm{kg}$ Ketamine and $9 \mathrm{mg} / \mathrm{kg}$ Xylazine) with a booster dosage of Ketamine only $(9 \mathrm{mg} / \mathrm{kg})$ for 
administration during prolonged surgeries where recovery of the mouse was evident prior to procedure completion as described in the protocol.

Surgical procedures for electrode implantation, although well described in the guidelines presented by the Bear lab, were also modified based primarily on apparatus differences and recording failures. These included alterations to ensure stable post fixation, accurate electrode placement and elimination of potential sources of circuitry conflicts (i.e. improper conduction by use of a conductive acrylic applied to protect surgical site and cement electrodes in position or through accidental skull contact with wire of recording electrode).

Although effective for recording purposes the procedure is currently limited in that electrode placement is only extremely reliable for a period of one to two weeks. Beyond this time period, especially in younger animals when the skull is growing more rapidly, the entire "skull cap" (acrylic with embedded electrodes and fixation post) frequently becomes dislodged and the animal is no longer useable for recording. Thus data analysis can only be conducted between groups of animals under the same treatment conditions.

Multiple visual stimuli were tested prior to development of final protocol. A specially designed flash stimulus was designed and manufactured by Alan Gibson (UNIVERSITY, Location). Testing of this stimulus revealed two concerns. The first was an intensity of response that was too strong to be useful for our research and the second 
was that while the frequency of the stimulus was adjustable, it was not specifically measurable to be accurately set to a determined rate for repeat recordings. It was determined that a standard computer-generated gradient was the most effective stimulus for our research, ultimately it was determined that a 0.03 cycle/degree square-wave gradient alternating at a set rate (approximately $2 \mathrm{~Hz}$ ) was the optimal stimulus. Numerous rates were tested and it was determined that with the one-second recording sweep of the Tektronix oscilloscope being used a frequency of $1.98 \mathrm{~Hz}$ created the most reliable VEPs with minimal 60-cycle background noise.

Numerous issues arose in attempts to synchronize the trigger pulse (that initiates the recording sweep of the oscilloscope) with the visual stimulus. The flash stimulus was optimal in this regard because it generated an impulse with each flash, but the other issues discussed above precluded its use. Dr. Gibson created a trigger module with a photocell that, when secured to the computer screen, generated a 9-volt impulse coincident with each cycle of the stimulus gradient. This was an effective tool for recording reliable VEPs however there was an unexplainable delay in the latency of the response (although consistent within and between recording sessions) that caused us to seek other alternatives. The initial software utilized for the computer generated grating was described as having the capability of generating a simultaneous trigger pulse through the parallel port but multiple channel analysis of this trigger pulse compared to the one generated by the photocell trigger revealed that the computer-generated trigger was not synchronized to the visual stimulus and shifted significantly over the 60 sweeps (one minute recording) that were averaged for one record. This resulted in an overall decline 
in VEP signal as each sweep was initiating a fraction of a second earlier or later than the previous essentially "averaging out," and eliminating the potential over the 60 sweeps. Through extensive efforts of Dr. Heywood Petry, and multiple software revisions, the program designer ultimately developed a computer-generated trigger pulse that was acceptably but still not perfectly synchronized with the onset of the visual stimulus. This system is currently in use and described in the Results section of this dissertation.

Successful development of this protocol allows for future monocular deprivation experiments. Both Munc13-3 and Dab-1 knockout animals will be tested to determine if either mutation causes any changes in VEP response indicating a physiological role in visual cortical plasticity. Modifications to the protocol are still being tested to obtain longer skull attachment times for electrodes in order to be able to implant electrodes, record from the mouse, monocularly deprive that animal for a period of time, reopen the eye and record again. This would allow for pre- and post-monocular deprivation comparisons within the same animal allowing it to be used as its own control for data analysis.

\section{Future Directions}

Based on the results presented here, the most logical immediate progression of this research will be to conduct the electrophysiological studies of the effects of monocular deprivation on visual cortical plasticity in the Munc13-3 and Dab-1 mutant animals. Now that a formal procedure and laboratory set-up have been established and 
the animals are viable and housed under the care of the Mower lab this should be a fairly straightforward experiment to determine whether there is a physiological effect on cortical plasticity due to the absence of either of these genes. As additional genes that express the critical period bidirectional regulation indicative of candidate plasticity are identified the opportunity will be present for knockout mice lacking these genes that could be tested in a similar manner (if the mice are viable).

Another worthwhile experiment for consideration for future research would include a developmental study of protein expression levels of both Dab-1and Munc13-3 in both normal and dark-reared animals from birth through the early critical period. While the results presented here address immunohistochemical changes in normal laminar and cellular expression of Dab-1 protein through this time period and protein expression levels in normal and dark reared animals at the peak and nadir of the critical period, they do not provide a complete quantification of total protein expression levels assessed through Western blot analysis. The results here showed a significant decline in immunopositive cells from one week that continued through the critical period into adulthood and the opposite direction of Dab-1 positive cell density seen in dark reared animals at the peak and nadir of the critical period. Perhaps a more extensive analysis of cortical protein expression throughout development would offer a greater understanding of whether lack of visual stimulus completely inverts protein expression levels of Dab-1 throughout visual cortex development or whether the rise in Dab-1 expression at the later time point in dark-reared animals is truly correlated with the delayed peak of the critical period and declines again subsequent to that developmental milestone. 
Likewise, extending the time course of investigation of both pre- and post-critical period for Munc13-3 protein expression and immunohistochemical analysis would be an insightful investigation into the theory of an overall delay in the entire time course of plasticity caused by dark rearing. If the basic premise holds true, then based on the results of these experiments a proposed expression pattern can be predicted for Munc13-3 that will be high at birth (or perhaps even prenatally), diminish as observed through the peak of the critical period, return to high levels by the nadir and remain elevated throughout adulthood while cortical plasticity remains low. If this pattern is indeed revealed, immunohistological and electrophysiological evaluations would certainly be merited to determine if there are laminar differences in Munc13-3 expression that correlate with known developmental milestones in visual cortical plasticity. Further considerations of Munc13-3 in this research should also include the relatively low expression of Munc13-3 compared to the other Munc13 subunits that do not show any susceptibility to darkrearing (Yang et al., 2007). While the changes in Munc13-3 expression are significant throughout the critical period in visual cortex the low overall expression levels would seem to indicate that very small changes in protein expression may have very significant physiological effects.

The knowledge gained from the Dab-1 and Munc13-3 electrophysiological studies and a complete developmental protein analysis, when considered with ongoing research in other labs identifying and clarifying the ever-increasing functions of the Dab1 protein and Reelin/Dab-1 pathway, and the potential significance of relatively small 
changes in Munc13-3 expression levels, may help further the understanding of which of these functions might be simply developmentally regulated and which are regulated based on visual experience. 


\section{REFERENCES}

Abel T, Martin KC, Bartsch D, Kandel ER (1998) Memory suppressor genes: inhibitory constraints on the storage of long-term memory. Science 279:338-341.

Alcantara S, Ruiz M, D'Arcangelo G, Ezan F, de Lecea L, Curran T, Sotelo C, Soriano E (1998) Regional and cellular patterns of reelin mRNA expression in the forebrain of the developing and adult mouse. J Neurosci 18:7779-7799.

Andrade N, Komnenovic V, Blake SM, Jossin Y, Howell B, Goffinet A, Schneider WJ, Nimpf J (2007) ApoER2/VLDL receptor and Dab1 in the rostral migratory stream function in postnatal neuronal migration independently of Reelin. Proc Natl Acad Sci U S A 104:8508-8513.

Antonini A, Stryker MP (1993) Rapid remodeling of axonal arbors in the visual cortex. Science 260:1819-1821.

Antonini A, Stryker MP (1996) Plasticity of geniculocortical afferents following brief or prolonged monocular occlusion in the cat. J Comp Neurol 369:64-82.

Antonini A, Fagiolini M, Stryker MP (1999) Anatomical correlates of functional plasticity in mouse visual cortex. J Neurosci 19:4388-4406.

Augustin I, Rosenmund C, Sudhof TC, Brose N (1999a) Munc13-1 is essential for fusion competence of glutamatergic synaptic vesicles. Nature 400:457-461.

Augustin I, Betz A, Herrmann C, Jo T, Brose N (1999b) Differential expression of two novel Munc13 proteins in rat brain. Biochem J 337 ( Pt 3):363-371.

Augustin I, Korte S, Rickmann M, Kretzschmar HA, Sudhof TC, Herms JW, Brose N (2001) The cerebellum-specific Munc13 isoform Munc13-3 regulates cerebellar synaptic transmission and motor learning in mice. J Neurosci 21:10-17.

Basu J, Betz A, Brose N, Rosenmund C (2007) Munc13-1 C1 domain activation lowers the energy barrier for synaptic vesicle fusion. J Neurosci 27:1200-1210.

Bear MF, Kleinschmidt A, Gu QA, Singer W (1990) Disruption of experience-dependent synaptic modifications in striate cortex by infusion of an NMDA receptor antagonist. J Neurosci 10:909-925. 
Beaver CJ, Ji Q, Daw NW (2001) Layer differences in the effect of monocular vision in light- and dark-reared kittens. Vis Neurosci 18:811-820.

Beffert U, Weeber EJ, Durudas A, Qiu S, Masiulis I, Sweatt JD, Li WP, Adelmann G, Frotscher M, Hammer RE, Herz J (2005) Modulation of synaptic plasticity and memory by Reelin involves differential splicing of the lipoprotein receptor Apoer2. Neuron 47:567-579.

Berardi N, Maffei L (1999) From visual experience to visual function: roles of neurotrophins. J Neurobiol 41:119-126.

Betz A, Okamoto M, Benseler F, Brose N (1997) Direct interaction of the rat unc-13 homologue Munc13-1 with the N terminus of syntaxin. J Biol Chem 272:25202526.

Betz A, Ashery U, Rickmann M, Augustin I, Neher E, Sudhof TC, Rettig J, Brose N (1998) Munc13-1 is a presynaptic phorbol ester receptor that enhances neurotransmitter release. Neuron 21:123-136.

Blakemore C, Van Sluyters RC (1975) Innate and environmental factors in the development of the kitten's visual cortex. J Physiol 248:663-716.

Bock HH, Jossin Y, Liu P, Forster E, May P, Goffinet AM, Herz J (2003) Phosphatidylinositol 3-kinase interacts with the adaptor protein Dabl in response to Reelin signaling and is required for normal cortical lamination. J Biol Chem 278:38772-38779.

Breustedt J, Gundlfinger A, Varoqueaux F, Reim K, Brose N, Schmitz D (2009) Munc13-2 Differentially Affects Hippocampal Synaptic Transmission and Plasticity. Cereb Cortex.

Brose N, Hofmann K, Hata Y, Sudhof TC (1995) Mammalian homologues of Caenorhabditis elegans unc-13 gene define novel family of $\mathrm{C} 2$-domain proteins. $\mathrm{J}$ Biol Chem 270:25273-25280.

Buisseret P, Imbert M (1976) Visual cortical cells: their developmental properties in normal and dark reared kittens. J Physiol 255:511-525.

Campo CG, Sinagra M, Verrier D, Manzoni OJ, Chavis P (2009) Reelin secreted by GABAergic neurons regulates glutamate receptor homeostasis. PLoS One $4: \mathrm{e} 5505$.

Carter AR, Chen C, Schwartz PM, Segal RA (2002) Brain-derived neurotrophic factor modulates cerebellar plasticity and synaptic ultrastructure. J Neurosci 22:13161327. 
Chen L, Cooper NG, Mower GD (2000) Developmental changes in the expression of NMDA receptor subunits (NR1, NR2A, NR2B) in the cat visual cortex and the effects of dark rearing. Brain Res Mol Brain Res 78:196-200.

Chen WS, Bear MF (2007) Activity-dependent regulation of NR2B translation contributes to metaplasticity in mouse visual cortex. Neuropharmacology 52:200214.

Chen Y, Beffert U, Ertunc M, Tang TS, Kavalali ET, Bezprozvanny I, Herz J (2005) Reelin modulates NMDA receptor activity in cortical neurons. J Neurosci 25:8209-8216.

Corriveau RA, Huh GS, Shatz CJ (1998) Regulation of class I MHC gene expression in the developing and mature CNS by neural activity. Neuron 21:505-520.

Corriveau RA, Shatz CJ, Nedivi E (1999) Dynamic regulation of cpg15 during activitydependent synaptic development in the mammalian visual system. J Neurosci 19:7999-8008.

Cragg BG (1975) The development of synapses in the visual system of the cat. J Comp Neurol 160:147-166.

Crair MC, Horton JC, Antonini A, Stryker MP (2001) Emergence of ocular dominance columns in cat visual cortex by 2 weeks of age. J Comp Neurol 430:235-249.

Crowley JC, Katz LC (2000) Early development of ocular dominance columns. Science 290:1321-1324.

Cynader M (1983) Prolonged sensitivity to monocular deprivation in dark-reared cats: effects of age and visual exposure. Brain Res 284:155-164.

Cynader M, Mitchell DE (1980) Prolonged sensitivity to monocular deprivation in darkreared cats. J Neurophysiol 43:1026-1040.

Czepita D, Reid SN, Daw NW (1994) Effect of longer periods of dark rearing on NMDA receptors in cat visual cortex. J Neurophysiol 72:1220-1226.

Daw NW (1994) Mechanisms of plasticity in the visual cortex. The Friedenwald Lecture. Invest Ophthalmol Vis Sci 35:4168-4179.

Daw NW, Reid SN, Beaver CJ (1999) Development and function of metabotropic glutamate receptors in cat visual cortex. J Neurobiol 41:102-107.

Daw NW, Fox K, Sato H, Czepita D (1992) Critical period for monocular deprivation in the cat visual cortex. J Neurophysiol 67:197-202.

Deguchi K, Inoue K, Avila WE, Lopez-Terrada D, Antalffy BA, Quattrocchi CC, Sheldon M, Mikoshiba K, D'Arcangelo G, Armstrong DL (2003) Reelin and 
disabled-1 expression in developing and mature human cortical neurons. $J$ Neuropathol Exp Neurol 62:676-684.

Fagiolini M, Hensch TK (2000) Inhibitory threshold for critical-period activation in primary visual cortex. Nature 404:183-186.

Fagiolini M, Katagiri H, Miyamoto H, Mori H, Grant SG, Mishina M, Hensch TK (2003) Separable features of visual cortical plasticity revealed by N-methyl-D-aspartate receptor 2A signaling. Proc Natl Acad Sci U S A 100:2854-2859.

Feng L, Cooper JA (2009) Dual functions of Dab1 during brain development. Mol Cell Biol 29:324-332.

Fregnac Y, Imbert M (1978) Early development of visual cortical cells in normal and dark-reared kittens: relationship between orientation selectivity and ocular dominance. J Physiol 278:27-44.

Fregnac Y, Imbert M (1984) Development of neuronal selectivity in primary visual cortex of cat. Physiol Rev 64:325-434.

Frenkel MY, Bear MF (2004) How monocular deprivation shifts ocular dominance in visual cortex of young mice. Neuron 44:917-923.

Frotscher M, Chai X, Bock HH, Haas CA, Forster E, Zhao S (2009) Role of Reelin in the development and maintenance of cortical lamination. J Neural Transm 116:14511455 .

Gandhi SP, Yanagawa Y, Stryker MP (2008) Delayed plasticity of inhibitory neurons in developing visual cortex. Proc Natl Acad Sci U S A 105:16797-16802.

Garey LJ (1971) A light and electron microscopic study of the visual cortex of the cat and monkey. Proc R Soc Lond B Biol Sci 179:21-40.

Garey LJ, Powell TP (1971) An experimental study of the termination of the lateral geniculo-cortical pathway in the cat and monkey. Proc R Soc Lond B Biol Sci 179:41-63.

Gibson A, Baker J, Mower G, Glickstein M (1978) Corticopontine cells in area 18 of the cat. J Neurophysiol 41:484-495.

Giffin F, Mitchell DE (1978) The rate of recovery of vision after early monocular deprivation in kittens. J Physiol 274:511-537.

Gilbert CD, Wiesel TN (1979) Morphology and intracortical projections of functionally characterised neurones in the cat visual cortex. Nature 280:120-125.

Gordon JA, Stryker MP (1996) Experience-dependent plasticity of binocular responses in the primary visual cortex of the mouse. J Neurosci 16:3274-3286. 
Guillery RW, Stelzner DJ (1970) The differential effects of unilateral lid closure upon the monocular and binocular segments of the dorsal lateral geniculate nucleus in the cat. J Comp Neurol 139:413-421.

Guire ES, Lickey ME, Gordon B (1999) Critical period for the monocular deprivation effect in rats: assessment with sweep visually evoked potentials. J Neurophysiol 81:121-128.

He HY, Hodos W, Quinlan EM (2006) Visual deprivation reactivates rapid ocular dominance plasticity in adult visual cortex. J Neurosci 26:2951-2955.

Hensch TK, Fagiolini M (2005) Excitatory-inhibitory balance and critical period plasticity in developing visual cortex. Prog Brain Res 147:115-124.

Hensch TK, Fagiolini M, Mataga N, Stryker MP, Baekkeskov S, Kash SF (1998) Local GABA circuit control of experience-dependent plasticity in developing visual cortex. Science 282:1504-1508.

Hollander H (1974) On the origin of the corticotectal projections in the cat. Exp Brain Res 21:433-439.

Honda T, Nakajima K (2006) Mouse Disabled1 (DAB1) is a nucleocytoplasmic shuttling protein. J Biol Chem 281:38951-38965.

Horton JC, Hocking DR (1996) An adult-like pattern of ocular dominance columns in striate cortex of newborn monkeys prior to visual experience. J Neurosci 16:17911807.

Horton JC, Hocking DR (1997) Timing of the critical period for plasticity of ocular dominance columns in macaque striate cortex. J Neurosci 17:3684-3709.

Horton JC, Adams DL (2005) The cortical column: a structure without a function. Philos Trans R Soc Lond B Biol Sci 360:837-862.

Howell BW, Gertler FB, Cooper JA (1997a) Mouse disabled (mDab1): a Src binding protein implicated in neuronal development. EMBO J 16:121-132.

Howell BW, Hawkes R, Soriano P, Cooper JA (1997b) Neuronal position in the developing brain is regulated by mouse disabled-1. Nature 389:733-737.

Huang ZJ, Kirkwood A, Pizzorusso T, Porciatti V, Morales B, Bear MF, Maffei L, Tonegawa S (1999) BDNF regulates the maturation of inhibition and the critical period of plasticity in mouse visual cortex. Cell 98:739-755.

Hubel DH, Wiesel TN (1962) Receptive fields, binocular interaction and functional architecture in the cat's visual cortex. J Physiol 160:106-154. 
Hubel DH, Wiesel TN (1970) The period of susceptibility to the physiological effects of unilateral eye closure in kittens. J Physiol 206:419-436.

Hubel DH, Wiesel TN (1972) Laminar and columnar distribution of geniculo-cortical fibers in the macaque monkey. J Comp Neurol 146:421-450.

Hubel DH, Wiesel TN (1977) Ferrier lecture. Functional architecture of macaque monkey visual cortex. Proc R Soc Lond B Biol Sci 198:1-59.

Hubel DH, Wiesel TN, LeVay S (1977) Plasticity of ocular dominance columns in monkey striate cortex. Philos Trans R Soc Lond B Biol Sci 278:377-409.

Huh GS, Boulanger LM, Du H, Riquelme PA, Brotz TM, Shatz CJ (2000) Functional requirement for class I MHC in CNS development and plasticity. Science 290:2155-2159.

Huppe-Gourgues F, Bickford ME, Boire D, Ptito M, Casanova C (2006) Distribution, morphology, and synaptic targets of corticothalamic terminals in the cat lateral posterior-pulvinar complex that originate from the posteromedial lateral suprasylvian cortex. J Comp Neurol 497:847-863.

Iwai Y, Fagiolini M, Obata K, Hensch TK (2003) Rapid critical period induction by tonic inhibition in visual cortex. J Neurosci 23:6695-6702.

Junge HJ, Rhee JS, Jahn O, Varoqueaux F, Spiess J, Waxham MN, Rosenmund C, Brose $\mathrm{N}$ (2004) Calmodulin and Munc13 form a Ca2+ sensor/effector complex that controls short-term synaptic plasticity. Cell 118:389-401.

Kirkwood A, Bear MF (1994) Hebbian synapses in visual cortex. J Neurosci 14:16341645 .

Kratz KE, Spear PD (1976) Effects of visual deprivation and alterations in binocular competition on responses of striate cortex neurons in the cat. J Comp Neurol 170:141-151.

Lanahan A, Worley P (1998) Immediate-early genes and synaptic function. Neurobiol Learn Mem 70:37-43.

Lemmon V, Pearlman AL (1981) Does laminar position determine the receptive field properties of cortical neurons? A study of corticotectal cells in area 17 of the normal mouse and the reeler mutant. J Neurosci 1:83-93.

LeVay S, Gilbert CD (1976) Laminar patterns of geniculocortical projection in the cat. Brain Res 113:1-19.

LeVay S, Stryker MP, Shatz CJ (1978) Ocular dominance columns and their development in layer IV of the cat's visual cortex: a quantitative study. J Comp Neurol 179:223-244. 
LeVay S, Wiesel TN, Hubel DH (1980) The development of ocular dominance columns in normal and visually deprived monkeys. J Comp Neurol 191:1-51.

Lowel S, Singer W (1987) The pattern of ocular dominance columns in flat-mounts of the cat visual cortex. Exp Brain Res 68:661-666.

Lund JS, Lund RD, Hendrickson AE, Bunt AH, Fuchs AF (1975) The origin of efferent pathways from the primary visual cortex, area 17 , of the macaque monkey as shown by retrograde transport of horseradish peroxidase. J Comp Neurol 164:287-303.

Luskin MB, Shatz CJ (1985a) Studies of the earliest generated cells of the cat's visual cortex: cogeneration of subplate and marginal zones. J Neurosci 5:1062-1075.

Luskin MB, Shatz CJ (1985b) Neurogenesis of the cat's primary visual cortex. J Comp Neurol 242:611-631.

Mitchell DE (1988) The extent of visual recovery from early monocular or binocular visual deprivation in kittens. J Physiol 395:639-660.

Monyer H, Burnashev N, Laurie DJ, Sakmann B, Seeburg PH (1994) Developmental and regional expression in the rat brain and functional properties of four NMDA receptors. Neuron 12:529-540.

Mower GD (1991) The effect of dark rearing on the time course of the critical period in cat visual cortex. Brain Res Dev Brain Res 58:151-158.

Mower GD, Berry D, Burchfiel JL, Duffy FH (1981) Comparison of the effects of dark rearing and binocular suture on development and plasticity of cat visual cortex. Brain Res 220:255-267.

Mower GD, Caplan CJ, Christen WG, Duffy FH (1985) Dark rearing prolongs physiological but not anatomical plasticity of the cat visual cortex. J Comp Neurol 235:448-466.

Muller CM (1992) Astrocytes in cat visual cortex studied by GFAP and S-100 immunocytochemistry during postnatal development. J Comp Neurol 317:309323.

Nakanishi S (1992) Molecular diversity of glutamate receptors and implications for brain function. Science 258:597-603.

Nakanishi S (1994) Metabotropic glutamate receptors: synaptic transmission, modulation, and plasticity. Neuron 13:1031-1037.

Nedivi E, Hevroni D, Naot D, Israeli D, Citri Y (1993) Numerous candidate plasticityrelated genes revealed by differential cDNA cloning. Nature 363:718-722. 
Nicholls J, Martin AR, Wallace BG, Fuchs PA (2001) From Neuron to Brain, 4th Edition Edition. Sunderland, MA: Sinauer Associates, Inc.

Niu S, Renfro A, Quattrocchi CC, Sheldon M, D'Arcangelo G (2004) Reelin promotes hippocampal dendrite development through the VLDLR/ApoER2-Dab1 pathway. Neuron 41:71-84.

Olson CR, Freeman RD (1980) Profile of the sensitive period for monocular deprivation in kittens. Exp Brain Res 39:17-21.

Palmer LA, Rosenquist AC (1974) Visual receptive fields of single striate corical units projecting to the superior colliculus in the cat. Brain Res 67:27-42.

Perez-Otano I, Schulteis CT, Contractor A, Lipton SA, Trimmer JS, Sucher NJ, Heinemann SF (2001) Assembly with the NR1 subunit is required for surface expression of NR3A-containing NMDA receptors. J Neurosci 21:1228-1237.

Pesold C, Pisu MG, Impagnatiello F, Uzunov DP, Caruncho HJ (1998a) Simultaneous detection of glutamic acid decarboxylase and reelin mRNA in adult rat neurons using in situ hybridization and immunofluorescence. Brain Res Brain Res Protoc 3:155-160.

Pesold C, Liu WS, Guidotti A, Costa E, Caruncho HJ (1999) Cortical bitufted, horizontal, and Martinotti cells preferentially express and secrete reelin into perineuronal nets, nonsynaptically modulating gene expression. Proc Natl Acad Sci U S A 96:3217-3222.

Pesold C, Impagnatiello F, Pisu MG, Uzunov DP, Costa E, Guidotti A, Caruncho HJ (1998b) Reelin is preferentially expressed in neurons synthesizing gammaaminobutyric acid in cortex and hippocampus of adult rats. Proc Natl Acad Sci U S A 95:3221-3226.

Pettigrew JD (1974) The effect of visual experience on the development of stimulus specificity by kitten cortical neurones. J Physiol 237:49-74.

Philpot BD, Cho KK, Bear MF (2007) Obligatory role of NR2A for metaplasticity in visual cortex. Neuron 53:495-502.

Pizzorusso T, Medini P, Berardi N, Chierzi S, Fawcett JW, Maffei L (2002) Reactivation of ocular dominance plasticity in the adult visual cortex. Science 298:1248-1251.

Prasad SS, Cynader MS (1994) Identification of cDNA clones expressed selectively during the critical period for visual cortex development by subtractive hybridization. Brain Res 639:73-84.

Qian Z, Gilbert ME, Colicos MA, Kandel ER, Kuhl D (1993) Tissue-plasminogen activator is induced as an immediate-early gene during seizure, kindling and longterm potentiation. Nature 361:453-457. 
Quinlan EM, Olstein DH, Bear MF (1999) Bidirectional, experience-dependent regulation of $\mathrm{N}$-methyl-D-aspartate receptor subunit composition in the rat visual cortex during postnatal development. Proc Natl Acad Sci U S A 96:12876-12880.

Rakic P (1976) Prenatal genesis of connections subserving ocular dominance in the rhesus monkey. Nature 261:467-471.

Rambhadran A, Gonzalez J, Jayaraman V (2010) Subunit arrangement in NMDA receptors. J Biol Chem.

Rice DS, Curran T (2001) Role of the reelin signaling pathway in central nervous system development. Annu Rev Neurosci 24:1005-1039.

Rice DS, Sheldon M, D'Arcangelo G, Nakajima K, Goldowitz D, Curran T (1998) Disabled-1 acts downstream of Reelin in a signaling pathway that controls laminar organization in the mammalian brain. Development 125:3719-3729.

Rice DS, Nusinowitz S, Azimi AM, Martinez A, Soriano E, Curran T (2001) The reelin pathway modulates the structure and function of retinal synaptic circuitry. Neuron 31:929-941.

Roberts EB, Meredith MA, Ramoa AS (1998) Suppression of NMDA receptor function using antisense DNA block ocular dominance plasticity while preserving visual responses. J Neurophysiol 80:1021-1032.

Roberts RC, Xu L, Roche JK, Kirkpatrick B (2005) Ultrastructural localization of reelin in the cortex in post-mortem human brain. J Comp Neurol 482:294-308.

Rosenmund C, Sigler A, Augustin I, Reim K, Brose N, Rhee JS (2002) Differential control of vesicle priming and short-term plasticity by Munc13 isoforms. Neuron $33: 411-424$.

Sawtell NB, Frenkel MY, Philpot BD, Nakazawa K, Tonegawa S, Bear MF (2003) NMDA receptor-dependent ocular dominance plasticity in adult visual cortex. Neuron 38:977-985.

Shatz CJ, Stryker MP (1978) Ocular dominance in layer IV of the cat's visual cortex and the effects of monocular deprivation. J Physiol 281:267-283.

Shatz CJ, Luskin MB (1986) The relationship between the geniculocortical afferents and their cortical target cells during development of the cat's primary visual cortex. J Neurosci 6:3655-3668.

Shatz CJ, Lindstrom S, Wiesel TN (1977) The distribution of afferents representing the right and left eyes in the cat's visual cortex. Brain Res 131:103-116. 
Sheldon M, Rice DS, D'Arcangelo G, Yoneshima H, Nakajima K, Mikoshiba K, Howell BW, Cooper JA, Goldowitz D, Curran T (1997) Scrambler and yotari disrupt the disabled gene and produce a reeler-like phenotype in mice. Nature 389:730-733.

Sheng M, Cummings J, Roldan LA, Jan YN, Jan LY (1994) Changing subunit composition of heteromeric NMDA receptors during development of rat cortex. Nature 368:144-147.

Sherman SM (1973) Visual field defects in monocularly and binocularly deprived cats. Brain Res 49:24-45.

Sherman SM, Spear PD (1982) Organization of visual pathways in normal and visually deprived cats. Physiol Rev 62:738-855.

Shin OH, Lu J, Rhee JS, Tomchick DR, Pang ZP, Wojcik SM, Camacho-Perez M, Brose N, Machius M, Rizo J, Rosenmund C, Sudhof TC (2010) Munc13 C2B domain is an activity-dependent $\mathrm{Ca} 2+$ regulator of synaptic exocytosis. Nat Struct Mol Biol 17:280-288.

Silva LR, Gutnick MJ, Connors BW (1991) Laminar distribution of neuronal membrane properties in neocortex of normal and reeler mouse. J Neurophysiol 66:20342040.

Simmons PA, Lemmon V, Pearlman AL (1982) Afferent and efferent connections of the striate and extrastriate visual cortex of the normal and reeler mouse. J Comp Neurol 211:295-308.

Sinagra M, Verrier D, Frankova D, Korwek KM, Blahos J, Weeber EJ, Manzoni OJ, Chavis P (2005) Reelin, very-low-density lipoprotein receptor, and apolipoprotein E receptor 2 control somatic NMDA receptor composition during hippocampal maturation in vitro. J Neurosci 25:6127-6136.

Skangiel-Kramska $J$ (1988) Neurotransmitter systems in the visual cortex of the cat: possible involvement in plastic phenomena. Acta Neurobiol Exp (Wars) 48:335370 .

Southwell DG, Froemke RC, Alvarez-Buylla A, Stryker MP, Gandhi SP (2010) Cortical plasticity induced by inhibitory neuron transplantation. Science 327:1145-1148.

Stolt PC, Chen Y, Liu P, Bock HH, Blacklow SC, Herz J (2005) Phosphoinositide binding by the disabled-1 PTB domain is necessary for membrane localization and Reelin signal transduction. J Biol Chem 280:9671-9677.

Swindale NV (1981) Absence of ocular dominance patches in dark-reared cats. Nature 290:332-333.

Timney B (1983) The effects of early and late monocular deprivation on binocular depth perception in cats. Brain Res 283:235-243. 
Trachtenberg JT, Trepel C, Stryker MP (2000) Rapid extragranular plasticity in the absence of thalamocortical plasticity in the developing primary visual cortex. Science 287:2029-2032.

Tusa RJ, Palmer LA, Rosenquist AC (1978) The retinotopic organization of area 17 (striate cortex) in the cat. J Comp Neurol 177:213-235.

Van den Bergh G, Clerens S, Cnops L, Vandesande F, Arckens L (2003) Fluorescent two-dimensional difference gel electrophoresis and mass spectrometry identify age-related protein expression differences for the primary visual cortex of kitten and adult cat. J Neurochem 85:193-205.

Varoqueaux F, Sigler A, Rhee JS, Brose N, Enk C, Reim K, Rosenmund C (2002) Total arrest of spontaneous and evoked synaptic transmission but normal synaptogenesis in the absence of Munc13-mediated vesicle priming. Proc Natl Acad Sci U S A 99:9037-9042.

Weeber EJ, Beffert U, Jones C, Christian JM, Forster E, Sweatt JD, Herz J (2002) Reelin and $A$ poE receptors cooperate to enhance hippocampal synaptic plasticity and learning. J Biol Chem 277:39944-39952.

Wiesel TN, Hubel DH (1963) Effects of Visual Deprivation on Morphology and Physiology of Cells in the Cats Lateral Geniculate Body. J Neurophysiol 26:978993.

Winfield DA (1983) The postnatal development of synapses in the different laminae of the visual cortex in the normal kitten and in kittens with eyelid suture. Brain Res 285:155-169.

Yabut O, Renfro A, Niu S, Swann JW, Marin O, D'Arcangelo G (2007) Abnormal laminar position and dendrite development of interneurons in the reeler forebrain. Brain Res 1140:75-83.

Yamagata K, Andreasson KI, Kaufmann WE, Barnes CA, Worley PF (1993) Expression of a mitogen-inducible cyclooxygenase in brain neurons: regulation by synaptic activity and glucocorticoids. Neuron 11:371-386.

Yang C, Silver B, Ellis SR, Mower GD (2001) Bidirectional regulation of mitochondrial gene expression during developmental neuroplasticity of visual cortex. Biochem Biophys Res Commun 287:1070-1074.

Yang CB, Zheng YT, Li GY, Mower GD (2002) Identification of Munc13-3 as a candidate gene for critical-period neuroplasticity in visual cortex. J Neurosci 22:8614-8618.

Yang CB, Zheng YT, Kiser PJ, Mower GD (2006) Identification of disabled-1 as a candidate gene for critical period neuroplasticity in cat and mouse visual cortex. Eur J Neurosci 23:2804-2808. 
Yang CB, Kiser PJ, Zheng YT, Varoqueaux F, Mower GD (2007) Bidirectional regulation of Munc13-3 protein expression by age and dark rearing during the critical period in mouse visual cortex. Neuroscience 150:603-608.

Zikich D, Mezer A, Varoqueaux F, Sheinin A, Junge HJ, Nachliel E, Melamed R, Brose $\mathrm{N}$, Gutman M, Ashery U (2008) Vesicle priming and recruitment by ubMunc13-2 are differentially regulated by calcium and calmodulin. J Neurosci 28:1949-1960.

Zucker RS (1989) Short-term synaptic plasticity. Annu Rev Neurosci 12:13-31. 


\section{CURRICULUM VITAE}

NAME: Paul Joseph Kiser

ADDRESS: 3429 Stony Farm Dr

Louisville, KY 40299

DOB: $\quad$ Hammond, $\mathbb{I N}$ - September 10, 1969

EDUCATION

\& TRAINING: $\quad$ B.S., Biology

The Florida State University

1987-1992

M.S., Anatomical Sciences and Neurobiology

University of Louisville School of Medicine

1993-1997

CERTIFICATIONS: Internationally Certified Prevention Specialist, 2008

PROFESSIONAL

SOCIETIES: $\quad$ Kentucky Prevention Network, 2009

PUBLICATIONS: $\quad$ Yang CB*, Kiser PJ*, Zheng YT, Varoqueaux F, Mower GD (2007) Bidirectional regulation of Munc13-3 protein expression by age and dark rearing during the critical period in mouse visual cortex. Neuroscience 150(3):603-8.

Yang CB, Zheng YT, Kiser PJ, Mower GD (2006) Identification of disabled-1 as a critical period neuroplasticity gene in cat and mouse visual cortex. Eur J Neurosci 23: 2804-2808.

Kiser PJ, Cooper NGF, Mower GD (1998) Expression of two forms of Glutamic Acid Decarboxylase (GAD67 and GAD65) during postnatal development of rat somatosensory barrel cortex. $\mathrm{J}$ Comp Neurol 402:62-74.

${ }^{*}$ Co-First Authors 